\title{
A PROBABILISTIC METHOD FOR DETERMINING EFFLUENT TEMPERATURE LIMITS FOR FLOW INSTABILITY FOR SRS REACTORS (U)
}

by B. J. Hardy

WSRC-TM--90-005

Westinghouse Savannah River Company

Savannah River Site

Aiken, South Carolina 29808

Other Authors:

A. M. White

This paper was prepared in connection with work done under Contract No. DE-AC09-89SR18035 with the U. S. Department of Energy. By acceptance of this paper, the publisher and/or recipient acknowledges the U.S. Government's right to retain a nonexclusive, royalty-free license in and to any copyright covering this paper, along with the rint to reproduce and to authorize others to reproduce all or part of the copyrighted paper. 


\section{DISCLAIMER}

This report was prepared as an account of work sponsored by an agency of the United States Government. Neither the United States Government nor any agency thereof, nor any of their employees, makes any warranty, express or implied, or assumes any legal liability or responsibility for the accuracy, completeness, or usefulness of any information, apparatus, product, or process disclosed, or represents that its use would not infringe privately owned rights. Reference herein to any specific commercial product, process, or service by trade name, trademark, manufacturer, or otherwise does not necessarily constitute or imply its endorsement, recommendation, or favoring by the United States Government or any agency thereof. The views and opinions of authors expressed herein do not necessarily state or reflect those of the United States Government or any agency thereof.

This report has bee i reproduced directly from the best available copy.

Available to DOE and DOE contractors from the Office of Scientific and Technical Information, P.O. Box 62, Oak Ridge, TN 37831; prices available from (615) 576-8401, FTS 626-8401.

Available to the public from the National Technical Information Service, U.S. Department of Commerce, 5285 Port Royal Rd., Springfield, VA 22161. 


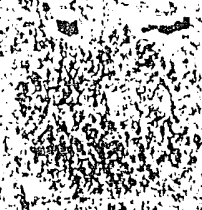

and
(1)

tons

is.

ind

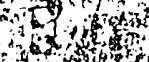

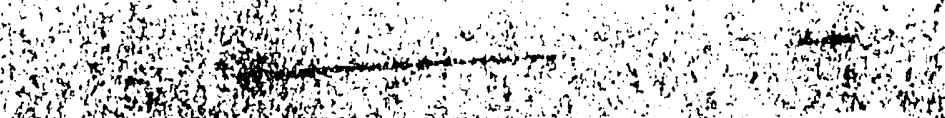

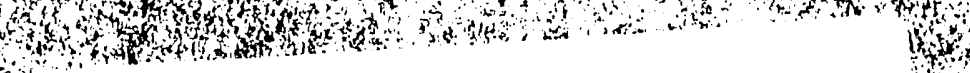

is

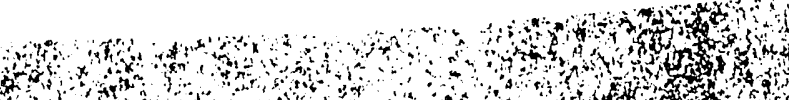

WSR C-TM $-90 \div 5$

(DPSTM-160)

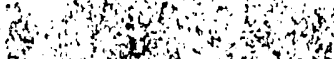

(n)

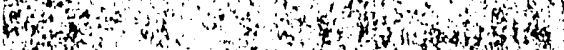

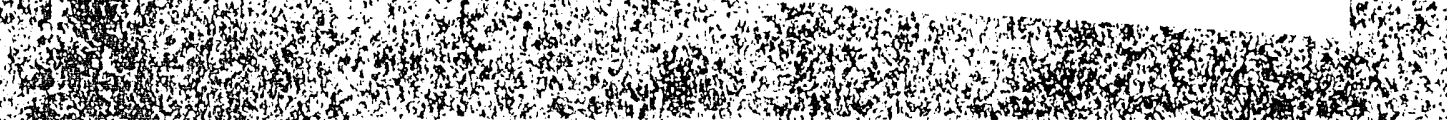

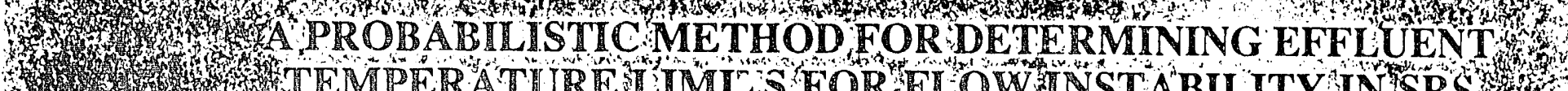

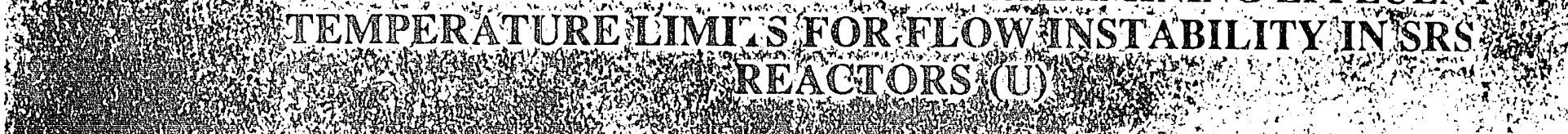

the

3.

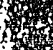

7.

4.456

H. W

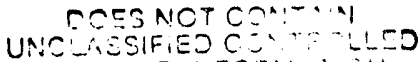

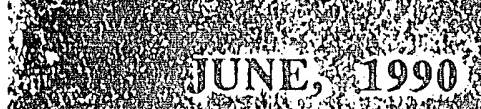

\section{}

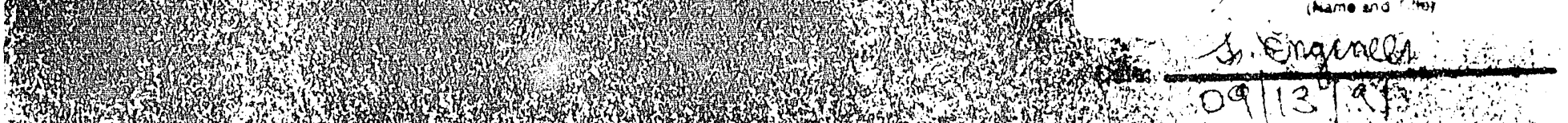
.6.

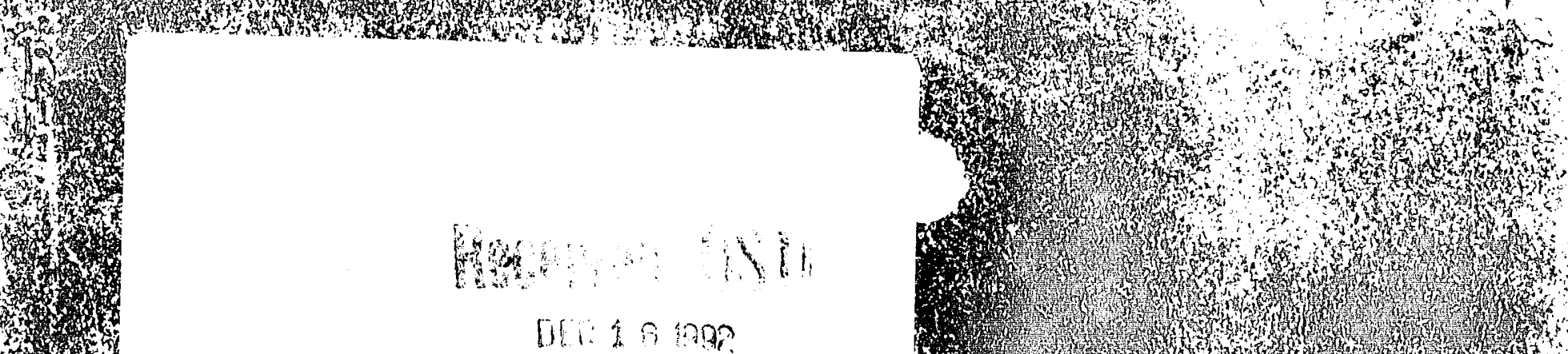


WSRC-TM-90-5

(DPSTM-160)

NRTSC
NUCLEAR REACTOR TECHNOLOGY
AND SCIENTIFIC COMPUTATIONS

\author{
KEYWORDS: LOCA LIMITS \\ FLOWTRAN \\ FLOW INSTABILITY \\ K-14.1 LIMITS
}

RETENTION: PERMANENT

A PROBABILISTIC METHOD FOR DETERMINING EFFLUENT TEMPERATTIRE LIMITS FOR FLOW INSTABILITY FOR SRS REACTORS (U)

by

B. J. HARDY

A. M. WHITE

ISSUED: JUNE, 1990

$\frac{\text { Op Fanaci }}{6 / 11 / 90}$

SRL SAVANNAH RIVER LABORATORY, AIKEN, SC 29808 Westinghouse Savannah River Company Prepared for the U. S. Department of Energy under Contract DE-AC09-88SR18035 
PROJECT: LOCA LIMITS

DOCUMENT: WSRC-TM-90-5 (DPSTM-160)

TITLE: A PROBABILISTIC METHOD FOR DETERMINING EFFLUENT TEMPERATURE LIMITS FOR FLOW INSTABILITY IN SRS REACTORS (U)

QA TASK NUMBER: 88-024-1

REVISION NUMBER: 0

APPROVALS

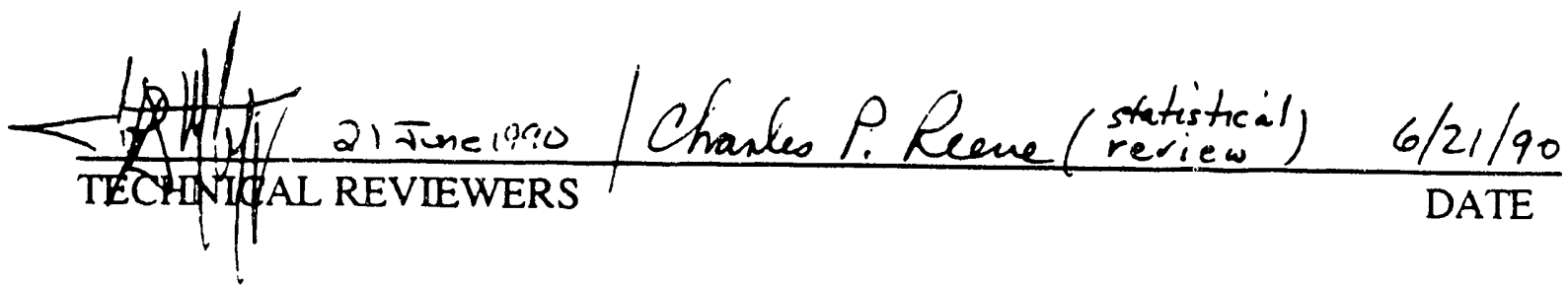

Pl

N. H. KUEHN, ADVISORY ENGINEER $\frac{6-2 /-90}{\text { DATE }}$

T) Merne $(i-2)-7 i$

7. D. MENNA, RESEARCH SUPERVISOR

DATE

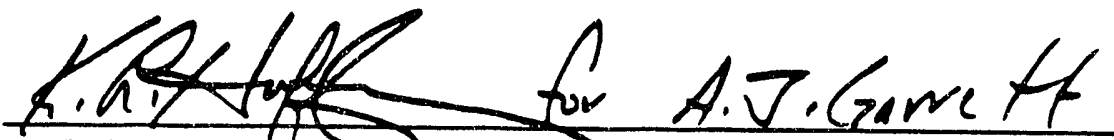

A. J. GARRETW, TEeTINICAL MANAGER

DATE

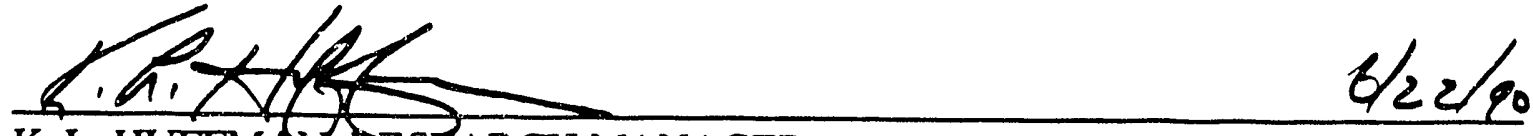

K. L. HUFFMAN, RESEARCH MANAGER

DATE 


\section{Table of Contents}

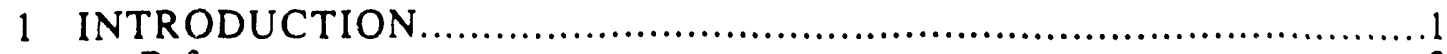

References ..............................................................

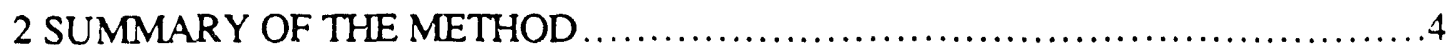

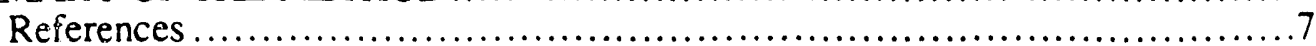

3 DESCRIPTION OF THE REACTOR AND OPERATIONS............................

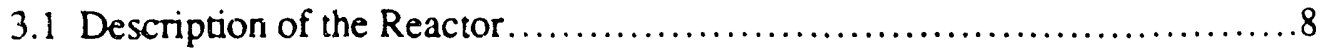

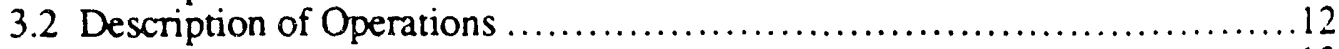

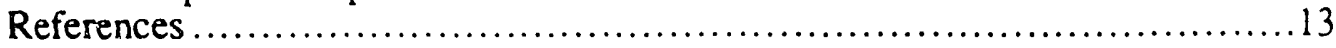

4 DESCRIPTION OF THE ASSEMBLY AND STATISTICAL MODELS $\ldots \ldots \ldots \ldots \ldots 14$

4.1 Description of the Accident ............................................14

4.2 Codes Used for the Assembly Model............................................15

4.2.1 The TRAC Code ...........................................15

4.2.2 The UNCERT Code Versions 16.1, 16.1b and 16.3 ...........15

4.3 The Statistical Model for an Assembly .................................. 17

4.3.1 The UNCERT Assembly Model.................................20

4.3.2 Heated Wall and Void Effects ................................

4.3.3 Pressure Boundary Conditions and System Parameters ...........22

4.3.4 Relative Power Shapes and Transients.............................22

4.3.5 Model of Azimuthal Variations......................................22

4.3.5.1 Azimuthal Power Distribution ...........................23

4.3.5.2 Flow Channel Eccentricity ...........................26

4.3.5.3 Rib Effects ....................................27

4.3.5.4 Uncertainty Analysis of the Asymmetric Effects

Multiplier..........................................28

4.3.5.5 Summary of POWCOMB Calculations....................... 31

4.3.5.6 Independence of $\beta_{3 D}$ From the Axisymmetric

Parameters ............................................32

4.3.5.7 Extension of Model for $\beta_{3 D}$ to Other Charges and

Other Parts of the Fuel Cycle..............................35

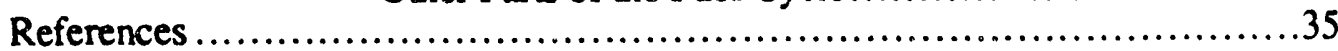

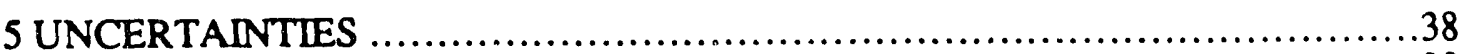

5.1 Description of the Uncertainties for an Assembly Without Cavitation .........38

5.2 Description of the Cavitation Model Uncertainties ........................46

5.3 Summary .............................................................. 47

References ............................................................. 49

6 SINGLE ASSEMBLY PROBABILITY CALCULATIONS..........................52

6.1 The Statistical Model for the Critical Effluent Temperature .................55

6.2 The Cumulative Distribution Function for the Critical Effluent

Temperature.............................................................53

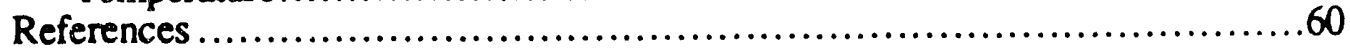


7 CORE PROBABILITY CALCULATIONS

7.1 The Assumption of Statistically Independent Assemblies....................62

7.2 Estimating the Distribution for All Assemblies ..........................62

7.3 Determining the Flowzone Limits ...................................66

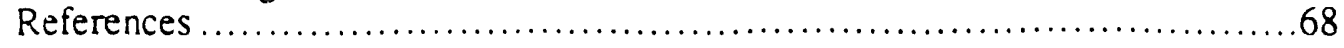

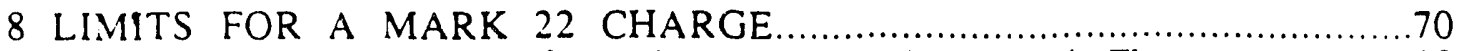

8.1 Uncertainty Analysis for the Most Limiting Assembly in Flowzone 1 . . . . . 70

8.2 Assembly Limits ..................................................... 73

References .......................................................... 77

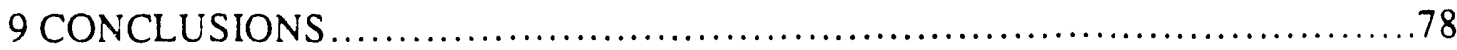

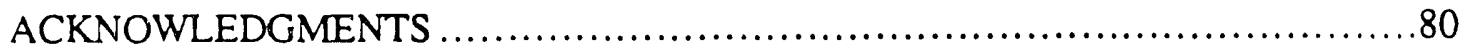

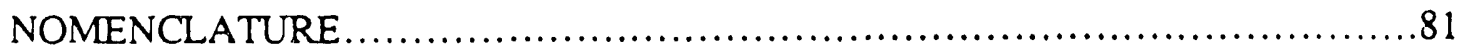

APPENDIX A - PROPERTIES OF THE ASYMMETRIC EFFECTS MULTIPLIER .84

APPENDIX B - LIST OF UNCERTAINTIES $\ldots \ldots \ldots \ldots \ldots \ldots \ldots \ldots \ldots \ldots \ldots \ldots \ldots . \ldots \ldots$

APPENDIX C - PARAMETERS FOR THE SIGNIFICANT UNCERTAINTIES ......96

APPENDIX D - AZIMUTHAL FUEL DISTRIBUTIONS .......................97

APPENDIX E - JUSTIFICATION OF THE ASSUMPTION OF

STATISTICALL Y INDEPENDENT ASSEMBLIES. .99

E.1 Proof that the Assumption is Conservative if the Assemblies are

Positively Correlated.

E. 2 Covariance in the Critical Effluent Temperatures 99

E. 3 Conclusions

APPENDIX F - SUMMARY OF SENSITIVITY COEFFICIENTS 106 


\section{INTRODUCTION}

The "Safety Analysis of Savannah River Production Reactor Operation" [1] states that a coolable core geometry must be maintained in the event of the worst double-ended guillotine break loss-of-coolant accident (DEGB/LOCA) which is accompanied by the worst single active failure. This criterion can be met by assuring that the assembly metal temperatures during this design basis accident do not exceed values that result in a loss of structural integrity.

The worst postulated DEGB/LOCA is a coolant pipe break at the plenum inlet. This accident is divided into two phases, the first of which is addressed in the uncertainty analysis. The first phase of the accident includes all events prior to the start of the emergency core cooling system while the second phase includes all events after the start of the emergency core cooling system. In the first phase of the accident, coolant flow from the break results in plenum depressurization, which in turn results in a reduction in core flowrate. Safety rod insertion does not begin until approximately 1 second after the occurrence of the break and the rods are not completely inserted until approximately 2 seconds after the break [2]. The resulning flow-power mismatch causes the assembly fuel temperarure and the bulk coolant temperature to increase. For a Mark 22 charge, the structural integrity of an assembly will be maintained duritg the initial phase of a doubleended break if the coolant flow is maintained. The mechanism for disrupting the flow during the first phase of the transient is Ledinegg flow instability. Thus, a coolable geometry will be maintained during the first few seconds of the accident if flow instability does not occur in any assembly in the core. Because flow instability is used as the safety criterion during this phase of the accident, it is called the flow instability (FI) phase. During the first phase of the accident, the failure of the safety rod of highest worth to insert during the SCRAM is the worst single active failure. However, in modeling the accident, 9 out of 64 safety rods are assumed not to enter the core. This accounts for rods which are assumed to be tied off and rods whose performance is assumed to degrade during operations.

Two criteria are used to preclude the occurrence of flow instability during the first phase of the accident. The first criterion is that the bulk coolant temperature must be below the saturation temperature at all locations in all assemblies. The second criterion is that the local Stanton number $\left(\mathrm{q}^{\prime \prime} / \mathrm{Gc} \mathrm{c}_{\mathrm{p}}\left(\mathrm{T}_{\text {sat }}-\mathrm{T}_{\text {bulk }}\right)\right.$ ) must not exceed 0.00455 at any location in any assembly [3]. The latter criterion is based on the assumption that significant voiding precedes flow instability. A Stanton number of 0.00455 is 70 per cent of the minimum Stanton number given by the Saha-Zuber correlation for onset of significant voiding [4]. At the power levels at which the reactor will be operating, the Stanton number criterion is the most limiting of the two criteria during the flow instability phase of the accident [5], and prototypical test data have shown this criterion to be a conservative predictor of flow instability [0].

Several best estimate computer codes are used to model an assembly but the principal codes are TRAC and FLOWTRAN. TRAC-PFI/MOD1 [7] is used to calculate the system response and provide transient pressure boundary conditions for the assembly model. FLOWTRAN [8] is the assembly model which calculates the maximum assembly power allowed by the Stanton number criterion. Modified versions of FLOWTRAN, renamed as UNCERT Versions 16.1,16.1b and 16.3, are used for flexibility in obtaining assembly power limits for a variety of assembly boundary conditions. 
In order to be useful during reactor operations, the assembly power limits are expressed as assembly effluent temperanure limits. The steady-state effluent temperature corresponding to the maximum power allowed by the Stanton number criterion, for a given set of parameters, is called the critical effluent temperature.

The effluent temperature limits calculated with the TRAC/FLOWTRAN assembly model are subject to uncertainties in the model and to uncertainties actually occurring in the reactor. Uncertinties in the assembly model are the result of uncertainty in the model parameters, approximations used for the FLOWTRAN model, and approximations in the codes used to generate the boundary conditions for the FLOWTRAN model. Uncertainties actually occurring for the reactor operation arise from manufacturing tolerances, variations in process operations, and process measurement errors. These uncertainties must be quantified and propagated through the analysis. Probability distributions are used to quantify many of the uncertainties; however, it is difficult to characterize some of the uncertainties with probability distributions. Therefore, bounding values are used in these
cases.

The uncertainty ana!ysis for a single assembly yields the probability of not exceeding the Stanton number criterion in that assembly. Because the power profile in the Savannah River reactors is relatively flat, the probability of not exceeding the Stanton number limits. There are more liming assembly in the core is not a sufficient basis for setting power limits. There are more than 400 assemblies in the Savannah River reactors; and even though the single worst assembly may have a low probability of exceeding the Stanton number criterion, the probability that at least one assembly in the entire cor will exceed this criterion may be large. Therefore, it is necessary to express the safety margin in terms of the probability that the Stanton number criterion is satisfied for every assembly in the core.

Because the double,ended guillotine break is a low probability accident, an $84 \%$ core probability level is used to set the effluent temperanure limits for the reactors. Thus, the goal of the flow instability limits analysis is to determine the assembly effluent temperature limits such that there is an $84 \%$ probability that no assembly exceeds the Stanton number
criterion.

In summary, the operating limits for the SRS reactors are given in terms of bounding assembly effluent temperatures, which are measured during operation. If the assembly model and the reactor operation were perfect, an assembly operating with effluent temperatures at or below the limits would not ente- into flow instability in the event of a DEGB/LOCA. Because of uncertainties in the model and process there will be uncertainties in the effluent temperature limits. The procedure for calculating the effluent temperature limits for a DEGB/LOCA is:

1. Define a limit criterion for each assembly.

2. Define a corewide probability of no assembly failure.

3. Compute a distribution of the assembly critical effluent temperatures, based on the assembly limit criterion, which accounts for the uncertainies in the model and reactor operations.

4. Use the assembly critical effluent temperature distributions to determine assembly effluent temperanure limits which satisfy the the required corewide probability of no assembly failure. 
This manual describes the methods used to obtain limits for a Mark 22 charge based on the requirement that there is at least an $84 \%$ probability that no assembly exceeds the Stanton number criterion. This manual serves several purposes: it is a comprehensive summary of the method, it is a guide for those who are performing the uncertainty analysis and it is a source of detailed information for those wishing to improve or extend the analysis in the future. The manual includes a description of the uncertainties in both the model and the actual reactor operation, a discussion of the codes and models used in the analysis, a discussion of the methods used to obtain the probability distributions for a single assembly, and a description of the method used to relate the single assembly analysis to the entire core. The specifics of the method described in this manual apply only to a Mark 22 charge in the $\mathrm{K}$ reactor, but with some revisions, the basic method can be applied to any type of charge.

\section{References}

1. Brith, T. , Editor, "Safety Analysis of Savannah River Production Reactor Operation," E. I. du Pont de Nemours \& Company Report DPSTSA-100-1 (1987).

2. Dehart, M. D., Griggs, D. P., Hardy, B. J., Massey, W. M. "LOCA FI Limits Methodology," Westinghouse Savannah River Company Report WSRC-TM-90-4 (1990).

3. Buckner, M. R., "Follow Up to Review of F.I. Limits Methodology Meeting August 30 to September 2, 1988, SRL, " E. I. du Pont de Nemours \& Company Memorandum to L. C. Sjostrom (September 28, 1988).

4. Saha, P. and N. Zuber, "Point of Net Vapor Generation and Vapor Void Fraction in Subcooled Boiling," International Heat Transfer Conference, 5th Proceeding, Tokyo, Japan, Vol. 4 (Sepiember 1974).

5. Massey, W., D. Griggs, and S. Painter, "Flow Instability Analysis of a Design Basis LOCA for the K14.1 Subcycle," Westinghouse Savannah River Company Report WSRC-RP-1287 (1989).

6. Chen, K., P. Paul, and K. Bartour, "FLOWTRAN Benchmarking With Onset of Flow Instability Data From 1988 Columbia University Single-Tube OFI Experiment," Westinghouse Savannah River Company Report WSRC-RP-89-870, June (1990).

7. "TRAC-PF1/MOD1: An Advanced Best-Estimate Computer Program for Pressurized Water Reactor Thermal-Hydraulic Analysis," Los Alamos National Laboratory Report NUREG/CR-3858 (1987) (Revised).

8. Aleman, S. E., M. V. Gregory, L. L. Hamm, L. D. Koffman, R. E. Pevey, W. H. Reed, and F. G. Smith, "FLOWTRAN: An Algorithm for Describing the ThermalHydraulic Behavior of SRP Assemblies," E. I. du Pont de Nemours \& Company Report DPSTM-140, Version 16.1, Rev. B (1988). 


\section{SUMMARY OF THE METHOD}

This manual describes the uncertainty analysis used to determine the effluent temperature limits for a Mark 22 charge in the Savannah River Site production reactors. The postulated accident scenario is a DEGB/LOCA resulting from a coolant pipe break at the plenum inlet accompanied by the safery rod failure described in the previous chapter. The analysis describad in this manual is used to calculate the limits for the flow instability phase of the accident. For this phase of the accident, the limits criterion is that the Stanton number does not exceed 0.00455 [1]. The limits are determined for a specified $84 \%$ probability that the Stanton number will not exceed 0.00455 in any assembly in the core.

A Mark 22 charge in the Savannah River Production Reactors consists of about 400 fuel assemblies. An assembly consists of concentric fuel and target tubes inside a housing tube. Each assembly represents a separate flow path. These assemblies are grouped into flowzones. Assembly effluent temperature limits are set for each flowzone to ensure that a coolable core geometry is maintained in the event of the postulated DEGB/LOCA. The difference between the assembly effluent temperature limit and the assembly inlet temperaiure is called the limiting temperature rise actoss an assembly.

The problem of determining the flow instability limits would be straight forward if the models and actual reactor operational parameters were exact. However, the data and the correlations are subject to uncertainty, and the models and codes contain inaccuracies, which must be accounted for in determining the limits. Some of the uncertainties in the data and the models are described by probability distributions, so that the limits criterion is satisfied in a probabilistic sense. For a given set of values for the uncertainty parameters, the effluent temperature limit is called the critical effluent temperature. Therefore, there is a critical effluent temperature corresponding to each set of assembly parameters. By characterizing the assembly parameters with distributions and bounding values, a distribution of critical effluent temperatures is obtained for each assembly.

The assembly critical effluent temperature is calculated with models based on the TRAC [2] system code and the FLOWTRAN [3] assembly code. In order to facilitate variations in a wider range of parameters, a modified version of FLOWTRAN called UNCERT, is used to model an assembly. There are three versions of UNCERT which are used to model variations in different groups of parameters. The tansient plenum and tank bottom pressure boundary conditions for an assembly are obtained from TRAC using a reasonable estimate of the power. The limiting assembly power is calculated by using these transient pressure boundary conditions, together with other assembly boundary conditions, as input to the UNCERT code. The UNCERT code is used to determine the steady-state assembly effluent temperature such that the Stanton number limit is not exceeded during the transient.

Power is the primary source of feedback between the system and the assemblies. If cavitation in the external loops does not occur during the flow instability phase of the transient, the system response is relatively independent of power. In this case, there is no need to be concerned with mechanisms for feedback between TRAC and UNCERT.

Under certain conditions, cavitation can occur in the coolant pump suction piping and the coolant pumps. Cavitation will cause a decrease in the plenum pressure beyond that due to the hydrodynamics of the break. As a result of cavitation, the transient pressure boundary conditions on the assembly are a function of power. Because a cavitation model is not included in the TRAC system code and because it is impractical to iterate between TRAC and the FLOWTRAN, a code called UNCERT Version 16.3 [4] was developed to incorporate the effects of cavitation into the analysis. UNCERT Version 16.3 is a version 

of FLOWTRAN which uses power dependent boundary conditions to mimic the effects of
cavitation.

Even without cavitation effects, limitations on computer time make it impractical to directly calculate a distribution of critical effluent temperatures from the TRAC/UNCERT assembly model. To overcome this difficulty, a simplified statistical model for the critical effluent temperature is developed. The statistical model for the critical effluent temperature will produce a critical effluent temperature distribution which is statistically equivalent to that obtained by direct calculation. Other factors entering into the the statistical model are
described below.

During the DEGB/LOCA transient, the formation of voids on the heated surfaces of the assembly in the flow regime between the onser of nucleate boiling and the onset of significant voiding will result in increased flow losses. This effect is called the void effect.

The heating of fluid adjacent to the heated surfaces of an assembly will result in a reduction in the local fluid viscosity. The local viscosity reduction will result in a reduction in the flow losses. This effect is called the heated wall effect.

Direct calcuiation of the heated wall and void effects requires a large amount of computer time and it is found that these effects do not significantly affect the effluent temperature limits. Therefore, the heated wall and void effects are calculated by treating them as constant multiplicative biases on the limiting temperature rise across an axisymmetric
assembly.

Reductions in flow channel area result from thermal expansion and manufacturing tolerances in the assemblies. Variations in the surface heat flux are caused by azimuthally asymmetric distribution of fuel and lithium, flux tilt across assemblies and the effects of ribs. These three dimensional effects affect the effluent temperature limit. Ideally, FLOWTRAN could be run in three dimensional mode to calculate the impact of these effects, but such calculations would require an excessively large amount of computer time. It is shown that these three dimensional asymmetric effects are separable from the boundary conditions on an axisymmetric assembly. Therefore, the asymmetric effects are invoked as a multiplier on the temperature rise across an axisymmetric assembly. The value of the asymmetric effects multiplier depends on the degree of fuel/lithium azimuthal maldistribution, the orientation of the maldistribution to the flux tilt, and other parameters. Therefore, there is a statistical distribution of values for the asymmetric effects multiplier.

The statistical model for the critical effluent temperature of a given assembly is:

$$
T_{c t}=T_{\text {in }}+\beta_{\text {void }} \beta_{h w} \beta_{3 D} \Delta T_{\text {ideal }} \text {. }
$$

where: $\quad T_{c r}=$ the assembly critical effluent temperature

$T_{\text {in }}=$ assembly inlet temperature

$\beta_{\text {void }}=$ void effect multiplier, a constant

$\beta_{\text {hw }}=$ heated wall effect multiplier, a constant

$\beta_{3 D}=$ asymmetric effects multiplier, an uncertainty parameter

$\Delta \mathrm{T}_{\text {ideal }}=$ the limiting steady stare temperature rise for an idealized assembly.

An idealized assembly is an axisymmetric assembly, without cavitation effects, for which the void and heated wall effects are not included. 
In equaticn $2.1 \mathrm{~T}_{\mathrm{cr}}$ is expressed as a function of random variables. This equation is the basis for the uncertainty analysis and is used to generate a distribution for $\mathrm{T}_{\mathrm{cr}}$. Sources of uncertainty in the critical effluent temperature were identified by a qualitative assessment of the phenomena, examination of input parameters and correlations for the UNCERT code, and historical operating experience. The uncertainties can be placed into five categories:

1. Manufacturing uncertainties, which include tolerances, geometric alignment, and material composition.

2. Data base uncertainties, which include solid properties, fluid properties, heat transfer correlations, and flow parameters.

3. Uncertainties in input obtained from other codes, which include TRAC and the neutronics codes.

4. Uncertainties resulting from model idealization, which include UNCERT approximations, nodalization, and convergence criteria.

5. Errors in process measurements used to apply the limits.

An exhaustive list of uncertainties was compiled. In the absence of cavitation, there are 91 possible uncertainties that affect the asymmetric effects multiplier and the UNCERT model for an axisymmetric assembly [5]. Sensitivity studies show that only 27 of these uncertainties are significant. Only six of the 23 identified uncestainties [6] that affect the cavitation model in UNCERT Version 16.3 were found to be significant. Probability distributions were used to describe most uncertainties; however, worst case values were used for six of the uncertainties because these uncertainties are too complex to be described by a simple probability distribution.

The standard deviation of the assembly critical effluent temperature distribution does not vary significantly with the position in the core, so the distribution having the largest standard deviation is used for all assemblies in the core. For reference this distribution is called the limiting critical effluent temperature distribution.

The flowzone effluent temperature limits are determined by partitioning the corewide $84 \%$ probability of no assembly damage among the flowzones. The approximate mean critical effluent temperature for each assembly in a given flowzone is determined by interpolating on the mean critical effluent temperanures of assemblies locatec, at the center of the TRAC plenum cells. This interpolation is used to get the relative separation between the mean assembly effluent temperatures for all assemblies in each flowzone. The limiting critical effluent temperature distribution is applied about the mean critical effluent ternperature of each assembly in the flowzone. The flowzone effluent temperature limit is such that the product of the integrals of the assembly distributions, from $-\infty$ to the temperature limit, is equal to the flowzone probability for no assembly damage. From a knowledge of the flowzone effluent temperature limit and the minimum mean effluent temperature for any assembly in the flowzone, the distance between the two values can be calculated in terms of the number, $\mathrm{N}$, of sti adard deviations for the uritical effluent temperature distribution. The final flowzone effluent temperature limit is calculated by subtracting the product of $\mathrm{N}$ and the standard deviation from the mean limiting effluent temperature for an assembly in the flowzone calculated from FLOWTRAN. 
The effluent temperature limit for the $\mathrm{k}^{\text {th }}$ flowzone is given by:

$$
T_{\text {lin } k}=\mu_{T_{\text {in }}}+\beta_{\text {void }} \beta_{h w} \mu_{\beta_{3 D}} \mu_{\Delta T_{\text {ideal } k}}-N_{k} \sigma
$$

where:

$$
\begin{aligned}
\mu_{T_{\text {in }}} & =\text { mean inlet temperature } \\
\mu_{\beta_{3 D}} & =\text { mean value of } \beta_{3 D} \\
\mu_{\Delta T_{\text {ideal } k}} & =\text { minimum mean value of } \Delta T_{\text {ideal }} \text { for any assembly in the } k^{\text {th }}
\end{aligned}
$$

$N_{k}=$ number of standard deviations that the effluent temperature limit lies below the minimum mean flowzone effluent temperature limit in the $\mathbf{k}^{\text {th }}$ flowzone

$$
\begin{aligned}
& \sigma=\text { the standard deviation of the limiting critical effluent temperature } \\
& \text { distribution. }
\end{aligned}
$$

\section{References}

1. Chen, K., Paul, P. K., Barbour, "FLOWTRAN Benchmarking With Onset of Flow Instability Data From 1988 Columbia University Single-Tube OFI Experiment," WSRC-RP-89-870 (June, 1990).

2. TRAC-PF1/MOD1: An Advanced Best-Estimate Computer Program for Pressurized Water Reactor Thermal-Hydraulic Analysis," Los Alamos National Laboratory Report NUREG/CR-385\& (1987) (Revised).

3. Aleman, S. E., M. V. Gregory, L. L. Hamm, L. D. Koffman, R. E. Pevey, W. H. Reed, and F. G. Smith, "FLOWTRAN: An Algorithm for Describing the ThermalHydraulic Behavior of SRP Assemblies," E. I. du Pont de Nemours \& Company, Inc. Report, DPS TM. 140, Version 16.1, Rev. B (1988).

4. Laurinat, J. E., "Documentation of CVTTN Version 1, Revision 1," Westinghouse Savannah River Corporation Memorandum, NES-RFI-900032, Rev. 1 (1990).

5. Kubic, W. L., "The Identification and Quantification of Uncertainties for the Flow Instability Limits Uncertainty Analysis for a Mark 22 Assembly", Westinghouse Savannah River Corporation Memorandum, NES-RFI-900047, FIU-90-22 (April 30, 1990).

6. Kubic, W. L., "The Identification and Quantification of the Uncertainties Affecting Cavitation," Westinghouse Savannah River Corporation Memorandum, NES-RFI900048, FIU-90-23 (April 30,1990). 


\section{DESCRIPTION OF THE REACTOR AND OPERATIONS}

The uncertainty analysis is applied to uncertainties in the design of the reactors, their operational characteristics and the analytical model used to predict the operating limits. The analytical models themselves are based on the reactor design and operations. It is therefore natural to begin a description of the uncertainty analysis methodology with a description of the reactor and reactor operations.

\subsection{Description of the Reactor}

The Savannah River Site reactors are heavy water moderated reactors, which operate at low temperatures and low pressures. These reactors are used to produce a variety of special nuclear materials. This manual considers one particular type of charge, the Mark 22 charge, in the $\mathrm{K}$ reactor. The Mark 22 charge is the primary tritium producing charge.

The flow instability limits for the Savannah River reactors are based on the behavior of the reactor and the Primary Cooling System during the first few seconds of the worst postulated double-ended guillotine break. The Primary Cooling System consists of the reactor tank, the circulating pumps, the heat exchangers, the valves, the plenum and all connecting piping [1]. The reactor tank contains the nuclear fuel and targets, the control rods, other reactor intermals, and heavy water, wich serves both as the coolant and the moderator. The circulating pumps, the heat exchangers, and the connecting piping form the primary cooling loops. The primary cooling loops provide heat removal during normal operations. There are six parallel primary cooling loops with a steady-state flow of approximately 25,000 gpm per loop. The secondary side cooling water in the heat exchangers is obtained from the cooling ponds. A schematic of the primary cooling system is given in Figure 3.1.

The primary coolant enters the reactor inlet plenum at the top of the reactor tank through six inlet nozzles. The inlet plenum distributes the flow to the assemblies. The primary coolant enters an assembly at the top and flows down through the entire length of the assembly. Upon exiting the assembly, the primary coolant is mixed with the bulk moderator in the tank. The coolant exits the reactor through six outlet nozzles along the circumference of the reactor tank bottom.

A Mark 22 assembly is composed of an inner target tube, surrounded by the inner and outer fuel tubes, which are surrounded by an outer target tube. These tubes are placed inside of a universal sleeve housing. The target tubes are composed of a lithium- 6 /aluminum alloy clad in aluminum. The fuel tubes are composed of a uranium/aluminum alloy with an aluminum cladding. Some tubes have aluminum ribs, which are used as spacers to center the tubes. A cross section of a Mark 22 assembly is shown in Figure 3.2. The ribs on the universal sleeve housing, the outer target, and the inner fuel are staggered at $45^{\circ}$ intervals. The ribs on the inner target do not have a specified orientation with respect to the other ribs. The annular spaces between the tubes are called channels, and the segments of a channel bounded by the ribs are called subchannels [2].

The fuel ard target tubes are extruded so the tolerances are extremely small. The nominal length of the inner and outer fuel tubes are 163.0 and 161.5 in. respectively, and the nominal length of the inner and outer targets are 170.5 and 174.4 in. respectively. The active region of a tube is the portion of the tube that contains fuel or target material, the nominal length of the active region is 152 in. [2] The universal sleeve housing extends above and below the fuel and target tubes. This extension allows for the placement of top 


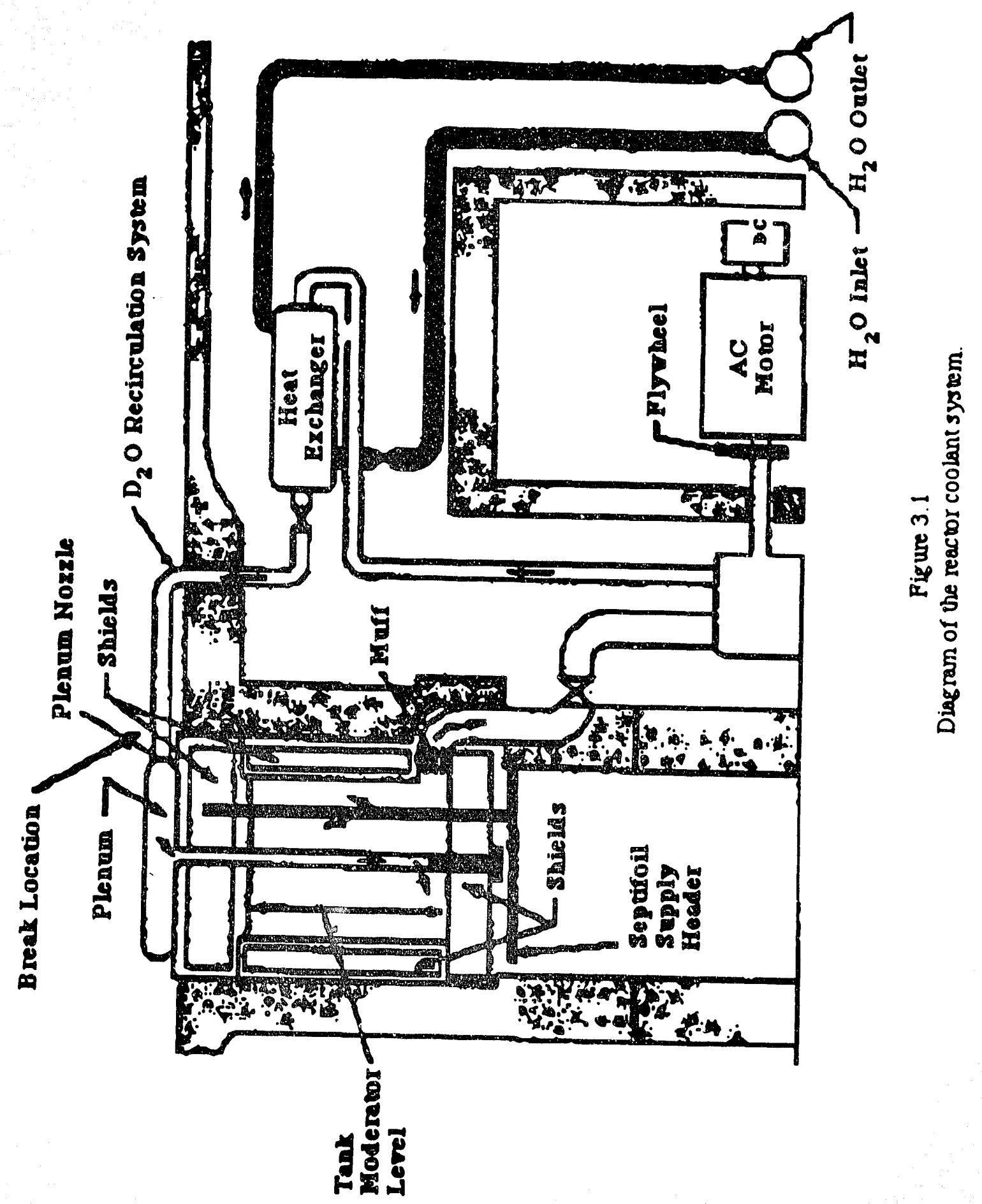




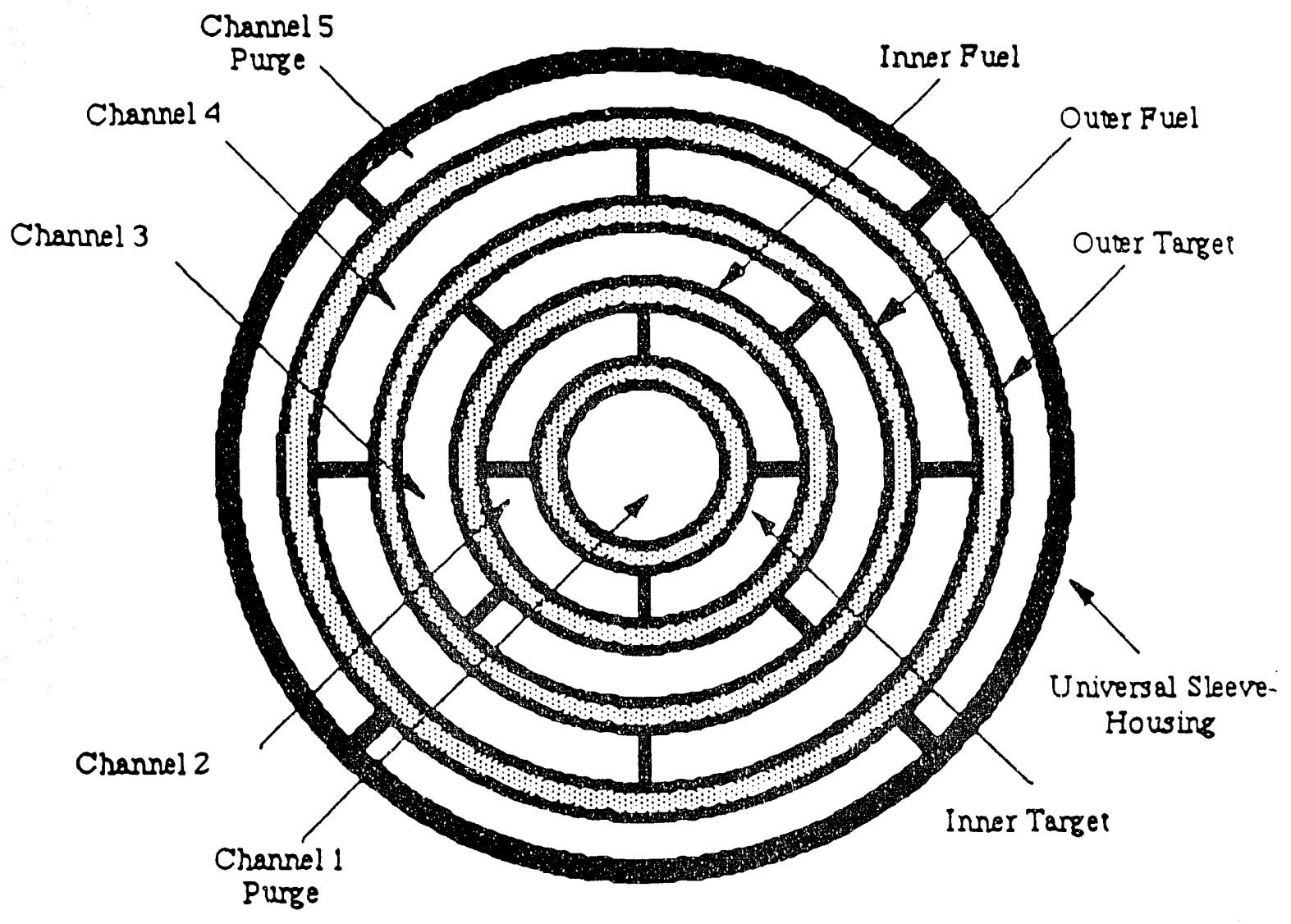

Figure 3.2

A Mark 22 assembly cross section.

and bottom end fittings. The end fittings are used to position the assemblies in the core and to regulate the assembly flow. The coolant enters the universal sleeve housing through slots in the permanent sleeve at the top of the assembly and leaves through the shell holes at the bottom of the assembly. The shell holes at the bottom of the assembly have a net flow area that is less than the assembly flow area. This reduction in flow area causes the pressure in the shell holes to be lower than in the heated length of the assembly. In addition, the coolant temperature is greatest at the bottom of the assembly. The combination of these effects makes the assembly shell holes the most likely location for coolant flashing to occur.

Most of the core of a Mark 22 charge consists of super cells that contain six assemblies surrounding a single control position to form a hexagonal lattice [3]. A super cell is illustrated in Figure 3.3. The control position is composed of six lithium/aluminum rods and a cadmium rod. The cadmium rod is not inserted during operation. The assemblies are positionti so that the ribs for all assemblies are oriented in the same direction. The symmetry of the super cell is such that there are two possible orientations of the ribs with respect to the central control position as shown in Figure 3.3. There are four assemblies with orientation A and two with orientation B. The interstitial positions contain the heavy water moderator, safety rods, and instrument ports. 


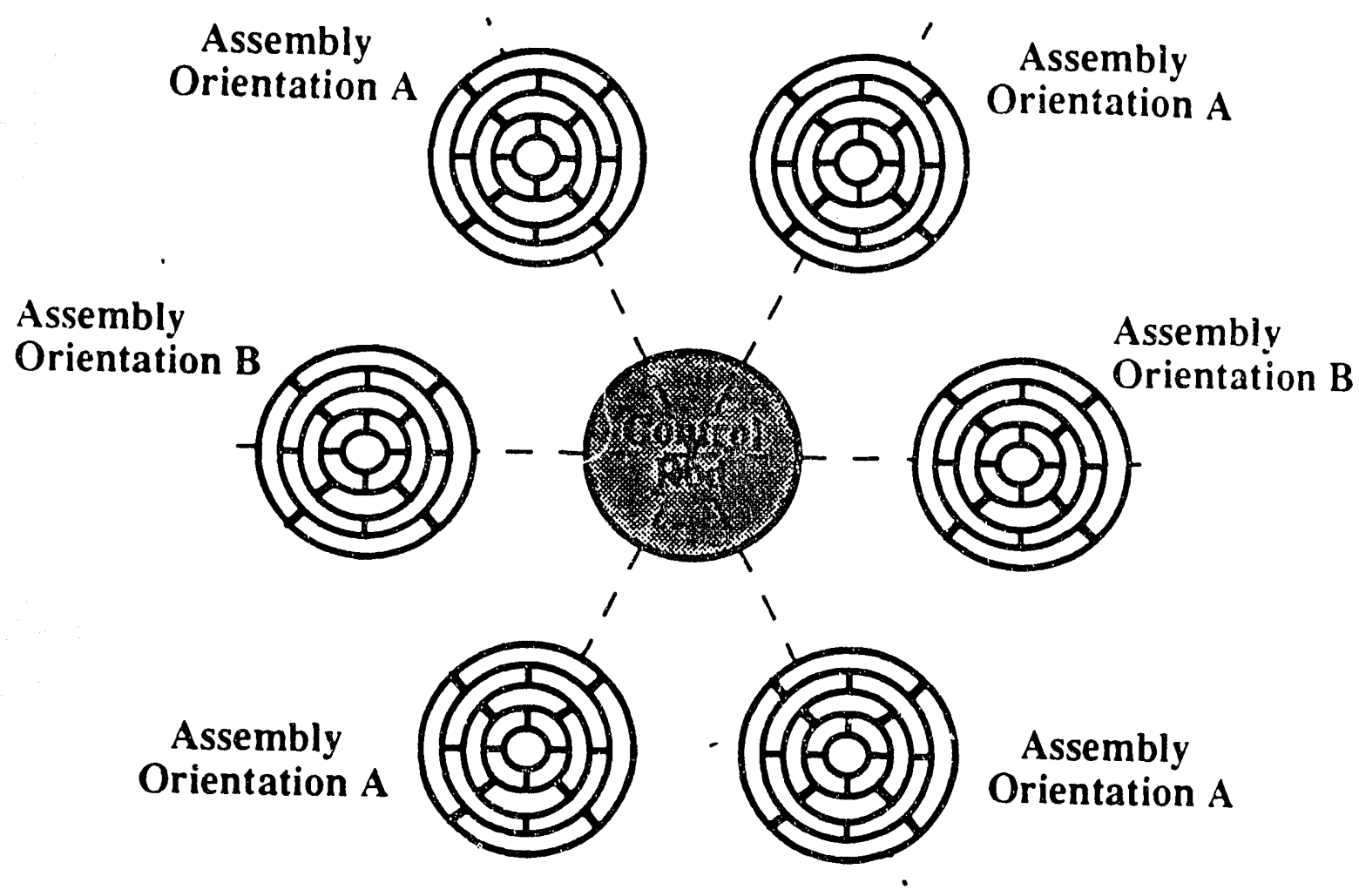

Figure 3.3

Assembly rib orientation relative to a control rod.

There are 61 of these super cells in the core [3]. This lattice is surrounded by Mark 22 assemblies that are not part of any super cell, and Mark 60B lithium target assemblies. The Mark 22 assemblies which are not in super cells are near the edge of the core, so they operate at low powers. The Mark 60B assemblies are low power assemblies with no coolant flow. The Mark 22 assemblies are grouped into flowzones. Flowzones are groups of assemblies which have similar operating powers and flows. All of the assemblies within a flowzone have the same orifices and the same number of shell holes in the top and bottom
of the assembly.

Ideally, the fuel and target tubes in a Mark 22 assembly would be concentric and the uranium and lithium concentrations in the fuel and target tubes would be uniform. Real Mark 22 assemblies deviate from this ideal axisymmetric geometry because the assemblies are manufactured with non-zero tolerance specifications. The fuel thickness in the fuel tubes and the lithium thickness in the target tubes vary azimuthally and axially as a result of variations in the manufacturing processes. Technical specifications exist for the maximum deviation in fuel thickness from its nominal value [4]. No specification exists for the allowable azimuthal variation in the lithium thickness. However, similarities in manufacturing processes for fuel and target tubes will give similar azimuthal variation in the lithium thickness. Because there is some clearance between the tubes and the ribs, the fuel and target tubes will not be concentric. Eccentricity in the fuel and target rubes causes the
subchannel flow areas to deviate from their nominal values. Variations in the dimensions of the fuel and target tubes do not contribute significantly to the deviations in the subchannel flow areas. 


\subsection{Description of Operations}

A Mark 22 charge remains in the reactor for a period of one to one and one-half years depending on the power level [4]. There is no movement of the fuel assemblies during the cycle; however, the inner targets may be removed and replaced by fresh targets about halfway through the cycle.

Power profiles and shapes are adjusted with the control rods. Technical specifications exist for the dishing and tilt of the power [5]. The objective is to maintain a flat profile in the reactor. The axial power shape is also controlled. A technical specification exists for the axial power shape [5]. The axiil power monitors in the core are used to measure and control the power shape.

The control rods in the center of a super cell cause a flux tilt across an assembly. The lithium in the control rods is not as strong a thermal neutron absorber as the fuel and lithium in the assembly. Therefore, the thermal neutron flux in the region of a control rod is greater than the flux in the region of the assemblies. The flux tilt causes an azimuthal power variation within an assembly. The magnitude of the flux tilt depends on the rod positions and the exposure.

During normal operations, coolant is supplied to the core by the six primary cooling loops. The inlet temperature is a function of the reactor power level and the temperature of the cooling pond water. Because the inlet temperature is a function of the pond water temperature, the inlet temperature will vary from season to season. Typically, the inlet temperature varies between 20 and $45^{\circ} \mathrm{C}$ for expocted restart power levels.

The overall reactor power is determined by setting steady-state effluent temperature limits for each assembly. The assembly effluent temperature limits are a function of the reactor inlet temperature. This functionality is such that the power decreases with increasing inlet temperature. The effluent temperature limit for every assembly as a function of the inlet temperature is programmed into the process control computer.

The inlet temperaiure is measured at each of the six inlet nozzles in the reactor iniet plenum. Two resistive thermal devices (RTDs) are located in each nozzle. Because of variations in each of the six primary cooling loops, the temperature at each inlet nozzle varies. The two RTDs will also give slightly different readings because of instrument errors and possible temperature gradients in the nozzles. The average inlet temperature for a nozzle is the average of the readings of tire two RTDs located in that nozzle. The inlet temperature used by the control computer is the minimum of the six average inlet temperatures. The effluent temperature limits are expressed in terms of the nominal inlet temperature read by the control computer.

There are four thermocouples located at the bottom of every assembly to measure the effluent temperature. The measured assembly effluent temperature is the average of the four thermocouple readings. Together with the assembly inlet temperature, the average temperature given by the four thermocouples is used to determine the assembly power. 
In the event of an accident, safety systems exist to protect the core from damage. The critical safety system during the flow instability phase of the double-ended guillotine break is the safety rod system. There are 66 safety rods in the reactor [3]. The number of safety rods that drop and the safety rod drop times govern the rate at which the power decreases. The technical specifications state that 64 of the safety rods must be functioning at the beginning of a cycle [5]. There also are technical specification for the rod drop times that must be satisfied prior to the beginning of a fuel cycle [5]. Satisfying the rod drop time specification at the beginning of the cycle does not guarantee that this specification is satisfied at other times during the cycle because there is some degradation of performance during operations. Therefore, the rods are modelled conservatively in the uncertainty analysis.

\section{References}

1. Kuehn, N. H., "NBB-1 Limits Methodology Roadmap," E. I. du Pont de Nemours \& Company, Inc. Report DPST-88-397 (1988).

2. Boswell, J. M., "Hydraulics and Heat Transfer of Mark 22 Fuel Assemblies," E. I. du Pont de Nemours \& Company, Inc. Report DPSTM-22(H) (1974).

3. Cefus, G. R., "Revised Flow Design for the K-14.1 Mark 22 Charge," Westinghouse Savannah River Company Draft Report WSRC-RP-89-1289 (1989).

4. Swingle, R. F., "K-14 Mark 22 Charge Specifications," Westinghouse Savannah River Company Report WSRC-TR-90-00080 (1990).

5. Andrachek, J. et al., "Savannah River Site Technical Specifications for K Production Reactor," Westinghouse Draft Report WCAP-12529 (1990). 


\section{DESCRIPTION OF THE ASSEMBLY AND STATISTICAL MODELS}

The safety criterion for the flow instability phase of the worst double-ended guillotine break is that the Stanton number be less than or equal to 0.00455 during the transient on the surface of any tube in any assembly. The effluent temperanure limits are calculated with an assembly model which is based on the TRAC-PF1/MOD1 [1] system code and the FLOWTRAN [2] assembly code. A modified version of FLOWTRAN called UNCERT Version 16.3 [3] has been developed to treat the effects of cavitation. In principle, the input parameters could be randomly varied according to their distributions and, by using UNCERT Version 16.3 in three dimensional mode, the critical effluent temperature distribution for every assembly in the core could be calculated. However, the enormous amount of computer ime required to make sufficient runs to describe the critical effluent temperature distributions for all assemblies in the core makes this approach impractical. The assembly model is therefore not suitable for direct application to an uncertainty analysis of the assembly effluent temperature limits.

In order to make the problem tractable, a simplified approach for generating the limits is taken. This approach involves the development of a simplified statistical model for describing the assernbly critical effluent temperanure distributions. The assembly model, based on TRAC and UNCERT is used to generate the parameters used in the statistical model.

The statistical model must account for the response of the critical effluent temperature to all important uncertainties in:

1. Physical phenomena that occur during the flow instability phase of the accident .

2. Reactor process parameters.

3. The TRAC/UNCERT assembly model itself.

The statistical model must produce critical effluent temperature distributions which are equivalent to those which would be obtained by a large number of repetitions of the TRACINCERT assembly model.

\subsection{Description of the Accident}

In order to give a complete description of the of the models used for the DEGB/LOCA it is necessary to begin with a brief description of the accident.

The postulated DEGB/LOCA is initiated by an instantaneous break of one of the primary cooling loops at the entrance to the inlet plenum. As a result of the break, the pressure throughout the reactor decreases, the assembly flows are reduced, the reactor tank level drops, and the blanket gas expands. A SCRAM is initiated as soon as the inlet plenum pressure drops by $10 \%$. This pressure drop occurs in less than $0.01 \mathrm{~s}$. At about $1 \mathrm{~s}$ into the accident, safety rod inserion begins and the power begins to decrease. The core flow rate is nearly constant at this time. At about $2 \mathrm{~s}$, the safety rods are fully inserted; and the critical part of the flow instability phase of the accident is over [4]. Because the duration of the flow instability phase of the transient is small compared to the residence time of the coolant system, the reactor inlet temperature and the pump suction temperature are nearly constant during this phase of the accident. 
Flow within an assembly is single phase and turbulent. The assembly model must be able to predict the overall flow rate as well as the distribution of the flow among the subchannels. The total flow and the flow distribution depend on the hydraulic resistances, the fuel and target tube tolerances, and the eccentricities of the subchannels.

The assembly modid must incorporate the power shapes and power transients. The assembly model must be able to handle axial power variations as well as azimuthal variations. Azumuthal power variations are the result of a flux tilt and nonuniformities in the target and fuel material thicknesses. The power transients will depend on the safety rod drop times and the safety ror' worth. Because of the axial and azimuthal variations in the power, the assembly model must account for transient, three-dimensional conduction. The effect of ribs on the local heat flux also must be considered.

The assembly model must account for turbulent forced convection and subcooled nucleate boiling. Convective and subcooled nucleate boiling heat transfer affect the assembly flow. Temperature gradients near the hot fuel and target tubes decrease wall friction, and this decrease in friction is called the heated wall effect. Bubbles formed at the tube walls when subcooled nucleate boiling occurs reduce the flow area, which reduces the flow. This phenomenon is called void effect. Convective heat transfer, the heated wall effect, and the void effect must be considered in the assembly model.

\subsection{Codes Used for the Assembly Model}

To a certain extent, the form of the thermal-hydraulic model of an assembly and the amount of detail incorporated into the assembly will be dictated by the capabilities and limitations of the available computer codes and computer resources. The thermal-hydraulics codes used in the analysis are: the TRAC-PF1/MODI system code, and modified versions of the FLOWTRAN assembly code, called UNCERT Versions 16.1,16.1b and 16.3 [5]. This section describes the capabilities and limitations of each of these codes and how they are used for calculating the critical effluent temperature for an assembly.

\subsubsection{The TRAC Code}

TRAC-PF1/MOD1 [1] is a general thermal-hydraulics system code for pressurized water reacto:s. TRAC can model three-dimensional two-phase and single-phase flow and twodimensional conduction in the axial and radial directions. This code includes a pump model, but it does not include a cavitation model for the pump or system piping. TRAC does not account for the heated wall effect or the void effoct. In principle, TRAC could be used to model the system and the details of an assembly simultaneously; but such a model is not practical. First, the model would require too much computer time. Second, TRAC cannot account for azimuthal conduction, which is important for modelling azimuthal power variations, Third, TRAC cannot be used to calculare a limiting power based on the Stanton number criterion. Therefore, TRAC is best suited to calculate assembly boundary conditions based on a model of the reactor system.

\subsubsection{The UNCERT Code Versions 16.1, 16.1b and 16.3}

The UNCERT code, versions $16.1,16.1 \mathrm{~b}$ and 16.3 are modified versions of the FLOWTRAN code. FLOWTRAN was specifically written to model the Savannah River fuel and target assemblies and is better suited for detailed assembly analysis than the TRAC code. FLOWTRAN requires assembly boundary conditions as input, the transient 
pressure boundary conditions are obtained from TRAC calculations. The version of FLOWTRAN used for the flow instability phase of the accident models one-dimensional single-phase flow in the assembly subchannels given the transient pressure boundary conditions. The code also calculates three-dimensional conduction in the fuel and target tubes. Three-dimensional transient power profiles can be input to this code. FLOWTRAN has the capability for calculating the limiting power and critical effluent temperature, for a given set of boundary conditions, based on :

1. The Stanton number criterion St $\leq 0.00455$.

2. The onset of bulk boiling or flashing.

3. The onset of nucleate boiling.

4. The onset of film boiling or burnout.

For the postulated DEGB/LOCA, the Stanton number criterion provides a closer limit to flow instability than nucleate boiling and, when uncertainties are considered, yields power limits which preclude film boiling, bulk boiling, and shell hole flashing [6]. Hence, in the flow instability phase, the Stanton number criterion is used to calculate the limiting assembly power and the limiting effluent temperature.

Three special versions of the FLOWTRAN code are used to calculate pammeters for the statistical model used in the uncertainty analysis. UNCERT Version 10, is a version of FLOWTRAN that permits perturbations of the heat transfer and physical properties correlations. UNCERT Version $16.1 \mathrm{~b}$ is used to calculate the heated wall and void effects. UNCERT Version 16.3 modifies the transient plenum press:ure obtained from the TRAC code to account for the effects of cavitation. A more detailed description of UNCERT Version 16.3 is given below.

Neither TRAC nor FLOWTRAN can perform both the system calculations and the detailed assembly calculations simultaneously, so both codes must be used in tandem. TRAC is used to calculate the system response and FLOWTRAN is used to calculate the limiting assembly power. If cavitation does not occur, the system calculations can be decoupled from the assembly calculations. If there is no cavitation, the system response is governed primarily by single phase liquid flow; so it is relatively independent of the heat transfer and the power. When TRAC and FLOWTRAN are decoupled, the calculation of the limiting power and the critical effluent temperature is straightforward. First, a TRAC model with a reasonable estimate of the power is used to calculated the system response. Next, the limiting power and the critical effluent temperature are obtained using a FLOWTRAN assembly model with the boundary conditions obtained from TRAC. Bocause the system response is not a strong function of power, there is no need to repeat the TRAC calculation.

If cavitation does occur, the plenum pressure during the transient will be reduced. The reduction in the plenum pressure during the transient will result in an reduced assembly power limit. The reduced assembly power limit will result in a reduced assembly effluent temperature and thus, a reduced tank temperature. The reduced tank temperature will result in reduced cavitation effects and an increased plenuns pressure during the transient. The increased plenum pressure during the transient will now result in an increased assembly power limit and so on. In this way it can be seen that, if cavitation occurs, the system and assembly responses are coupled through the assembly power. Neither TRAC nor FLOWTRAiv contain models for cavitation, and calculations have shown that cavitation must be considered [7]. 
The concept of using power dependent boundary conditions to mimic the effects of Cavitation on an assembly is implemented in the code UNCERT Version 16.3 [3]. conditions. The code 16.3 is a version of FLOWTRAN with power dependent boundary approximate nodel developed by TRAC results for the effects of cavitation using an of cavitation is a reduction in the iniet play $[7,8]$. This model assumes that the only effect pump suction piping and the pump. UNCERT Version 16 only treats cavitation in the of the heat transfer correlations and the physical properties 3 , also permits the perturbation

\subsection{The Statistical Model for an Assembly}

The critical effluent temperature for an assembly may be written as:

$$
\mathrm{T}_{\mathrm{cr}}(\mathbf{x})=\mathrm{T}_{\text {in }}+\Delta \mathrm{T}_{\mathrm{cr}}(\mathbf{x})+\varepsilon
$$

where: $\quad T_{c r}(x)=$ the assembly critical effluent temperature at the parameter values $:$

$$
\mathrm{T}_{\text {in }}=\text { the assembly inlet temperature }
$$

$$
\begin{aligned}
\Delta \mathrm{T}_{\mathrm{cr}}(\mathrm{x})= & \mathrm{T}_{\mathrm{cr}}(\mathrm{x})-\mathrm{T}_{\text {in }} \\
= & \text { the critical effluent temperature rise across an assembly at a value } \mathrm{x} \\
& \text { of the parameters } \\
\mathbf{x}= & \text { all parameters which affect the critical effluent temperature of an } \\
& \text { assembly } \\
\varepsilon= & \text { error in effluent temperature measure ment. }
\end{aligned}
$$

Three dimensional heat transfer effects caused by azimuthal variation in power and eccentricity in the flow channels must be considered in the limits analysis. The void and heated wall effects must also be included in the limits analysis. However, implicit treatment of these effects would require an impractically large amount of computer time. For the statistical model it is assumed that these effects may be treated separately from the axisymmetric model for the critical effluent temperafures. The axisymmetric model for assembly critical effluent temperatures which does not include three dimensional effects, cavitation, the heated wall effect or the void effect, is called the idealized model of an
assembly.

The effects are separated as follows:

$$
T_{c r}(x)=T_{\text {in }}+\beta_{h w} \beta_{\text {void }} \beta_{3 D}(y) \Delta T_{\text {ideal }}(z)+\varepsilon
$$

$$
\text { where: } \quad \begin{aligned}
\quad \beta_{h w} & =\frac{\Delta T_{\text {as with heated wall effects }}}{\Delta T_{\text {as without heated wall effects }}} \\
& =\text { heated wall effect multiplier, a constant multiplicative bias }
\end{aligned}
$$




$$
\begin{aligned}
& \beta_{\text {void }}=\frac{\Delta T_{\text {as with void effect }}}{\Delta T_{\text {as without void effect }}} \\
& \text { = void effect multiplier, a constant multiplicative bias } \\
& \beta_{3 D}(y)=\frac{\Delta T_{\text {asymmetric assembly }}}{\Delta T_{\text {axisymmetric assembly }}} \\
& =\text { asymmetric effects multiplier as a function of the asymmetric } \\
& \text { parameters } \mathbf{y} \\
& \Delta \mathrm{T}_{\text {ideal }}(\mathbf{z})=\text { limiting coolant temperature increase across an idealized } \\
& \text { (axisymmetric, no cavitation, no heated wall and no void effects) } \\
& \text { assembly as a function of axisymmetric parameters } \mathbf{z} \\
& \mathbf{y}=\text { parameters describing asymmetric effects, not including any } \\
& \text { axisymmetric parameters, heated wall or void effects } \\
& \mathbf{z}=\text { parameters describing axisymmetric effects, including } T_{\text {in }} \text {, not } \\
& \text { including any asymmetric parameters, heated wall or void effects. }
\end{aligned}
$$

The parameters which affect the limiting temperature rise across an idealized assembly include all parameters affecting an axisymmetric assembly with no cavitation, no heated wall and no void effects. These parameters include steady state and transient plenum pressures, assembly inlet temperatures, etc. Because these parameters have uncertainties associated with them, $\Delta \mathrm{T}_{\text {ideal }}$ is subject to uncertainty. The non-ideal effects multipliers, the $\beta$ 's, are assumed to be independent of the axisymmetric parameters and the position in the core. The heated wall and void effect muitipliers are approximated as constant multiplicative biases on the limiting temperature rise across an assembly and are obtained from Laurinat [9]. The asymmetric effects multiplier is dependent upon asymmetric parameters which have uncertainties associated with them. Hence, the asymmetric effects multiplier is also subject to uncertainty. With this separation, the non-ideal effects multipliers are calculated with a small number of three dimensional mode FLOWTRAN Version 16.1, and two dimensional mode UNCERT Version 16.1b runs.

The next step is to expand equation 4.2 about the nominal values of the uncertainty parameters. The expansion variables the $\gamma_{i}$, include $\beta_{3 D}, \varepsilon$ and other uncertainty parameters, but do not include any of the cavitation variables. 
The expansion takes the following form:

$$
\begin{aligned}
T_{c r}(x) & =T_{\text {in }}+\beta_{h w} \beta_{\text {void }} \beta_{3 D}(y) \Delta T_{\text {ideal }}(z)+\varepsilon \\
& =T_{c r_{0}}+\sum_{i} a_{i}\left(\gamma_{i}-\gamma_{i_{0}}\right)+e(x)
\end{aligned}
$$

where:

$$
\begin{aligned}
T_{c r_{0}}= & \text { reference value of the critical effluent temperature } \\
a_{i}= & \frac{\partial T_{c r}\left(x_{0}\right)}{\partial \gamma_{i}}=\text { sensitivity coefficient for the } i^{\text {th }} \text { uncerainty parameter } \\
x_{0}= & \text { nominal value of } x \\
\gamma_{i}= & i^{\text {th }} \text { expansion variable which includes } \beta_{3 D} \text { and } \varepsilon, \text { but does not } \\
& \text { include any cavitation parameters } \\
\gamma_{i_{0}}= & \text { reference value of the } i^{\text {th }} \text { expansion variable } \\
e(x)= & \text { error term which includes cavitation effects and higher non-linear } \\
& \text { components of } T_{c r}(x) \text {. }
\end{aligned}
$$

In equation 4.3 the values, $\gamma_{\mathrm{i}}$, are parameters which have uncertainties associated with them. Equation 4.3 is the basis for the statistical model of the assembly critical effluent temperature distribution. If cavitation and non-linear effects are not significant, the critical effluent temperature is given by the linear part of equation 4.3. The sensitivity parameters in the linear part of equation 4.3 are calculated with UNCERT Version 16.1 in two dimensional mode. If cavitation or non-linear effects are significant, a Monte Carlo analysis with UNCERT Version 16.3, in two dimensional mode, is used to estimate corrections to the linear model. Corrections for the effects of cavitation are discussed
further in Chapter 6 .

In Chapter 6 it is shown that the critical effluent temperature distribution given by the linear part of equation 4.3 yields conservative assembly effluent temperature limits for the may be written as:

$$
T_{c r}(x)=T_{c r_{0}}+\sum_{i} a_{i}\left(\gamma_{i}-\gamma_{i_{0}}\right)
$$


The mean value of the critical effluent temperature is then:

$$
\mu_{T_{c r}}=T_{c r_{0}}+\sum_{i} a_{i}\left(\mu_{\gamma_{i}}-\gamma_{i_{0}}\right)
$$

where: $\quad \mu_{T_{c r}}=$ mean critical effluent temperature

$$
\mu_{\gamma_{i}}=\text { mean of the } i^{\text {th }} \text { uncertainty parameter, } \gamma_{i} \text {. }
$$

The variance of the critical effluent temperature is:

$$
\sigma_{\mathrm{cr}}^{2}=\sum_{i} a_{i}^{2} \sigma_{\gamma_{i}}^{2}+\sum_{j} \sum_{k \neq j} r_{j k} g_{j} a_{k} \sigma_{\gamma_{j}} \sigma_{\gamma_{k}}
$$

where: $\quad \sigma_{\mathrm{T}}^{2}=$ the variance of the critical effluent temperature

$$
\begin{aligned}
\sigma_{\gamma_{i}}^{2} & =\text { the variance of the } i^{\text {th }} \text { uncertainty parameter, } \gamma_{i} \\
r_{j k} & =\text { the correlation coefficient between } \gamma_{j} \text { and } \gamma_{k} \text {, defined as }
\end{aligned}
$$

$$
r_{j k}=\frac{\left\langle\left(\gamma_{j}-\gamma_{j_{0}}\right)\left(\gamma_{k}-\gamma_{k_{0}}\right)\right\rangle}{\sigma_{\gamma_{j}} \sigma_{\gamma_{k}}}
$$

The notation, $<>$, denotes an average.

The relative contribution of the variance of a given uncertainty parameter to the total variance of the critical effluent temperature is used to determine the relative significance of that uncertainty parameter. This technique is discussed further in Chapter 5.

\subsubsection{The UNCERT Assembly Model}

UNCERT uses a finite difference approximation to estimate the assembly response. The heated length of the assembly contains 10 axial nodes. The fuel and target tubes are divided into nine radial nodes each, and the universal sleeve housing is divided into three nodes. The portion of the assembly above the heated length in divided into 7 axial nodes, and the portion below the heated length is divided into 13 axial nodes. A maximum time step of 0.01 second is used in the calculations. Studies have shown that the norting and 
time step used in the analysis are adequate [2]. The form loss coefficients are determined from the Mark 22 hydraulics manual [10]. The surface roughness used in the friction factor correlation is adjusted so that the overall assembly flows correspond to the overall flows given in the hydraulics manual.

\subsubsection{Heated Wall and Void Effects}

The heated wall effect is modelled using the Seider-Tate correlation [11]. The isothermal friction factor is multiplied by the ratio of the bulk fluid viscosity to the wall viscosity raised to the 0.14 power $\left(\left(\mu_{\text {bulk }} / \mu_{\text {wall }}\right)^{0.14}\right)$. To be consistent, the heated wall effect was applied not only to the coolant flow in the assembly channels but also to the flow in the primary coolant loop. To account for the heated wall effect on the system, the plenum pressure boundary condition was adjusted. This adjustment was estimated by comparing assembly pressure drops during reactor operation with pressure drops during neutronic shutdown. Historical reactor operating data show that the assembly pressure drop was less during powered operation than at neutronic shutdown. The observed decrease in pressure drop was less than $7 \%$. To be conservative, the steady-state plenum pressure was reduced by $7 \%$ of the steady-state pressure drop. During the transient, the plenum pressure was reduced by $3 \% 0$ the steady-state pressure drop. The smaller adjustment reflects a decrease in the assembly flow.

A homogeneous equilibrium model was used to estimate the magnitude of the void effect. The Hancox and Nicoll two-phase multiplier [12] was employed in this calculation. The homogeneous equilibrium model and the two-phase frictional pressure drop correlation require void fraction and quality correlations for closure. The void fraction and quality correlations are related through a drift flux correlation. Following a suggestion by Rouhani [13], both the void fraction and quality were varied linearly with the thermodynamic equilibrium quality from zero at the onset of nucleate boiling to their values at the onset of significant voiding. Rouhani's bubble boundary layer model was used to calculate the void fraction at the onset of significant voiding. This model estimates the thickness of a bubble layer along the wall at which the bubbles break away from the surface. A drift flux model relates the void fraction at the onset of significant voiding to the quality at the onset of significant voiding. The Kroeger and Zuber drift flux model [14], which was developed for bubbly churn flow, was used to calculate the drift velocity.

The heated wall and void effects multipliers for the critical effluent temperature were calculated for the beginning of subcycle K-14.1 using UNCERT Version 16.1b. The results of these calculations are summarized in Table 4.1.

Table 4.1

Impact of the Heated Wall and Void Effects on the Critical Effluent Temperature for a Mark 22 Charge

\begin{tabular}{|c|c|c|}
\cline { 2 - 3 } \multicolumn{1}{c|}{} & $\begin{array}{c}\text { Critcal Effluent } \\
\text { Temperanure }\end{array}$ & Mulaplier \\
\hline Nominal Case & $50.27679^{\circ} \mathrm{C}$ & - \\
Heated Wall Effoct & $50.13049^{\circ} \mathrm{C}$ & 0.9971 \\
Void Effect & $50.12534^{\circ} \mathrm{C}$ & 0.9970 \\
Combined Heated Wall and & $49.97702^{\circ} \mathrm{C}$ & 0.9940 \\
Void Effects & & \\
\hline
\end{tabular}




\subsubsection{Pressure Boundary Conditions and System Parameters}

As stated previously, the FLOWTRAN model of an assembly requires transient pressure boundary conditions at the inlet plenum and at the tank bottom. In addition to the pressure boundary conditions, the UNCERT Version 16.3 code requires the total pump flow and the pressure drop in the pump suction piping to determine the effects of cavitation. The TRAC model of the system includes all six primary cooling loops, the moderator tank, the inlet plenum, and the core.

The primary cooling loops include the process piping, the primary cooling water pumps, and the heat exchangers. The break is modeled as a free jet into the atmosphere. A three dimensional model is used for flow in the moderator tank. The noding scheme for the tank consists of six azimuthal nodes, five radial nodes, and six axial nodes. The blanket gas and the resistance of the top shields are included in the model. A two dimensional model is used for the inlet plenum. The plenum is divided into six azimuthal nodes and five radial nodes. The core is modelled using 24 equivalent assemblies. The equivalent assemblies connect the nodes in the plenum model with the corresponding nodes at the tank bottom. A one dimensional model is used for the equivalent assembly. The equivalent assembly has the same flow resistance, area, and heat generation rate as all of the real assemblies in the node. The equivalent assemblies are divided into 20 axial nodes. The TRAC model considers power as a function of axial position, location in the core, and time.

Details of the TRAC model are given by Koffman [15]. Benchmarking studies for this TRAC model are reported by Griggs and Cozzuol [16].

\subsubsection{Relative Power Shapes and Transients}

To calculate the critical effluent temperature, the assembly model requires a steady-state axial power shape, a power transient, cransient axial power shapes, and radial and azimuthal power shapes. A worst case axial power shape is used in the analysis. The worst case power shape is based on the technical specifications, and details of this shape are given elsewhere [17]. The power transient is a function of the charge design, the steady-state power shape, the safety rod drop times, the safety rod worth, and various thermal-hydraulic parameters. The AA3 code [18] is used to calculate the power transient, and the details of the calculations are given by Massey et al [19]. The transient power shapes depend on the steady-state axial power shape, the power transient, and so forth. The transient axial power shapes are calculated with the WIGGLE code [20]. The LLAP code [21] combines all of the power shape and transient information obtained from the other neutronics codes to give power as a function of position and time.

The radial power fraction depends on the $235 \mathrm{U}$ content of the fuel tubes, the positions of the control rods and the exposure. The radial power profiles and the inner tube power fraction are determined using the GLASS code $[22,23,24,25]$.

\subsubsection{Model of Azimuthal Variations}

In this section, the modelling of the asymmetric effects multiplier, $\beta_{3 D}$, is discussed in detail. The computer code POWCOMB [26] is used to calculate a distribution of values for $\beta_{3 D}$ due to uncerainties in asymmetric effects. Asymmetric effects were specifically 
modelled for the first subcycle of a Mark 22 assembly in the $\mathrm{K}$ reactor. Other parts of the fuel cycle and other charges can be modelled in an analogous way.

In this manual, effects due to asymmetries in assembly geometry about the assembly axis are referred to as "three dimensional effects". This terminology is used because the assembly asymmetries result in variations in thermal-hydraulic effects in the azimuthal as well as in the axial and radial directions.

The asymmetric effects multiplier is defined as:

$$
\beta_{3 D}=\frac{\Delta T_{\text {acrual }}}{\Delta T_{\text {as }}}
$$

where: $\quad \beta_{3 D}=$ asymmerric (3D) effects multiplier

$$
\begin{aligned}
\Delta \mathrm{T}_{\text {actual }} & =\text { the limiting temperature rise across an asymmetric assembly } \\
\Delta \mathrm{T}_{\text {as }} & =\text { the limiting temperature rise across an axisymmetric assembly. }
\end{aligned}
$$

The dominating asymmetric effects which influence the assembly effluent temperature limit are azimuthal variations in the fuel and lithium thickness, flux tilt and eccentricity in the coolant flow channel areas.

\subsubsection{Azimuthal Power Distribution}

The fuel and lithium thickness in the fuel/target tubes of the assemblies is not circumferentially uniform. Slight offsets in the extrusion tooling lead to azimuthal variation in the fuel/hithium thickness Figure 4.1. The maximum thickness of the fuel/lithium varies with the amount of offset. The fuel and target tubes, however, do not vary significantly in roundness.

For small offsets of the centers of the inner and outer surfaces, the fuel/lithium thickness can be shown to vary as a cosine function of the azimuthal angle. The amplitude of the cosine function is the distance between the centers of the circles describing the inner and outer surfaces of the tube.

The effective macroscopic cross section for thermal neutron absorption by the lithium in the control rods is not as great as that for the fuel and lithium in an assembly. Therefore, the thermal neutron flux peaks in the control rod region and decreases in the assembly region. The azimuthal orientation of the location of the maximum thickness of the fuel/lithium in the fuel/target rubes to the gradient of the flux tilt influences the maximum power in the fuel tubes of the assembly. Because the flux peaks in the control rod region, the orientation of the fuel/target rubes with respect to the gradient of the flux ilt can be given relative to the control rod as shown in Figure 4.2. 


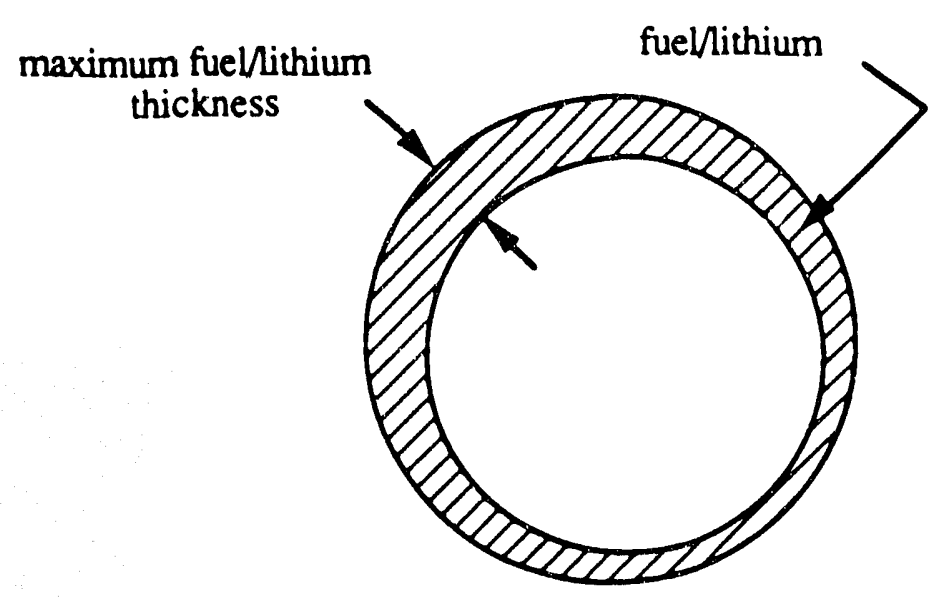

Figure 4.1

Azimuthal variation in fuel/hithium thickness

produced during the fabrication process

(exaggerated for purposes of illustration).

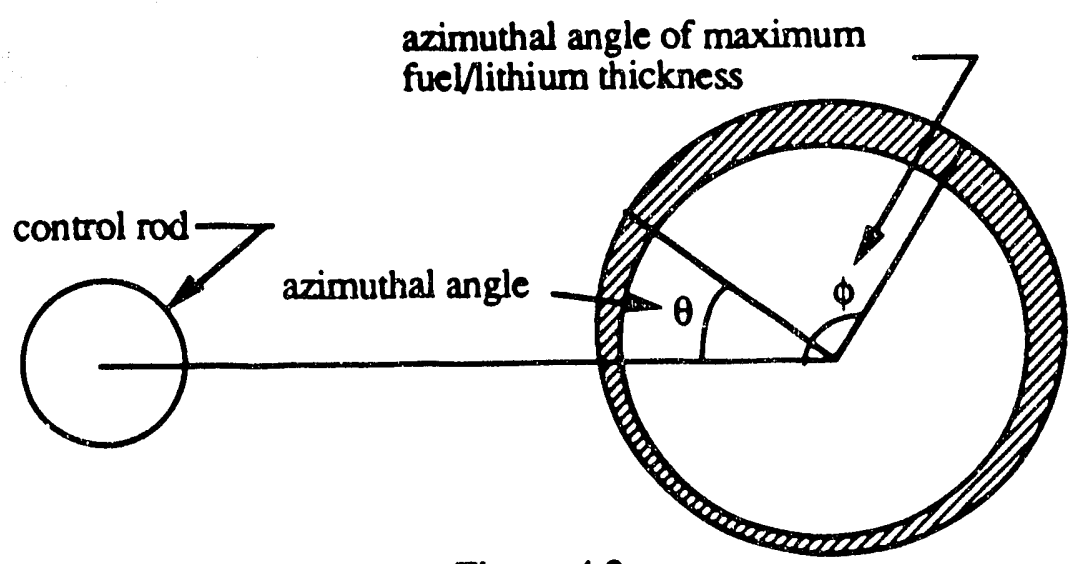

Figure 4.2

Definition of azimuthal fuelhithium distribution in a tube.

where: $\theta=$ the azimuthal angle relative to the flux tilt

$\phi=$ the azimuthal angle, relative to the gradient of the flux tilt, of the location of the maximum fuel/ithium thickness. 
The angle $\phi$, which gives the orientation of the fuel/target tubes to the gradient of the flux tilt, is treated as a random variable. The maximum fuel thickness in the inner and outer fuel tubes is randomly selected from a distribution which was obtained from actual fuel tubes. The maximum lithium thickness in the inner and outer target rubes is randomly selected from a uniform distribution from 0 to $30 \%$. The effect of the flux tilt is a given by a conservative histogram of power influence factors $[25,26]$.

The GLASS and TWOTRAN $[24,27,28]$ codes could be used to calculate the azimuthal power distribution, but this would require an impossibly large amount of computer time. Therefore, the local to average power ratio over each $1^{\circ}$ sector of the inner or outer fuel tubes is obtained from empirical expressions based on data from Webb [25].

The empirical expressions are of the form:

$P^{\text {if }}\left(\theta^{\text {if }}\right)=\xi^{\text {if }}\left(\theta^{i f}\right) P_{i l}^{i f}\left(\phi_{i 1}-^{i \text { if }}\right) P_{o l}^{\text {if }}\left(\phi_{o l}-\theta^{i f}\right) P_{i f}^{i f}\left(\phi_{i f}-\theta^{i f}\right) P_{o f}^{i f}\left(\phi_{o f}-\theta^{i f}\right)$

$\mathrm{P}^{\text {of }}\left(\theta^{\text {of }}\right)=\xi^{\text {of }}\left(\theta^{\text {of }}\right) \mathrm{P}_{\mathrm{il}}^{\text {of }}\left(\phi_{\mathrm{il}}-\theta^{\text {of }}\right) \mathrm{P}_{\mathrm{ol}}^{\text {of }}\left(\phi_{\mathrm{ol}}-^{-\theta^{\text {of }}}\right) \mathrm{P}_{\mathrm{if}}^{\text {of }}\left(\phi_{\mathrm{if}}-\theta^{\text {of }}\right) \mathrm{P}_{\text {of }}^{\text {of }}\left(\phi_{\mathrm{of}}-\theta^{\text {of }}\right)$

where: $\quad$ il denotes inner lithium

ol denotes outer lithium

$\mathrm{P}^{\mathrm{a}}\left(\theta^{\mathrm{a}}\right)=$ the ratio of the actual power to average power over a $1^{\circ}$ sector of the inner or outer fuel tube

a denotes inner fuel (if) or outer fuel (of)

$\theta^{\mathrm{a}}=$ the azimuthal angle for fuel tube a relative to the control rod in the super cell (see Figure 4.2)

$\xi^{2}\left(\theta^{2}\right)=$ the influence factor of the flux tilt on $\mathrm{P}^{\mathrm{a}}\left(\theta^{2}\right)$ over a $30^{\circ}$ sector which contains $\theta^{8}$

$P_{b}^{a}\left(\phi_{b}-\theta^{a}\right)=$ the influence factor for azimuthal variation in fuelhithium thickness in fuel/target tube $b$ on $\mathrm{P}^{\mathrm{a}}\left(\theta^{\mathrm{a}}\right)$ over a $1^{\circ}$ sector about $\theta^{\mathrm{a}}$

$\phi_{b}=$ the azimuthal angle of the location of the maximum fuel or lithium thickness in fuel or target tube $b$ relative to the control rod (see Fig. 4.2). 
The influence factors, $P_{b}^{2}\left(\phi_{b}-\theta^{2}\right)$, in equations. 4.8 and 4.9 are assumed to have the following form:

$$
P_{b}^{a}\left(\phi_{b}-\theta^{a}\right)=1+A_{b}^{a} T_{b, \max } \sin \left(\phi_{b}-\theta^{a}\right)
$$

where:

$$
\begin{aligned}
& \mathrm{A}_{\mathrm{b}}^{\mathrm{a}}= \mathrm{a} \text { factor relating the alloy thickness in fuel or target tube } \mathrm{b} \text { to power } \\
& \text { generation in fuel tube } \mathrm{a} \\
& \mathrm{T}_{\mathrm{b}, \mathrm{max}}= \text { the maximum thickness of the fuel or target material in fuel or target } \\
& \text { tube } \mathrm{b} \text { expressed in terms of per cent deviation from the average } \\
& \text { thickness. }
\end{aligned}
$$

The sinusoidal form of equation 4.10 is a reasonable approximation because the azimuthal variation in the fuel and target material thickness is approximately sinusoidal. The influence factors for the flux tilt, $\xi^{2}\left(\theta^{2}\right)$,were obtained over $30^{\circ}$ sectors from the GLASS code by Webb [25]. The influence factors for the azimuthal wickness variations, $\mathrm{P}_{b}^{\mathrm{a}}$, were obtained over $30^{\circ}$ sectors from the TWOTRAN code by Webb [25]. The $P_{b}^{a_{1}}$ s were fit to a continuous function to get values over $1^{\circ}$ sectors.

\subsubsection{Flow Channel Eccentricity}

Assembly eccentricity is caused by the camber of the fuel and target tubes produced during the manufacturing process and the bowing due to thermal gradients, see Figure 4.3. The effect of eccentricity is to reduce the areas of some of the coolant flow channels, thus resulting in flow redistribution in the assembly with reduced flow in the eccentric channel. The reduction in flow will result in an increase in the Stanton number for the eccentric chainnel.

During the first subcycle, and in the absence of assembly eccentricity, the lowest Stanton number is found at the location of the greatest azimuthal power in the outer fuel on the outer surface of the outer fiel tube in channel 4 , or on the inner surface of the outer fuel tube in channel 3, see Figure 3.1. It is assumed that temperature gradients resulting from azimuthal power peaking will cause bowing to be the major effect in flow channel eccenuricity. Due to the fact that the azimuthal section of the outer fuel with the greatest power will experience the greatest amount of thermal expansion, it is expected that the minimum subchannel area in the channels will occur next to the quadrant of the outer fuel having the greatest power. Although the amount of eccentricity in this subchannel is expected to vary with axial position, the exact magnitude and orientation of the eccentricity is unknown. Therefore, it is conservatively assumed that the minimum flow area in all channels will persist over the entire length of the assembly and be aligned with the outer fuel subchannel having the greatest power. Boucher $[29,30]$ showed that the eccentricity in channel 4 alone accounts for approximately 90 percent of the power reduction occurring when worst case eccentricities exist in all channels. The loss coefficients and subchannel flow splits for an eccentric assembly were calculated by Bor-cher [31]. 


\subsubsection{Rib Effects}

As illustrated in Figure 4.3, not all the rib tips in an eccentric assembly make contact with the surface of a fuel tube. It is assumed that a rib in contact with the surfase of a fuel tube acts as fin due to the high thermal conductivity of aluminum. If a rib does not contact the surface of a fuel tube, very little coolant flow will occur in the gap between the rib ip and the fuel tube surface. The low coolant flow in the gap will produce an insulating effect on the fuel tube surface. The reduced heat transfer at the surface of the fuel tube at the rib tip gap will cause heat flow around the rib sip gap region, thus increasing the fuel tube surface heat flux in the neighborhood of the non-contacting rib tip. The increase in the surface heat flux due to the ribs will result in an increase in the Stanton number and a corresponding decrease in the effluent temperature limit. Because there are assumed to be no intermediate degrees of rib contact effects, and because rib contact is as probable as non-contact for the outer fuel tube, rib contact is modeled as a discrete $50 / 50$ probability. Furthermore, in the eccentric subchannel, which also has the greatest outer fuel power, it is most likely that rib contact will occur. Therefore the use of a $50 / 50$ probability of rib contact is conservative. In a super cell there are two possible orientations of the ribs to the control rod, each having probabilities of $1 / 3$ and $2 / 3$, Figure 3.3. Because there is a flux tilt in the direction of the control position, the enhanced heat flux due to a rib will be applied to the fuel tube heat flux at one of these orientations.

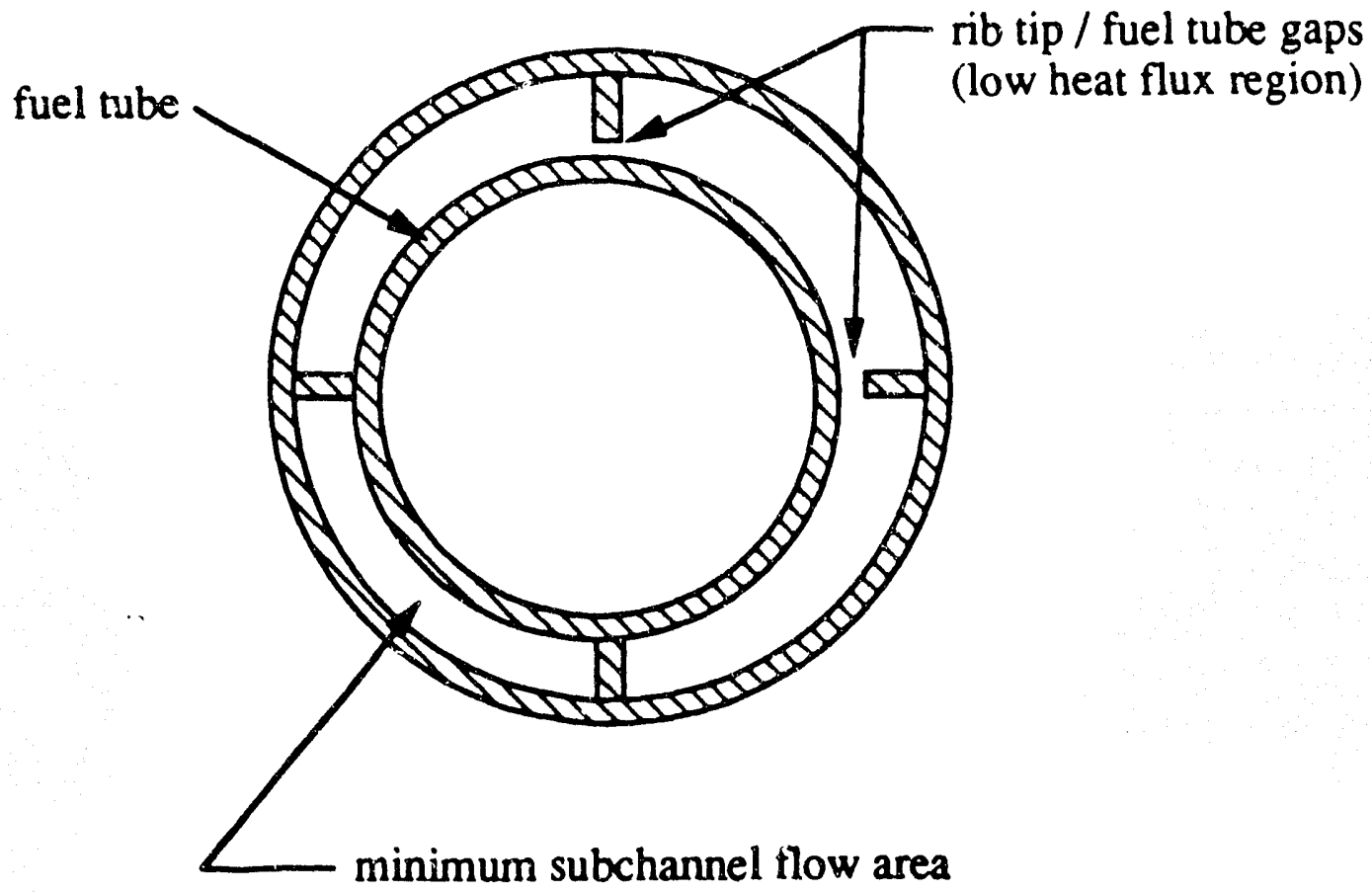

Figure 4.3

Illustration of the effect of assembly eccentricity on flow channel area. 
The effect of ribs on the surface heat flux is determined by using the finite element heat conduction code ABAQUS [32] for a Mark 22 assembly. The rib effect is conservatively modeled, in two dimensions, by assuming that a gap between a rib tip and the fuel rube surface results in perfect thermal insulation of the fuel tube surface. The width of this insulated region is the width of the rib tip. At the beginning of the first subcycle, fuel tube power splits are such that the most likely locations for incipience of OSV are the outer or inner surfaces of the outer fuel tube. In a Mark 22 assembly there is a potential for rib tip gaps on both the inner and outer surfaces of the outer fuel tube. On the inner surface of the outer fuel tube, the ratio of the maximum surface heat flux occurring for an insulated area to the surface heat flux without the insulated area is found to be approximately 1.209 [33].

On the outer surface of the outer fuel tube this ratio was found to be 1.167 [33].

Therefore, the value of 1.209 is conservatively taken as the ratio of maximum surface heat flux with ribs to the heat flux without ribs.

The rib effect is included through the use of a rib effect multiplier which is applied to the asymmetric effects multiplier $\beta_{3 D}^{\text {no rib }}$ calculated in the absence of ribs. The rib effect multiplier is of the form:

$$
\beta_{\mathrm{rib}}=\frac{\beta_{3 D}}{\beta_{3 D}^{\text {no rib }}}
$$

where: $\quad \beta_{\text {rib }}=$ the rib effect multiplier

$$
\beta_{3 D}^{\text {no rib }}=\text { the asymmetric effects multiplier without rib effects }
$$

$$
\beta_{3 D}=\text { the asymmetric effects multiplier including rib effects. }
$$

The value of $\beta_{\text {rib }}$ is approximated from the limiting temperature rises across an axisymmetric assembly with a rib effect and an axisymmetric assembly without a rib effect.

\subsubsection{Uncertainty Analysis of the Asymmetric Effects Multiplier}

The objective of the uncertainty analysis of the asymmetric effects multiplier, $\beta_{3 D}$, is to find its mean and variance from its cumulative distribution function (CDF). To accomplish this a Monte Carlo analysis is performed on $\beta_{3 D}$.

By randomly varying the maximum fuel/lithium thickness and the orientation of the maximum fuel/ithium thickness to the flux tilt in equations 4.5 and 4.6 , a set of azimuthal power distributions could be obtained for input to FLOWTRAN Version 16.1. This would permit, with the use of an axisymmetric case, the calculation of a distribution for $\beta_{3 D}$. An extremely large amount of computer time would be required to make sufficient runs of FLOWTRAN Version 16.1 in three dimensional mode to adequately describe a distribution 
for $\beta_{3 D}$. Therefore, a more efficient approach is taken. For the first subcycle, the onset of significant voiding occurs on the inner or outer surface of the outer fuel. Thus, $\beta_{3 D}^{\text {no rib }}$ is approximated by an expression in terms of the maximum ratio of the power to the average power over an outer fuel subchannel, $\mathrm{P}_{\max }^{\text {of }}$. The expression is of the form:

$$
\beta_{3 D}^{\text {no rib }}=h\left(P_{\max }^{\text {of }}\right)+\delta
$$

where: $\quad h\left(P_{\max }^{\text {of }}\right)=a$ quadratic polynomial expression in terms of $P_{\max }^{\text {of }}$

$\delta$ is an error term used to account for variables not treated explicitly in the expression for $\beta_{S D}^{\text {no rib }}$

This expression for $\beta_{3 D}^{\text {no rib }}$ was obtained by making 12 three dimensional mode

FLOWTRAN-Version 16.1 runs with randomly varied azimuthal power distributions over $90^{\circ}$ sectors in the inner and outer fuel. In these FLOWTRAN runs the eccentric flow subchannel in each flow channel are aligned with the highest power outer fuel subchannel. These calculations give 12 values of $\beta_{3 D}^{\text {no no }}$ as:

$$
\beta_{3 D i}^{\text {no rib }}=\frac{\Delta T_{\text {actual } i}^{\text {no rib }}}{\Delta T_{a s}^{\text {no rib }}}
$$

where: $\quad i=1, \ldots, 12$

$\Delta \mathrm{T}_{\text {actual }}^{\text {no rib }} i=$ the ith value of the limiting temperature rise across an asymmetric assembly with no ribs

$\Delta \mathrm{T}_{\mathrm{as}}^{\text {no rib }}=$ the ith value of the limiting temperature rise across an axisymmetric assembly with no ribs

A quadratic polynomial, $h\left(P_{\max }^{\text {of }}\right)$ was fit to the 12 values of $B_{3 D i}^{\text {no rib }}$ vs $P_{\max }^{\text {of }}$ as shown schematically in Figure 4.4. The scatter of values of $\beta_{3 \mathrm{D} i}^{\text {no rib }}$ about $h\left(\mathrm{P}_{\max }^{\text {of }}\right)$ is due to the dependence of $\beta_{3 D}^{\text {no rib }}$ on variables other than $P_{\max }^{\text {of }}$. The scatter is taken into account in the 
final distribution for $\beta_{3 D}$ by adding a random variable $\delta$ to the value of $h\left(P_{\max }^{\text {of }}\right.$ ) obtained from the quadratic fit to $\beta_{3 \mathrm{D} i}^{\text {no }} \mathrm{i}$. $\delta$ is assumed to have a normal distribution about $h\left(\mathrm{P}_{\max }^{\text {of }}\right)$. For an inlet temperature of $40^{\circ} \mathrm{C}$ the quadratic polynomial is of the form:

$$
\mathrm{h}\left(\mathrm{P}_{\max }^{\text {of }}\right)=3.8423-4.8707\left(\mathrm{P}_{\max }^{\text {of }}\right)+1.9179\left(\mathrm{P}_{\max }^{\text {of }}\right)^{2}
$$

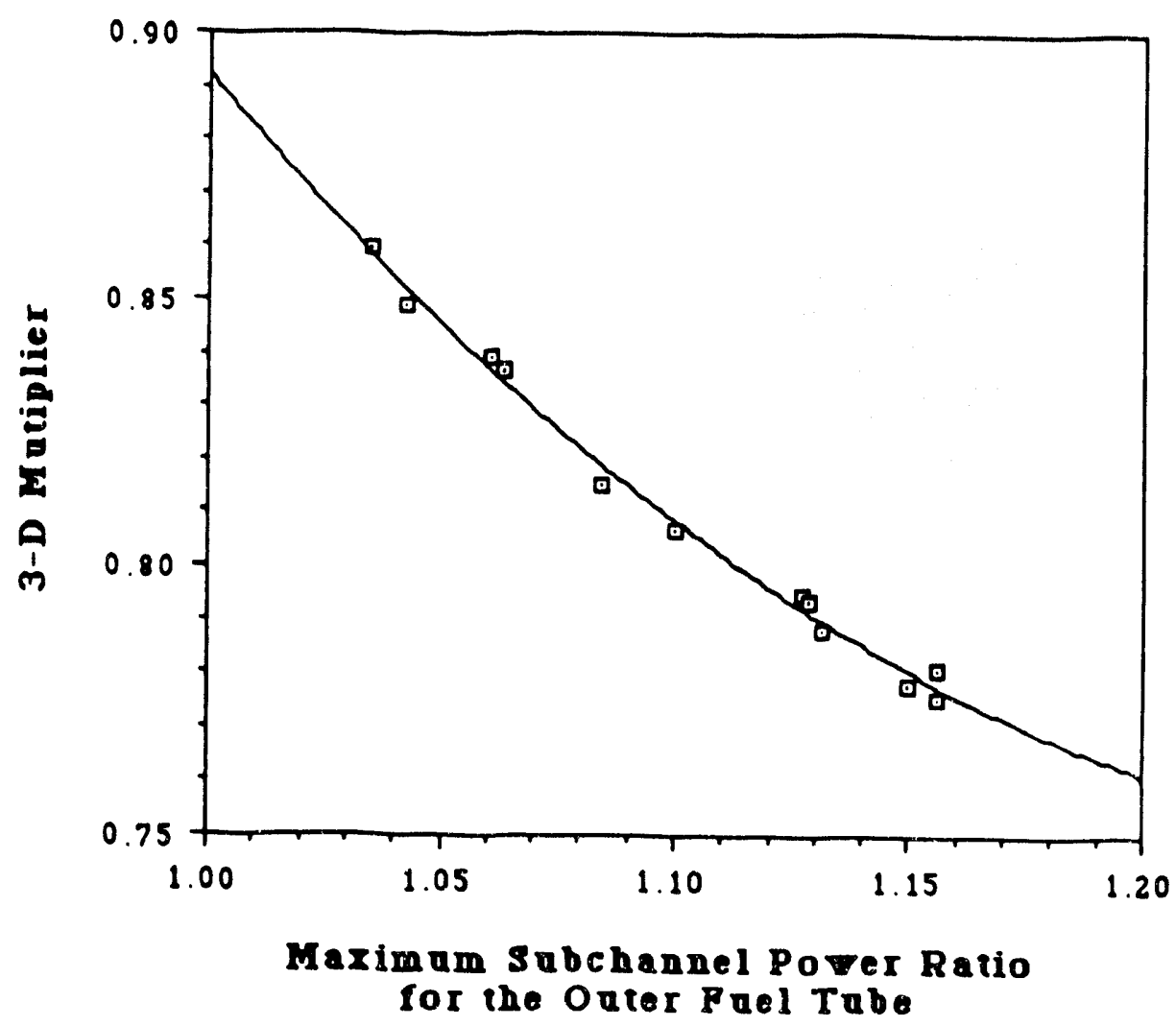

Figure 4.4

Fit of a quadratic polynomial to the values of $\beta_{3 D i}^{\text {no rib }}$ vs $P_{\max }^{\text {of }}$ obtained from FLOWTRAN. 
In the uncertainty analysis for $\beta_{3 D}$ the rib effect multiplier takes the form:

$$
\beta_{\text {rib }}=1-F \Delta q^{\prime \prime}
$$

where:

$$
\begin{aligned}
& F= \text { conversion factor from } q " \text { to } \beta_{\text {rib }} \text {, a constant obtained from an } \\
& \text { axisymmetric approximation }
\end{aligned}
$$

and

$$
\Delta q^{\prime \prime}=1.209 \times\left[\begin{array}{l}
\text { maximum surface heat } \\
\text { flux in a rib location } \\
\text { on the outer fuel } \\
\text { for a ribless assembly }
\end{array}\right]-\left[\begin{array}{l}
\text { maximum surface heal } \\
\text { flux anywhere on the } \\
\text { surface of the outer fuel } \\
\text { for a ribless assembly }
\end{array}\right]
$$

If $\Delta q^{\prime \prime} \leq 0$, the rib effect is neglected and it is assumed that $\beta_{3 D}=\beta_{3 D}^{\text {no rib }}$.

If $\Delta q^{\prime \prime}>0$, then $\beta_{3 D}=\beta_{\text {rib }} \beta_{3 D}^{\text {no rib }}$.

That is to say, the rib effect multiplier is applied to a rib free assembly if, and only if, the rib effect results in a heat flux which exceeds the maximum heat flux for the rib free assembly.

\subsubsection{Summary of POWCOMB Calculations}

The uncertainty analysis on the asymmetric effects multiplier is performed with the POWCOMB code [26]. POWCOMB calculates the distribution for $\beta_{3 D}$ using the following procedure:

1. The amplitudes of the fuel and lithium concentrations are randomly selected from their respective distributions.

2. The power influence factors for the inner and outer fuel are determined at every $1^{\circ}$ sector from equation 4.10.

3. The azimuthal orientations of the maximum fuel and lithium concentrations are randomly selected.

4. One of two rib orientations, having a $2 / 3$ and a $1 / 3$ probability, is selected.

5. The ratios of power over a $1^{\circ}$ sector to average power over a $1^{\circ}$ sector in the inner and outer fuel tubes is calculated from equations 4.8 and 4.9.

6. The maximum ratio of power to average power over a $90^{\circ}$ sector (a subchannel), and its location, is found for the outer fuel. This value is $\mathrm{P}_{\max }$.

7. A value for $\beta_{3 D}^{\text {no rib }}$ is calculated from equation 4.12 by using the value of $P_{\max }^{\text {of }}$ obtained in step 6 and a value of $\delta$ randomly selected from its distribution. 
8. The $50 / 50$ distribution for rib contact is applied. If rib non-contact occurs, and the enhanced heat flux at the rib location exceeds the maximum heat flux over any $1^{\circ}$ sector on the outer fuel tube, we take:

$$
\beta_{3 D}=\beta_{\text {rib }} \beta_{3 D}^{\text {no rib }}
$$

9. Steps 1-8 are repeated 9999 times to get adequate data points for the distribution of $\beta_{3 D}$

The CDF and moments for the asymmetric effects multiplier are given in Table A.1 and Figure A.1 of Appendix A.

\subsubsection{Independence of $\beta_{3 D}$ From the Axisymmetric Parameters}

To demonstrate that $\beta_{3 D}$ is independent of the axisymmetric parameters, scoping studies were performed for inlet temperatures of 20,30 and $40^{\circ} \mathrm{C}$ and for the TRAC cells adjacent to and opposite the break, see appendix A Tables A.2 - A.5. Because each TRAC cell has a different operating and transient plenum pressure, the steady state and transient plenum pressures are varied through the selection of different TRAC cells. The scoping studies consisted of making the twelve FLOWTRAN-Version 16.1 runs needed to calculate the polynomial expression for $\beta_{3 D}$ for each of the above inlet temperanures and TRAC cells. The resulting variations in $\beta_{3 D}$ for each value of $P_{\max }^{\text {of }}$ are shown in Figure 4.5.

The sensitivity of $\beta_{3 D}$ to individual and combined variations of the most significant axisymmetric uncertainty parameters (see Chapter 5 ) is given in Table 4.2. These sensitivities were obtained by perturbing the axisymmetric parameters by one standard deviation from a reference case using FLOWTRAN Version 16.1 in three dimensional mode.

The sensitivity of $\beta_{3 D}$ to perturbations in the axisymmetric parameters shown in Figure 4.5 and Table 4.2 , supports the assertion that $\beta_{3 D}$ is essentially independent of the axisymmetric parameters.

Because the effect of cavitation in the external loops is to change the plenum pressure, and because $\beta_{3 D}$ is nearly independent of plenum pressure, it is expected that $\beta_{3 D}$ is independent of cavitation effects. 


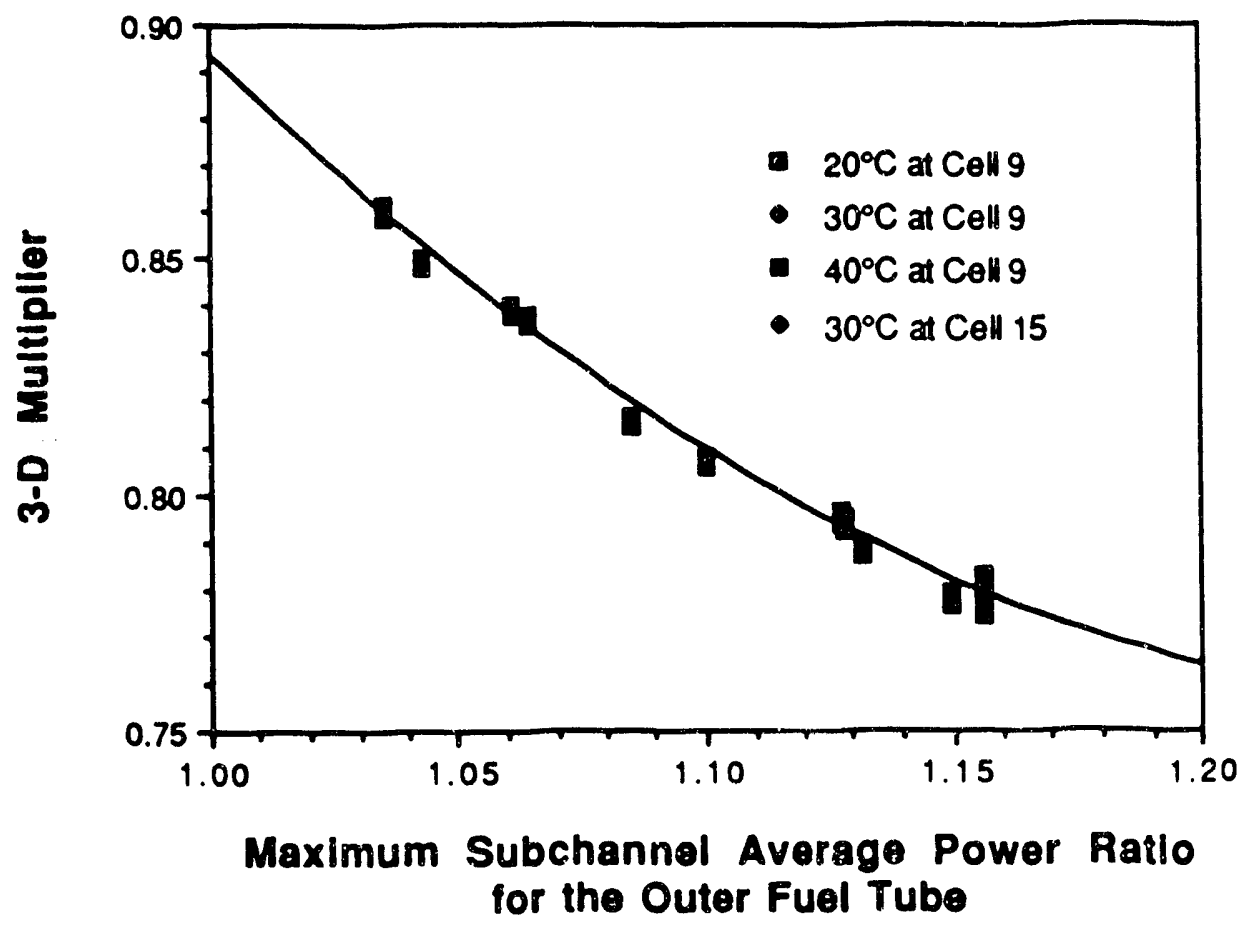

Figure 4.5

Variation of $\beta_{3 D}$ with assembly inlet temperature and flowzone. 
Table 4.2

Sensitivity of the Asymmetric Effects Multiplier to the Variation of Some of the Axisymmetric Model Parameters

\begin{tabular}{|c|c|c|c|}
\hline $\begin{array}{c}\text { Axisymmetric } \\
\text { Uncertainty }\end{array}$ & Perturbation & 3-D Multuplier & $\begin{array}{c}\text { Percent Difference } \\
\text { From the Reference } \\
\text { Value }\end{array}$ \\
\hline $\begin{array}{c}\text { Reference Case } \\
\text { Transient Plenum } \\
\text { Pressure }\end{array}$ & $+2.5 \mathrm{psi}$ & 0.7769 & - \\
$\begin{array}{c}\text { Transient Tank } \\
\text { Bottom Pressure }\end{array}$ & $+1.0 \mathrm{psi}$ & 0.7766 & 0.0324 \\
$\begin{array}{c}\text { Steady-Stare Plenum } \\
\text { Centerline Pressure }\end{array}$ & $+1.5 \mathrm{psi}$ & 0.7772 & 0.0354 \\
$\begin{array}{c}\text { Inlet Temperature } \\
\text { Inner Fuel Tube } \\
\text { Power Fraccion } \\
\begin{array}{c}\text { Subcooled Boiling } \\
\text { Heat Transfer Coef. }\end{array}\end{array}$ & $+1.1^{\circ} \mathrm{C}$. & 0.7770 & 0.0101 \\
$\begin{array}{c}\text { Simultaneous } \\
\text { Variation of All the } \\
\text { Above Uncertainties }\end{array}$ & $+1.7 \%$ & $0.777 !$ & 0.0245 \\
\hline
\end{tabular}




\subsubsection{Extension of Model for $\beta_{3 D}$ to Other Charges and Other Parts of the Fuel Cycle}

The asymmetric effects multiplier may be modelled for the DEGB/LOCA at other times in the fuel cycle and for other charges by making the necessary changes in the following quantities:

1. The power split between fuel tubes. The depletion of the fuel in a Mark 22 assembly will cause the power to shift to the inner fuel tube. The target irradiation, and possible changeout of the inner target, will also affect the power split between the assembly fuel tubes. Furthermore, different types of assemblies will have different power splits. The power split will determine the surface of incipience for the onset of significant voiding.

2. The modelling of the rib effect. The rib effect depends on the rib geometry, the azimuthal fuel distribution and the power split between the fuel tubes of an assembly.

3. The polynomial expression for $\beta_{3 D}$. The polynomial representation for $\beta_{3 D}$ is correlated to the subchannel maximum to average power ratio in the outer fuel. A shift in the power split may require a change in the correlation variable and modifications to the standard deviation of the error term, $\delta$, in the polynomial expression for $\beta_{3 D}$, given by equation 4.12 .

4. The fuel and target material distribution. For other charges, modifications will be required for the distributions used for the thickness of the fuel and target material.

5. The flowchannel eccentricity. For other charges, modifications will be required for the average flow channel area and the area of the eccentric channel.

\section{References}

1. TRAC-PF1/MOD1: An Advanced Best-Estimate Computer Program for Pressurized Water Reactor Thermal-Hydraulic Analysis," Los Alamos National laboratory Report NUREG/CR-3858 (1987) (Revised).

2. Aleman, S. E., M. V. Gregory, L. L. Hamm, L. D. Koffman, R. E. Pevey, W. H. Reed, and F. G. Smith, "FLOWTRAN: An Algorithm for Describing the ThermalHydraulic Behavior of SRP Assemblies," E. I. du Pont de Nemours \& Company Report DPSTM-140, Version 16.1, Rev. B (1988).

3. Laurinat J. E. ,"Documentation of UNCERT, Version 16.3," Westinghouse Savannah River Company Memorandum, NES-RFI-900036, FIU-90-15 (1990).

4. Kuehn, N. H., "NBB-1 Limits Methodology Roadmap," E. I. du Pont de Nemours \& Company Report DPST-88-397 (1988).

5. Laurinat, J. E., "Input Instructions for Versions 16-1, 16-1A, 16-1B, 16-2, and 16-3 of UNCERT," Westinghouse Savannah River Company Memorandum, NES-RFI900O26, FIU -90.11 (1990). 
6. Massey, W. M., Griggs, D. P., Painter , S. D., "Flow Instability Analysis of a Design Basis LOCA for the K-14.1 Subcycle," Westinghouse Savannah River Company Report WSRC-RP-89-1287 (1989).

7. Shadday, M. A. ,"The Impact of Cavitation During A DEGB LOCA, With Uncertainties," Westinghouse Savannah River Company Report WSRC-RP-89-1313 (1989).

8. Laurinat, J. E., "Documentation of CVTTN Version 1, Revision 1," Westinghouse Savannah River Company Memorandum NES-RFI-900032, Rev. 1 (1990).

9. Laurinat, J. E.,"Effects of Heated Wall, Wall Voidage, ans Dissolved Gasses on Flow Instability Limits," Westinghouse Savannah River Company Report WSRCRP-89-406, FIU-89-31 (1989).

10. Boswell, J. M.,"Hydraulics and Heat Transfer of Mark 22 Fuel Assemblies," E. I. du Pont de Nemours \& Company, Inc. Report DPSTM-22(H) (1974).

11. Seider, E. N. and G. E Tate, "Heat Transfer and Pressure Drop of Liquids in Tubes," Ind. Eng. Chern., 28:1429 (1936).

12. Hancox, W. T. and W. B. Nicoll, "Prediction of Time-Dependent Diabatic TwoPhase Water Flows," Progress in Heat and Mass Transfer, 6:119 (1972).

13. Rouhani,S. Z., "Calculation of Steam Volume Fraction in Subcooled Boiling," Trans. Am. Soc. Mech. Engrs., Series C, J. Heat Transfer, 90:158 (1968).

14. Kroeger, P. G. and N. Zuber, "An Analysis of the Effects of Various Parameters on the Average Void Fractions in Subcooled Boiling," Int. J. Heat Mass Transfer, 11:211(1968).

15. Koffman, L. D. et al., "TRAC Calculations of the Initial Flow Decay in L-1.1," E. I. du Pont de Nemours \& Company, Inc. Report DPST-87-737 (1987).

16. Griggs, D. and J. M. Cozzuol, "TRAC L Reactor Model: Geometry Review and Benchmarking," Westinghouse Savannah River Company Report WSRC-TR-90-32 (1990).

17. Massey, W. M., "Sensitivity of Mark 22 Flow Instability Limits to Axial Power Shape," E. I. Du Pont de Nemours \& Company, Inc. Report DPST-89-244 (Rev. 1) (1989).

18. Smith, J. A. and J. P. Church, "Accident Analysis Computer Program," E. I. du Pont de Nemours \& Company, Inc. Report DPSTM-120 (1984).

19. Massey, W. M. , DeHart, M. D., Griggs, D. P. and Hardy, B. J., "LOCA FI Limits Methodology," Westinghouse Savannah River Company Report WSRC-TM-90-4 (1990).

20. Pevey, R. E., "Axial Power Profiles in SRP Reactors During LOCA," E. I. du Pont de Nemours \& Company, Inc. Report DPST-87-511 (1987).

21. Gregory, M. V., "User's Guide to the DPOSIT OPTION in LLAP," Westinghouse Savannah River Company Report WSRC-RP-89-998 (1989). 
22. Honeck H. C., et al,"JOSHUA," E. I. du Pont de Nemours \& Company, Inc. Report DPSTM-500, Volumes 4 \& 4.1, "Lattice Physics," (1970).

23. Honeck H. C., et al,"The JOSHUA System," E. I. du Pont de Nemours \& Company, Inc. Report DP-1380 (1975).

24. Graves, W. E., "GLASS User's Manual," Westinghouse Savannah River Company Repor DPSTM-89-100-1 (1989).

25. Webb, R. L., "Radial and Azimuthal Power Profiles in Mark 22 Assemblies," Westinghouse Savannah River Company Report WSRC-RP-89-724 (1989).

26. Hardy, B. J., "Documentation for Computer Code POWCOMB.FOR," Westinghouse Savannah River Company Memorandurn NES-RFI-890133, FIU-89-66 (1989).

27. Lathrop, K. D., Brinkley, F. W., "TWOTRAN-II: An Interfaced, Exportable Version of the TWOTRAN Code for Two-Dimensional Transport," LA-4848 (1973).

28. Mallen, A. N., "TWOTRAN2: A Two Dimensional Transport Theory Code for JOSHUA," E. I. du Pont de Nemours \& Company, Inc. Report DPST-75-203 (1975).

29. Boucher, T. J., "Sensitivity Coefficients for Channel Eccentricity Uncertainties at the End of Subcycle One," Westinghouse Savannah River Company Memorandum, NED-RFI-890009, FIU-89-34, (1989).

30. Boucher, T. J., "Sensitivity Coefficienes for Channel Eccentricity Uncertainties at the End of Subcycle One," Westinghouse Savannah River Company Memorandum, NES-RFI-890010, FIU-89-35, (1989).

31. Boucher, T. J., "Program to Determine FLOWTRAN Input Channel or Subchannel Entrance, Length and Manual Loss Coefficients and Flow Splits for Channel Geometry Variations," Westinghouse Savannah River Company Memorandum, FIU-89-33, NES-RFI-890008, (1989).

32. ABAQUS Version 4.8, "Theory Manual," Hibbit, Karlsson and Sorenson, Inc. (1990).

33. Laurinat, J. E., "Effect of Ribs on the OSV Criterion Used for Flow Instability Limits, Rev. 1," Westinghouse Savannah River Company Memorandum NES-RFI-900004, FIU-98-68, Rev. 1 (1990). 


\section{UNCERTAINTIES}

In order to implement the statistical model discussed in Chapter 4, the uncertainties which affect the assembly critical effluent temperature distributions must be identified. The distribution of assembly critical effluent temperatures is dependent upon uncertainties arising from several sources. The sources of the uncertainties are; the physical phenomena occurring during the DEGB/LOCA, the reactor operational parameters, and the TRAC/FLOWTRAN assembly model. These uncerainties arising from these sources can be placed into five categories:

1. Manufacturing uncertainties, which include tolerances, geometric alignment, and material composicion.

2. Data base uncertainties, which include solid properties, fluid properties, heat transfer correlations, and flow parameters.

3. Uncertainties in input obtained from other codes, which include TRAC and the neutronics codes.

4. Uncertainties resulting from model idealization, which include UNCERT code approximations, noding, and convergence criteria.

5. Errors in the measurements used to apply the limits, which include critical effluent temperature measurements and inlet temperature measurements.

Individual uncertainties were identified from a qualitative assessment of the physical phenomena occurring during the DEGB/LOCA, an examination of input parameters to the UNCERT code, and historical operating experience. An exhaustive list of uncertainties was made $[1,2]$ and is given in Appendix B. Not all uncertainties will have a significant impact on the effluent temperature limits. The significant uncertainties used in the uncertainty analysis are described in this chapter.

The ranking of significant uncertainties was done in two parts. One set of significant uncertainties was determined from the uncertainties for an assembly without the effects of cavitation. The other set of significant uncertainties was determined from the uncertainties for the cavitation model. The ranking is done separately because cavitation uncertainties must be ranked relative to a different criterion than the other uncertainties for an assembly.

\subsection{Description of the Uncertainties for an Assembly Without Cavitation}

Ninety-one sources of uncertainty were identified for an assembly without cavitation effects. A rank ordering of these uncertainties showed that 17 of them contributed to more than $99.9 \%$ of the total variance in the critical effluent temperature. The sources of uncertainty for a non-cavitating assembly were put into two groups. One group consisted of uncertainties characterized by distributions and the other group consisted of uncertainties not readily characterized by distributions. 
The significance of uncertainties not characterized by distributions was determined from an assessment of their impact on the effluent temperature limit. Bounding values were used for those uncertainties found to be significant. Six significant uncertainties were identified, these are [1]:

1. Steady State Axial Power Shape - The allowable limits on the axial power shape are given by the technical specifications, and the shape is controlled using axial power monitors. Variations in the true axial power shape are the result of uncertainty in the axial power measurements and the length of exposure. The critical effluent temperature is determined using a conservative axial power shape. A conservative axial power shape is given by Massey [3].

2. Fission Power vs. Time - The fission power transient during a large-break loss-ofcoolant accident is governed by the number of control rods dropped and the drop times. The uncertainty in the fission power transients is the result of uncertainty in the number of control rod dropped and the drop times. Conservative values for the number of rods dropped and the rod drop times are used to determine a conservative fission power transient [4]. Power transients are determined using the AA3 code [5] and the GLASS code [6]. The uncertainties in these codes are assumed to be insignificant.

3. Exposure - Because a large break could occur at any time during the operating cycle, the length of exposure for a given fuel assembly is a random variable. The worst case exposure is used in the analysis.

4. Limits Criterion - A $30 \%$ reduction in the Saha-Zuber correlation for the onset of significant voiding is used to characterize flow instability. Uncertainty in the $30 \%$ reduction in the correlation is the result of variability in the flow instability test data [7]. The uncertainty in the correlation can be described by a normal probability distribution; however, as stated previcusly, a conservative bound has been established as the safe operating criterion. This bound is the minimum Stanton number given by the correlation minus a $30 \%$ safety factor $[7,8]$.

5. Void Effect - FLOWTRAN does not consider the effect of void formed by subcooled boiling on the frictional losses. This effect is incorporated into the analysis as a bias on the assembly temperature rise. A conservative value for this bias has been estimated by Laurinat et al. [9]. This value was found to be 0.9970 for the initial subcycle of the K 14.1 .

6. Heated Wall Effect - FLOWTRAN does not consider the effect of temperature variation near the wall on the viscous losses. This effect is incorporated into the analysis as a bias on the assembly temperature rise. A conservative value of this bias has been estimated by Laurinat et al.[9]. This value was found to be 0.9971 for the initial subcycle of the K 14.1. 
Uncertainties characterized by distributions were rank ordered according to their percent contribution to the variance of the critical effluent temperature. In this manual, the variance of the critical effluent temperarure is called the total variance. Assuming that the linear model, equation 4.4 , is valid and assuming that there is no correlation between uncertainties, equation 4.6 gives:

$$
\sigma_{\mathrm{c}}^{2}=\sum_{\mathrm{i}} \mathrm{a}_{\mathrm{i}}^{2} \sigma_{\gamma_{\mathrm{i}}}^{2}
$$

where: $\quad \sigma_{\mathrm{T}}^{2}=$ the variance of the critical effluent temperature

$$
\begin{aligned}
\sigma_{\gamma_{i}}^{2} & =\text { the variance of the } i^{\text {th }} \text { uncertainty parameter, } \gamma_{i} \\
a_{i} & =\text { the ith sensitivity coefficient }=\frac{\partial T_{\alpha}}{\partial \gamma_{i}}
\end{aligned}
$$

If the uncertainties are uncorrelated, the percent contribution to the total variance is:

$$
\text { Percent of Total Variance }=\frac{a_{i}^{2} \sigma_{\gamma_{i}}^{2}}{\sigma_{T}^{2}} \times 100
$$

Under the assumption of statistical independence, a rank ordering of the uncertainties according to their percent of total variance (for uncorrelated uncertainties) identified eleven significant uncertainties. These eleven uncertainties contribute to more than $99.9 \%$ of the total variance. The greatest contribution to the total variance is given by the uncertainty of rank one with decreasing contribution for increasing rank number. The eleventh uncertainty is the subcooled boiling heat transfer coefficient, which accounts for $0.16 \%$ of the total variance. The twelfth uncertainty is the heat capacity of aluminum, which accounts for $0.0057 \%$ of the total variance. The large difference between the percent contributions of the eleventh and twelfth ranked uncertainties clearly marks the cutoff between significant and non-significant uncertainties. A list of significant uncertainties characterized by distributions together with their contributions to the total variance is given in Appendix C.

In order of significance, the eleven uncertainties having the greatest contribution to the total variance are [1]:

1. Iransient Plenum Pressure - Uncertainties in hydraulic resistances for the process water system and other deficiencies and approximations in the TRAC model result in uncertainty in the transient plenum pressure. Like the steady state plenum pressure, the transient plenum pressure is a function of position in the plenum. The pressure transient used in the UNCERT model for a given flowzone is the most severe pressure transient for any TRAC cell which intersects that flowzone. The error in the transient plenum pressure is assumed to be a constant deviation from the TRAC predictions. The error could be a function of time, but it is conservative to treat it as a

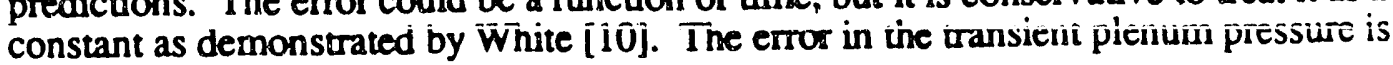


assumed to be normally distributed. Benchmarking runs show that TRAC errors corresponds to a standard deviation of about $2.5 \mathrm{psi}$ in plenum pressure [11]. This standard deviation is used for all flowzones.

2. Asymmetric Effects Multiplier $\left(\beta_{3 D}\right)$ - The asymmetric effects multiplier, which was described in detail in section 4.3.5, is a combination of uncertainties. The individuai uncertainties contributing to $\beta_{3 D}$ are described below. Random combinations of these uncerainties in the code POWCOMB [12] give the distribution for the asymmetric effects multiplier.

3. Transient Tank Bottom Pressure - Uncertainties in hydraulic resistances for the process water system and other deficiencies and approximations in the TRAC model result in uncertainty in the transient iank bottom pressure. The error in the transient tank bottom pressure is assumed i be a constant deviation from the TRAC predictions. The error could be a function of time, but it is conservative to treat it as a constant as demonstrated by White [10]. The error in the transient tank bottom pressure is assumed to be normally distributed. Benchmarking runs of the TRAC model show that the pressures are within $10 \%$ of the measured values. This errocorresponds to a standard ceviation of about $1.0 \mathrm{psi}$ in tank bottom pressure.

4. Steady State Plenum Pressure Gradient - The steady state plenum pressure varies with radial position. The plenum pressure gradient is the difierence between the pressure at a given radial position and the pressure at the plenum center. The average values were determined experimentally [3]. The largest value in a given flowzone is used for the steady state plenum pressure gradient. The uncertainty in this quantity is assumed to be normally distributed. The standard deviations for flowzones 1 through 4 are $1.2 \mathrm{psi}, 1.7 \mathrm{psi}, 2.4 \mathrm{psi}$, and $2.9 \mathrm{psi}$, respectively. The values are obtained from data given by Crowley and Hamm [13].

5. Inner Fuel Tube Power Eraction - Variations in power deposition are caused by variations in the ${ }^{235} \mathrm{U}$ content of the fuel. These variations are expressed in terms of the fractional power deposition in the inner fuel tube. Power variation may also occur in the outer fuel tube but this is not independent because the power fraction must sum to unity. In the uncertainty analysis, power deposition in the targets and moderator is assumed to be constant because it is small and contributes little to the overall uncertainty. This assumption allows the uncertainty in the power deposition to be represented by a single variable, the inner tube power fraction. Best estimate values of the inner fuel tube power fraction vary from about $36 \%$ at the beginning of cycle to about $41 \%$ at the end of cycle. The worst case exposure is used in this analysis, so the uncertainty in the inner tube power fraction is evaluated at the worst case exposure. At the beginning of the first subcycle the mean and standard deviation are 37.7 per cent and 1.7 per cent, respectively. Data shows that the variations in the inner tube power fraction should be normally distributed [14]. T: mean and standard deviation may be different for other charges and exposures.

6. Assembly Inlet Temperanure - Variations in the six plenum inlet temperatures, uncertainty in the plenum inlet temperature measurements, and uncertainty in the degree of mixing in the plenum result in uncertainty in the assembly inlet temperature. The reactor limits are based on the lowest of the six unlet temperatures. Because of the uncertainties, actual assembly inlet temperatures differ from the lowest inlet measurement. The mean deviation from the lowest measurement and the standard deviation were obtained using a Monte Carlo simuiation with a model based on the 
assumption of no mixing in the plenum [15]. The average assembly inlet temperature was estimated to be $1.2^{\circ} \mathrm{C}$ greater than the lowest temperature measurement, and the standard deviation was estimated to be $1.1^{\circ} \mathrm{C}$.

7. Steady State Plenum Center Pressure - The steady state plenum center pressure is determined from reactor test data [13]. The uncertainty in the experimental measurements is assumed to be normally distributed. The standard deviation is 1.5 psi and it is obtained from data given by Crowley and Hamm [13].

8. Effluent Temperanure Measurement - Four thermocouples are located at the effluent of each assembly, and the average of the four measurements is used to monitor assembly power. Data shows that the error in the average of the four thermocouple is normally distributed with a standard deviation of $0.225^{\circ} \mathrm{C}$ [16].

9. Heated Fuel Length - The length of the fuel in the fuel tube can vary as a result of variations in the dimensions of the billet from which the tube is extruded. There are uncertainties in the heated length of both inner and outer fuel tubes in a Mark 22 assembly, and these uncertainties are statistically independent. Because of limitations in the UNCERT code, the heated length of both tubes are assumed to be the same. A uniform distribution is used for this uncertainty with the extremes determined from the tube tolerances. The mean and standard deviation of the distribution are 152.0 in and 3.0 in, respectively.

10. Tumbulent Heat Transfer Coefficient - The Bjorge and Rohsenow [17] correlation is used for turbulent heat transfer coefficients. The uncertainty in this correlation is the result of variations in the correlation data base, geometry, etc. A normal distribution is used for this uncertainty. The standard deviation for errors in the correlation is 15 per cent of the correlation value [18].

11. Subcooled Boiling Hear Transfer Coefficient - The Bergles and Rohsenow [19] correlation is used for subcooled boiling heat transfer coefficients. The uncertainty in this correlation is the result of variations in the correlation data base. It has been found that this correlation tends to over predict the heat transfer coefficient. The average value of the subcooled boiling heat transfer coefficient was found to be 80 per cent of the correlation value and the standard deviation for the errors was found to be 44 per cent of the correlation value [18]. A Weibull distribution is used for this uncertainty.

Uncertainties are the result of random variations. If two uncertainties are the result of two independent random variations, they are statistically independent. For example, there are experimental errors in measuring the vapor pressure and the density of pure heavy water. The random errors in measuring the vapor pressure do not effect the density measurements. Because of the independence of the experiments, the two uncertainties are statistically independent. If uncertainties are partly the result of the same random variation, they are correlated. For example, part of the uncertainty in the physical properties of heavy water is the result of uncertainty in the heavy water composition. Therefore, the uncertainties in the vapor pressure and the density will be correlated to some degree. 
If the uncertainties are correlated, then the variance of the critical effluent temperature, equation 4.6 , is given by:

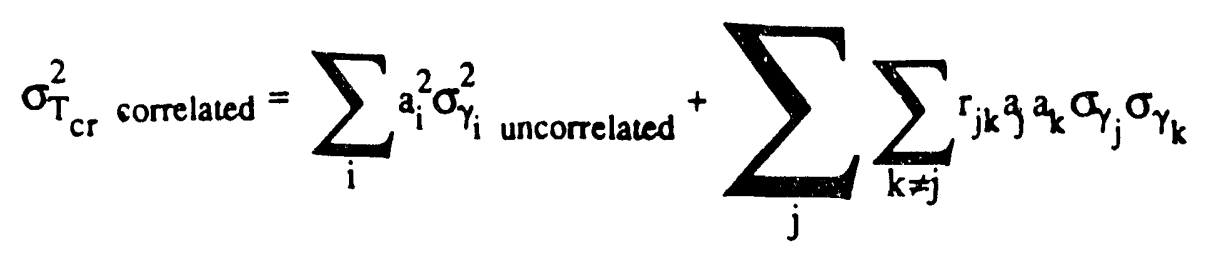

where: $\sigma_{\mathrm{T}}^{2}$ correlated $=$ the variance of the critical effluent temperature distribution if there exist correlations between uncertainties, if correlations exist this is the total variance

$$
\begin{aligned}
\sigma_{\gamma_{i} \text { uncorrelated }}^{2}= & \text { the variance of the critical effluent temperature distribution if the } \\
& \text { uncertainties are assumed uncorrelated }
\end{aligned}
$$

$$
\begin{aligned}
r_{j k}= & \text { the correlation coefficient between uncertainty parameters } \gamma_{j} \text { and } \\
& \gamma_{\mathbf{k}} \text {, defined as: }
\end{aligned}
$$

$$
r_{j k}=\frac{\left\langle\left(\gamma_{j}-\gamma_{j}\right)\left(\gamma_{k}-\gamma_{k_{0}}\right)\right\rangle}{\sigma_{\gamma_{j}} \sigma_{\gamma_{k}}} \quad-1 \leq r_{j k} \leq 1
$$

The notation $<>$ denotes an average.

If the uncertainties are correlated, the percent of the total variance for all uncertainty and covariance pairs must be considered. The percent of total variance is then:

$$
\begin{aligned}
& \text { Percent of Total Variance for an Uncertainty }=\frac{a_{i}^{2} \sigma_{\gamma_{i}}^{2}}{\sigma_{T_{c}}^{2}} \\
& \begin{array}{c}
\text { Percent of Total Variance for } \\
\text { a Covariance Pair } \gamma_{i} \text { and } \gamma_{j}
\end{array}=\frac{r_{i j} a^{a_{j}} \sigma_{\gamma_{i}} \sigma_{\gamma_{j}}}{\sigma_{T_{\alpha}}^{2}}
\end{aligned}
$$

It was assumed that every pair of uncertainties having a common source were correlated. Insufficient data exists to determine the exact value of the correlation coefficient, therefore a bounding approximation was used. The most conservative case is a value of the correlation coefficient, $r_{i k}$, for which the value of the total variance in equation 5.3 is maximized. This 
occurs when the value of the second term on the right hand side of equation 5.3 attains its largest value. If the sensitivity coefficients are of the same sign, then $r_{j k}$ is assumed to be +1 . If the sensitivity coefficients are of opposite sign, then $r_{j k}$ is assumed to be -1 . When this technique was a .lied [1] it was found that, with the worst possible contribution from covariance, the corre...ied variance was $14 \%$ greater than the uncorrelated variance. The major component of the contribution from the covariance is the correlation between the transient plenum pressure and the transient tank bottom pressure. This covariance pair accounts for $97 \%$ of the bounding value for the contribution from from covariance.

The asymmetric effects multiplier is calculated from a random combination of individual uncerainties which contribute to azimuthal variation in the assembly heat flux and geometry. These uncertainties are described below:

1. Azimuthal Flux Tilt - The power in a assembly can vary with circumferential position as a result of nonuniformities in the neutron tlux caused by the control rods. The neutronics codes used to obtain the power deposition are very accurate, so it is assumed that there is no uncertainty in calculating the azimuthal tilt [20]. Further, the septifoils are modelled with the control rods withdrawn, thereby adding conservatism to the flux peaking.

2. Eccentricity - The rubes in an assembly may not be concentric, this will result in variations in the subchannel areas. Calculations show that thermal bowing will be the principal cause of eccentricity [21]. Because the analysis of bowing and eccentricity are complex, a simple, but conservative, model is used. It is assumed that all rubes bow in the direction of the maximum power tilt in the outer fuel tube, which causes the smallest subchannel in each channel to be aligned with the maximum power in the outer fuel tube. The maximum Stanton number has been found to occur on the either on the outer or inner surface of the outer fuel tube, so this model of eccentricity is conservative. Because there are two possible orientations of the ribs with respect to the neighboring control rod, the exact position of the eccentric subchannel will depend on the orientation of the assembly.

3. Inner and Quter Fuel Thickness - The fuel alloy thickness in a fuel tube is not circumferentially unifonn. Slight offsets in the tooling cause variation in the maximum fuel thickness and azimuthal variation in the fuel thickness as illustrated in Figure 5.1.

Because the variation in fuel thickness is primarily the result of the dies being slightly off-center and not out-of-roundness, the fuel thickness varies as a cosine of the azimuthal angle. For small offsets, a, in the centers of the inner and outer surfaces, the fuel thickness as a function of the azimuthal angle is approximated by:

$$
\frac{h}{R-r} \approx\left(\frac{a}{R-r}\right) \cos \alpha+1
$$

where: $h=$ the fuel thickness

$$
\begin{aligned}
& R=\text { radius of the outer surface of the fuel } \\
& r=\text { radius of the inner surface of the fuel } \\
& \alpha=\text { the azimuthal angle }
\end{aligned}
$$




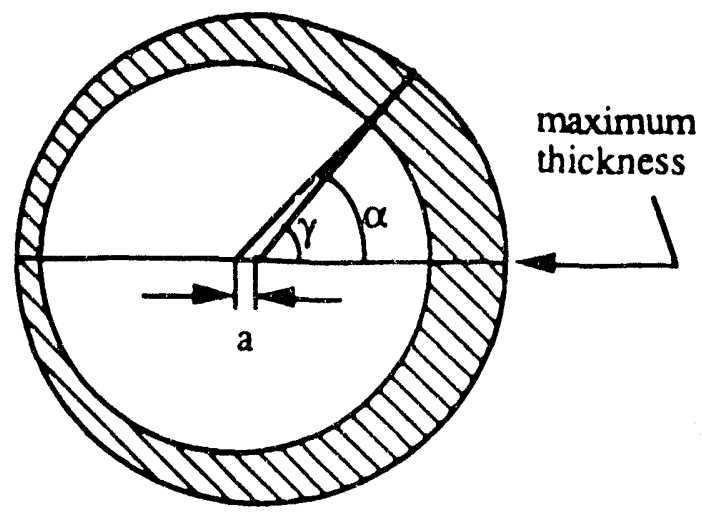

Figure 5.1

Dlustration of the variation in fuel thickness.

where:

$$
\begin{aligned}
& \alpha=\text { azimuthal angle of inner surface } \\
& \gamma=\text { azimuthal angle of outer surface } \\
& a=\text { distance, "offset", between the centers of the } \\
& \text { circles }
\end{aligned}
$$

For a given fuel tube, the maximum measured deviation from norinal is used for the amplitude of the circumferential variations. The distribution used for the maximum amplitude is obtained from the actual fuel distribution analyzer measurements. The distributions for both the inner and outer fuel tubes in a Mark 22 assembly are given in Appendix D.

4. Orientation of the Maximum Inner and Outer Fuel Thickness - The azimuthal power distribution will be influenced by the angular orientation of the maximum fuel thickness in the inner and outer fuel tubes to the flux tilt. The angular orientation of the maximum fuel thickness to the flux tilt is given by the angle, $\phi$, see Figure 4.2.

The angle, $\phi$, is assumed to be a uniformly distributed random variable on the interval of $0^{\circ}$ to $360^{\circ}$ because there is no physical reason to prefer one particular angular orientation over another.

5. Inner and Outer Target Lithium Thickness - Like the fuel tubes, the lithium thickness in the target tubes is not azimuthally uniform; and the azimuthal variation is the result of the tooling being of centered during the extrusion. Like the variation in the fuel thickness, the variation in the lithium thickness is approximately sinusoidal; and the relative thickness as a function of the azimuthal position is given by equation 5.6. There is uncertainty associated with the maximum lithium thickness. However, no experimental data or specifications are given. Because the same process is used to manufacture targets as is used for the fuel, it is expected that the tolerances for the targets should be at least as good as the fuel. The old specification for the fuel states that the fuel thickness cannot vary by more than $30 \%$ from the nominal value. The distribution for the amplitude of the circumferential variation in lithium thickness in a target is assumed to be uniformly distributed between $0 \%$ and $30 \%$ of the nominal value. The maximum variation in fuel thickness is actually much less than this 
specification, so the distribution for the maximum lithium thickness is expected to be conservative.

6. Qrientation of the Maximum Inner and Outer Lithium Thickness - The azimuthal power distribution will be influenced by the angular orientation of the maximum lithium thickness in the inner and outer target tubes to the flux tilt. The angular otientation of the maximum lithium thickness to the flux tilt is given by the angle, $\phi$,

see Figure 4.2. The angle, $\phi$, is assumed to be a uniformly distributed random variable on the interval of $0^{\circ}$ to $360^{\circ}$ because there is no physical reason to prefer one particular angular orientation over another.

7. Rib Effect - The UNCERT models do not include conduction in the ribs. If there is a region of low flow between the tip of a rib and the adjacent power tube the reduced flow will act as an insulator and cause an increase in the local heat flux in the neighborhood of the rib. This increased local heat flux increases the likelihood of flow instability. If there is contact between a rib and the adjacent power tube, the rib will act like a fin and increase rate of heat transfer from the fuel tube. In this case, there will be no rib effect. The rib effect is incorporated into the analysis as a peaking factor on the heat flux. The the local heat flux obtained from the axisymmetric model at a rib location is multiplied by this peaking factor to obtain the actual heat flux. The maximum peaking factor was estimated to be 1.209 from conduction calculations [22]. The onset of significant voiding is expected to occur in the subchannel with the minimum flow area. The ribs bounding this subchannel are expected to be touching the adjacent fuel tube, so the rib effect is expected to be minimal. However, the degree of contact is uncertain. To arcount for this uncertainty, the flux peaking factor is assumed to be a discrete random variable that takes on values of either 1.00 and 1.209 with a $50 / 50$ probability.

\subsection{Description of the Cavitation Model Uncertainties}

Twenty-three sources of uncertainty were identified for the cavitation model used in the UNCERT Version 16.3 code [2]. A common source analysis of the uncertainties identified 13 covariance pairs. Covariance plays a much larger role in the rank ordering of cavitation uncertainties than it did in the rank ordering of uncertainties for the assembly model without cavitation. Additionally, cavitation only occurs under certain conditions and is important only insofar as its effect on the plenum pressure transient. Therefore, a rank ordering of cavitation uncertainties and covariance pairs was done with respect to their impact on the plenum pressure transient. The rank ondering showed that 8 of the uncertainties, together with their covariance pairs, contributed to more than $99 \%$ of the total variance in the impact of cavitation on the plenum pressure transient [2]. Two of the 8 significant cavitation uncertainties, the TRAC transient plenum pressure and the the TRAC transient tank bottom pressure, were identified as significant uncertainties for an assembly without cavitation effects. The other six significant uncertainties for cavitation are:

1. TRAC Transient Pressure Drop in Pump Suction Piping - The uncertainty in the pressure drop in the pump suction piping is a result of uncertainty in resistances for the process water system and other deficiencies and approximations in the TRAC model which result in uncertainty in the transient tank bottom pressure. The error in TRAC is assumed to be time independent. The uncertainty is assumed to be described by a normal probability distribution. A conservative estimate of the uncertainty was obtained from benchmarking data [23]. 
2. IRAC Transient Pump Flow Rate - The uncertainty in the transient pump flow rate is the result of errors in the resistances of the process water system and other deficiencies and approximations in the TRAC model result in uncertainty in the transient tank bottom pressure. The error in TRAC is assumed to be time independent. The uncertainty is assumed to be described by a normal probability were obtained from benchmarking data. Estimates of uncertainty in this quantity are $375 \mathrm{gpm}$ and $875 \mathrm{gpm}$ respectively [23].

3. Ratio of the Pump Flow ar Cutoff to the Pump Flow at Onses - This parameter describes the reduction of flow as at the point at which pump cavitation begins. The uncertainty in this parameter is assumed to be described by an normal probability distribution. 'The mean and standard deviation were determined from test data
summarized by Hamm [24].

4. Change from Onser to Cutoff in the Pressure Drop in the Pump Suction Piping - This parameter describes the reduction in the pressure drop in the pump suction piping at the time of pump cutoff. The uncertainty in this parameter is assumed to be normally distributed. From test data summarized by Hamm [24], the mean and standard deviation were found to be 0.98918 and 0.00072 respectively.

5. Required Net Positive Suction Head for Onset of Cavitation - The required net positive suction head for the onset of cavitation in a pump is estimated from a correlation, which is based on plant test data [24]. The uncertainty in the correlation is the result of uncertainty in the test data and correlation errors. A normal distribution is used for the uncertainty in the correlation. The standard deviation for the distribution is determined from data summarized by Hamm [24].

6. Required Net Pesitive Suction Head for Pump Cut Off - The required net positive suction head for pump cutoff is estimated from a correlation, which is based on plant test data [24]. The uncertainty in the correlation is the result of uncertainty in the test data and correlation errors. A normal distribution is used for the uncertainty in the correlation. The standard deviation for the distribution is determined from data
summarized by Hamm [24].

\subsection{Summary}

There are 17 significant uncertainties for an assembly without cavitation. One of these uncertainties, the asymmetric effects multiplier, is a combination of 12 uncertainties. This gives a total of 28 significant uncertainties for an assembly without the effects of cavitation. There are 6 additional significant uncertainties for the cavitation model. Therefore, there are 34 total significant uncertainties which must be considered in the uncertainty analysis. These uncertainties account for over 99 per cent of the total variance in the critical effluent iemperature and they are summarized in Table 5.1.

The worst case correlation coefficients for pairs of uncertainties with significant covariance
are given in Table 5.2. 
Table 5.1

Summary of the Significant Uncertainties of the Flow Instability Limits Analysis

\begin{tabular}{|c|c|c|c|}
\hline Assembly Model Uncertainty & Distribution Type & Mean & Standard Deviation \\
\hline 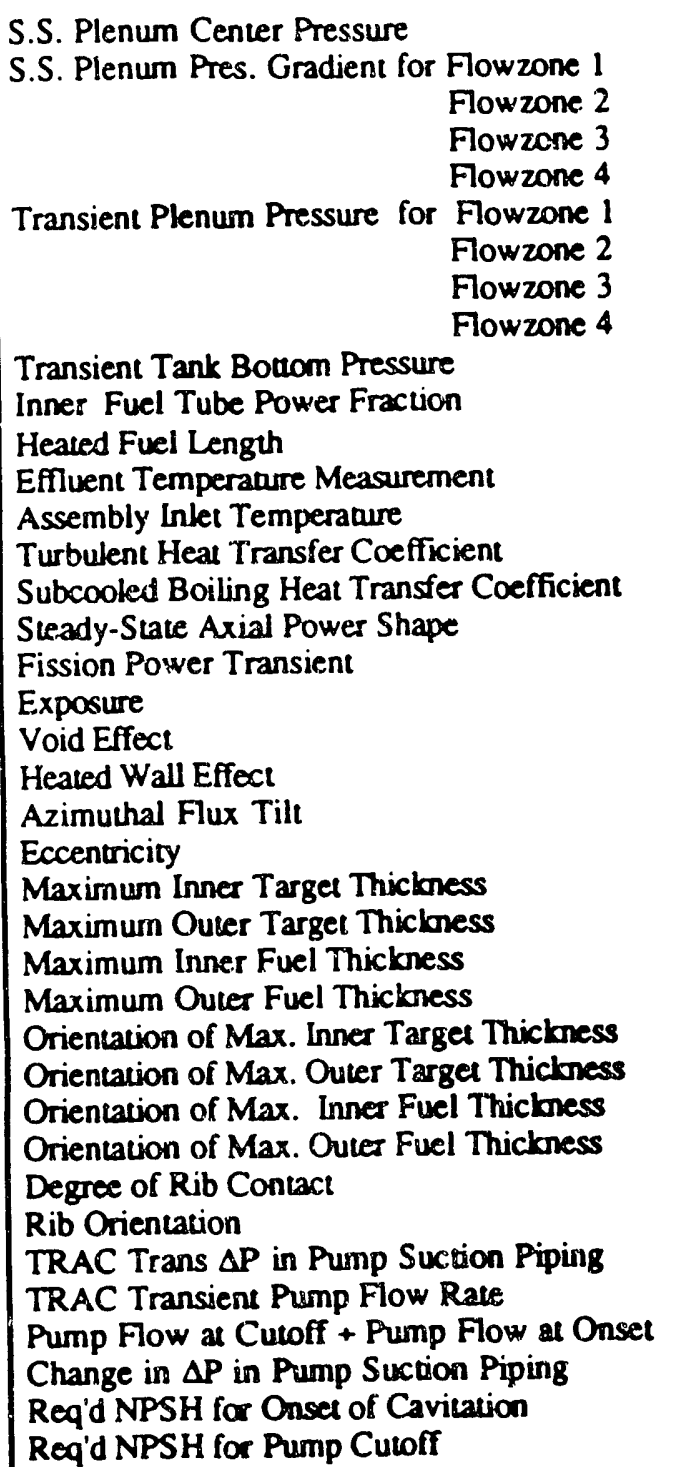 & $\begin{array}{l}\text { Normal } \\
\text { Normal } \\
\text { Normal } \\
\text { Normal } \\
\text { Normal } \\
\text { Nomal } \\
\text { Normal } \\
\text { Norma: } \\
\text { Normal } \\
\text { Normal } \\
\text { Normal } \\
\text { Uniform } \\
\text { Normal } \\
\text { Normal } \\
\text { Normal } \\
\text { Weibull } \\
\text { Bounding Value } \\
\text { Bounding Value } \\
\text { Bounding Value } \\
\text { Bounding Value } \\
\text { Bounding Value } \\
\text { Bounding Value } \\
\text { Bounding Value } \\
\text { Uniform } \\
\text { Uniform } \\
\text { Empirical } \\
\text { Enpirical } \\
\text { Uniform } \\
\text { Uniform } \\
\text { Uniform } \\
\text { Uniform } \\
\text { Discrete } \\
\text { Discrese } \\
\text { Normal } \\
\text { Normal } \\
\text { Normal } \\
\text { Normal } \\
\text { Normal } \\
\text { Normal }\end{array}$ & $\begin{array}{c}\text { Test Data } \\
\text { Correlation } \\
\text { Correlation } \\
\text { Correlation } \\
\text { Correlation } \\
\text { TRAC Value } \\
\text { TRAC Value } \\
\text { TRAC Value } \\
\text { TRAC Value } \\
\text { TRAC Value } \\
37.7 \% \\
152.0 \text { in. } \\
\text { Average Reading } \\
\text { Minimum + } 1.2^{\circ} \mathrm{C} \\
\text { Correlation } \\
\text { Correlation-20 \% } \\
- \\
- \\
- \\
- \\
- \\
- \\
\text { Nominal+375gpm } \\
0.98918 \\
6.45 \text { psi } \\
\text { Nominal } \\
\text { Nominal } \\
15 \% \\
7.74 \% \\
8.25 \% \\
180^{\circ} \\
180^{\circ} \\
180^{\circ} \\
180^{\circ} \\
- \\
\text { Nominal } \\
\text { Th }\end{array}$ & $\begin{array}{c}1.5 \mathrm{psi} \\
1.2 \mathrm{psi} \\
1.7 \mathrm{psi} \\
2.4 \mathrm{psi} \\
2.9 \mathrm{psi} \\
2.5 \mathrm{psi} \\
2.5 \mathrm{psi} \\
2.5 \mathrm{psi} \\
2.5 \mathrm{psi} \\
1.0 \mathrm{psi} \\
1.7 \% \\
3.0 \mathrm{in} . \\
0.225^{\circ} \mathrm{C} \\
1.1^{\circ} \mathrm{C} \\
15 \% \\
44 \% \\
- \\
- \\
. \\
. \\
. \\
- \\
8.7 \% \\
8.7 \% \\
1.6 \% \\
1.7 \% \\
103.9^{\circ} \\
103.9^{\circ} \\
103.9^{\circ} \\
103.9^{\circ} \\
- \\
3.0 \% \\
0.3 \mathrm{ft} \mathrm{D} 2 \mathrm{Opm} \\
0.3 \mathrm{ft} \mathrm{D} 2 \mathrm{O}\end{array}$ \\
\hline
\end{tabular}


Table 5.2

Worst Case Correlation Coefficients for Uncertainty Pairs With Significant Covariance

\begin{tabular}{|l|l|c|}
\hline \multicolumn{1}{|c|}{ Uncertainty 1 } & \multicolumn{1}{|c|}{ Uncertainty 2 } & $\begin{array}{c}\text { Worst Case } \\
\text { Correlation } \\
\text { Coefficient }\end{array}$ \\
\hline Transient Plenum Pressure & Transient Tank Bottom Pressure & -1.0 \\
Transient Plenum Pressure & Trans $\Delta P$ in Pump Suction Piping & +1.0 \\
Transient Plenum Pressure & Transient Pump Flow Rate & +1.0 \\
Transient Tank Botwom Pressure & Trans $\Delta P$ in Pump Suction Piping & -1.0 \\
Transient Tank Bottom Pressure & Transient Pump Flow Rate & -1.0 \\
Trans $\Delta P$ in Pump Suction Piping & Transient Pump Flow Ratc & +1.0 \\
Cutoff Pump Fow+Onset Pump Flow & Req'd NPSH for Pump Cutoff \\
Change in $\Delta P$ in Pump Suction Piping & Req'd NPSH for Onset of Cavitation & +1.0 \\
& & +1.0 \\
\hline
\end{tabular}

\section{References}

1. Kubic, W. L., "The Identification and Quantification of Uncertainties for the Flow Instability Limits Uncertainty Analysis of a Mark 22 Assembly," Westinghouse Savannah River Company Memorandum, NES-RFI-900047, FIU-90-22 (1990).

2. Kubic, W. L., "The Identification and Quantification of the Uncertainties Affecting Cavitation," Westinghouse Savannah River Company Memorandum, NES-RFI900048, FIU-90-23 (1990).

3. Massey, W. M., "Sensitivity of Mark 22 Flow Instability Limits to Axial Power Shape," E. I. Du Pont de Nemours \& Company, Inc. Report DPST-89-244 (Rev. 1) (1989).

4. Painter, S., "Relative Power Calculation for DEGB LOCA - FI Limits for K-14.2," Task 89-037-1 (1989).

5. Smith, J. A. and J. P. Church, "Accident Analysis Computer Program, " E. I. du Pont de Nemours \& Company, Inc. Report DPSTM-120 (1984).

6. Suich, J. E. and D. C. Irving, "The Joushua System, Vol. 2.1 User's Guide," E. I. du Pont de Nemours \& Company, Inc. Report DPSTM-500 (1975).

7. Chen, K. F., "Benchmarking of FIOUwTRAN Wyith Mark-22 Mockup Flow Excursion Test Data From Babcock \& Wilcox", Westinghouse Savannah River Company Report, WSRC-TR-90-97 (1990). 
8. Goodwin, K. E., Sjostrom, L. C., Witmer, F. E., and Buckner, M. L., signatories, "Agreements and Commitments: Review of FI Limits Methodology Meeting, August 30-September 2, 1988, Savannah River Laboratory," (1988).

9. Hamm, L. L., S. E. Aleman, and J. E. Laurinat, "Effects of Heated Wall, Wall Voidage, and Dissolved Gases on Flow Instability Limits," Westinghouse Savannah River Company Report, WSRC-RP-89-406 (1989).

10. White, A. M., "Pressure Transient to be Used in the Derivation of Sensitivity Coefficients," Westinghouse Savannah River Company Memorandum, NES-RFI890159, FIU-89-74 (1989).

11. Griggs, D. P.,"Uncertainties in TRAC Plenum Pressures for the FI Phase of a DEGB LOCA," Draft of a Westinghouse Savannah River Company Report , WSRC-TR-90-263 (1990).

12. Hardy, B. J., "Documentation for Computer Code POWCOMB.FOR," Westinghouse Savannah River Company Memorandum, NES-RFI-890133, FIU-8966 (1989).

13. Crowley, D. A. and L. L. Hamm, "Improved Plenum Pressure Gradient Facemaps for PKL Reactors," E. I. du Pont de Nemours \& Company, Inc. Report DPST-88527 (1988).

14. N.E.D., "LOCA Action Plan Weekly Highlights, January 13, 1989," E. I. du Pont de Nemours \& Company, Inc. Memorandum (1989).

15. Kubic, W. L., "Uncertainty in the Inlet Temperature - Revised Calculations," E. I. du Pont de Nemours \& Company, Inc. Memorandum, FIU-89-22 (1989).

16. Laurinat, J. E., "Uncertainties for Reactor Assembly Heat Transfer," Westinghouse Savannah River Corporation Memorandum, FIU-89-18 (1989).

17. Bjorge, R. W. and W. M. Rohsenow, "Correlation of Forced Convection Boiling Heat Transfer Data," Int. J. Heat Mass Transfer, 25: 753-757 (1982).

18. Laurinat, J. E., "Uncertainties for Reactor Assembly Heat Transfer," Westinghouse Savannah River Company Report WSRC-RP-89-15 (1989).

19. Bergles A. E. and W. M. Rohsenow, "The Determination of Forced Convection Surface-Boiling Heat Transfer," J. Heat Transfer, 86:365 (1964).

20. Webb, R. E., "Radial and Azimuthal Power Profiles in Mark 22 Assemblies," Appendix B, Westinghouse Savannah River Corporation Report WSRC-RP-89-724 (1989).

21. Boucher, T. J., "Program to Determine FLOWTRAN Input Channel or Subchannel Entrance, Length, and Exit Manual Loss Coefficients and Flow Splits for Channel Geometry Variation," Westinghouse Savannah River Corporation Memorandum, FIU-89-33, NED-RFI- 890008 (1989).

22. Laurinat, J. E., "Effect of Ribs on the OSV Criterion Used for Flow Instability Limits, Rev. 1," Westinghouse Savannah River Corporation Memorandum, NESRFI-900004, FIU 99-68, Rev. 1 (1990). 
23. Shadday, M. A. ,"The Impact of Cavitation During A DEGB LOCA, With Uncertainties," Westinghouse Savannah River Company Repor, WSRC-RP-89. 1313 (1989).

24. Hamm, L. L., "Reanalysis of Bingham Pump Cavitation Characteristics for PKL Reactors," E. I. du Pont de Nemours \& Company, Inc. Report DPST-84-624 (1984). 


\section{SINGLE ASSEMBLY PROBABILITY CALCULATIONS}

The flow instability linuts analysis must account for uncertainty in the assembly fabrication, the reactor operations, and the assembly model. In the previous two chapters, the important uncertainties have been identified and quantified. The next task in the limits analysis is to calculate a set of flowzone power limits for a pre-specified corewide probability that no assembly exceeds the Stanton number criterion. The first step in this process is to evaluate the probability of not violating the Stanton number criterion in a single assembly. This chapter discusses the method of evaluating this probability.

The Stanton number criterion can be satisfied by specifying a steady state assembly power limit, and thus a steady state assembly effiuent temperature limit. The assembly effluent temperature limit obtained for a given realization (a specific set of values) of the uncertainty parameters is called the critical effluent temperature. For different values of the uncertainty parameters, different critical effluent temperatures will be obtained. 'The probability that the effluent temperature limit is lower than a specified value is the probability that the uncertainty in the defining parameters will yield a lower critical effluent temperature.

\subsection{The Statistical Model for the Critical Emuent Temperature}

From Equation 4.3 the expression used in the statistical model for the critical effluent temperature is:

$$
\begin{aligned}
\mathrm{T}_{\mathrm{cr}}(\mathbf{x}) & =\mathrm{T}_{\mathrm{in}}+\beta_{\mathrm{hw}} \beta_{\text {void }} \beta_{3 \mathrm{D}}(\mathrm{y}) \Delta \mathrm{T}_{\text {ideal }}(\mathrm{z})+\varepsilon \\
& =\mathrm{T}_{\mathrm{cr}_{0}}+\sum_{\mathrm{i}} \mathrm{a}_{\mathrm{i}}\left(\gamma_{\mathrm{i}}-\gamma_{\mathrm{i}_{0}}\right)+\mathrm{e}(\mathbf{x})
\end{aligned}
$$

where: $\quad T_{c r}(x)=$ the assembly critical effluent temperature at the parameter values $x$

$$
\begin{aligned}
& x=\text { all parameters which affect the critical effluent temperature of an } \\
& \text { assembly }
\end{aligned}
$$

$\mathrm{T}_{\text {in }}=$ the assembly inlet temperature

$\beta_{h w}=$ heated wall effect multiplier, a constant multiplicative bias

$\beta_{\text {void }}=$ void effect multiplier, a constant multiplicative bias

$$
\begin{aligned}
\beta_{3 D}(y)= & \text { asymmetric effects multiplier as a function of the asymmetric } \\
& \text { parameters } y \\
y= & \text { parameters describing asymmetric effects, not including any } \\
& \text { axisymmetric parameters, heated wall or void effects }
\end{aligned}
$$




$$
\begin{aligned}
& \Delta T_{\text {ideal }}(z)=\text { limiting coolant temperature increase across an idealized } \\
& \text { (axisymmetric, no cavitation effects, no heated wall and no void } \\
& \text { effects) assembly as a function of axisymmetric parameters } \mathbf{z} \\
& \mathbf{z}=\text { parameters describing axisymmetric effects, including } T_{\text {in }} \text {, not } \\
& \text { including any asymmetric parameters, heated wall or void effects. } \\
& \varepsilon=\text { error in effluent temperature measurement } \\
& \mathrm{T}_{\mathrm{cr}_{0}}=\text { reference value of the critical effluent temperature } \\
& a_{i}=\frac{\partial T_{c r}\left(x_{0}\right)}{\partial \gamma_{i}}=\text { sensitivity coefficient for the } i^{\text {th }} \text { uncertainty parameter } \\
& \begin{array}{l}
\gamma_{i}=i^{\text {th }} \text { expansion variable which includes } \beta_{3 D} \text { and } \varepsilon \text {, but does not } \\
\text { include any cavitation parameters }
\end{array} \\
& \gamma_{\mathrm{i}_{0}}=\text { reference value of the } \mathrm{i}^{\text {th }} \text { expansion variable } \\
& \begin{aligned}
& e(x)= \text { error term which includes cavitation effects and higher non-linear } \\
& \text { components of } T_{c r}(\mathbf{x}) \text {. }
\end{aligned}
\end{aligned}
$$

The critical effluent temperature is a function of the random uncertainty variables $\mathbf{x}$ and therefore it is also a random variable. The cumulative distribution function for the critical effluent temperature gives the probability that the critical effluent temperature is less than a specified value, which is the probability of exceeding the working Stanton number criterion. The probability of not exceeding the Stanton number criterion is one minus the cumulative distribution function for the critical effluent temperature. Therefore, the first step is to evaluate the cumulative distribution function for the critical effluent temperature.

\subsection{The Cumulative Distribution Function for the Critical Effuent Temperature}

Combining all of the azimuthal variations into a single random variable simplifies the problem of determining the cumulative distribution function for the critical effluent temperature by eliminating a major source of nonlinearity in the probability calculations. However, the other nonlinearities in Equation 6.1 must be considered. Of these other nonlinearities, discontinuities in the derivatives of the critical effluent temperature have the greatest impact on the probability calculations. One of the major sources of discontinuous derivatives is the result of changes in the cavitation regime. Three cavitation regimes are possible: no cavitation, cavitation in the pump suction piping, and cavitation in the pumps. Because of these discontinuities, the linear variate method of Monte Carlo [1] will be used to determine the cumulative distribution function (CDF). It will be shown that the CDF for the linear part of Equation 6.1 gives limits which are lower than those obtained from the $\mathrm{CDF}$ for the full equation. 
The linear variate method combines Monte Carlo analysis with a linear response surface to reduce the errors in estimating the moments of the distribution. It is a special case of the control variate method [2]. In the linear variate method, the function is separated into a linear part and a nonlinear correction:

$$
T=T_{\text {linear }}(x)+\left(T(x)-T_{\text {linear }}(x)\right)=T_{\text {linear }}(x)+e(x)
$$

where: $\quad \mathrm{T}_{\text {linear }}(\mathbf{x})=\mathrm{a}$ linear approximation

$$
e(x)=\text { the error in the linear approximation. }
$$

The linear approximation has the following form:

$$
\mathrm{T}_{\text {linear }}(\mathbf{x})=\mathrm{T}_{\mathrm{ref}}+\sum_{\mathrm{i}} \mathrm{a}_{\mathrm{i}}\left(\mathbf{x}_{\mathrm{i}}-\mathbf{x}_{\mathrm{i}, \mathrm{ref}}\right)
$$

The first moment of $\mathrm{T}$ about zero is obtained as follows:

$$
\mu_{\mathrm{T}}=\int_{-\infty}^{\infty} \cdots \int_{-\infty}^{\infty} \mathrm{T}_{\text {linear }}(\mathbf{x}) \mathrm{p}(\mathbf{x}) \mathrm{d} \mathbf{x}+\int_{-\infty}^{\infty} \cdots \int_{-\infty}^{\infty} \mathrm{e}(\mathbf{x}) \mathrm{p}(\mathbf{x}) \mathrm{d} \mathbf{x}
$$

where: $\quad p(\mathbf{x})=$ the joint probability density function for $\mathbf{x}$.

$$
\mu_{\mathrm{T}}=\text { the first moment of } \mathrm{T} \text { about zero, the mean of } \mathrm{T}
$$

The first integral in Equation 6.4 is the average of the linear approximation. The second integral is the average of the approximation error:

$$
\mu_{\mathrm{T}}=\mu_{\mathrm{T}_{\text {linear }}}+\mu_{\mathrm{e}} \text {. }
$$

where: $\quad \mu_{e}=$ the first moment about zero of $e(x)$.

The linear approximation of the first moment about zero can be evaiuated exactly using Equation 6.3:

$$
\mu_{T_{\text {linear }}}=T_{\text {ref }}+\sum_{i} a_{i}\left(\mu_{x_{i}}-x_{i, r e f}\right)
$$

The error in the linear approximation can be determined from the thermal-hydraulic model. Any standard Monte Carlo procedure can be used to estimate the average value of the error in the linear approximation. This average error is a nonlinear correction to the linear approximation of the first moment. 
The $n^{\text {th }}$ moment of $\mathrm{T}$ about the mean, $\mu_{n} \mathrm{r}$, is estimated in a similar manner:

$$
\begin{aligned}
\mu_{n T}= & \int_{-\infty}^{\infty} \cdots \int_{-\infty}^{\infty}\left(T_{\text {linear }}(x)-\mu_{T_{\text {linear }}}\right)^{n} p(x) d x \\
& +\int_{-\infty}^{\infty} \cdots \int_{-\infty}^{\infty} \sum_{i=1}^{n}\left(\begin{array}{l}
n \\
i
\end{array}\right)\left(T_{\text {linear }}(x)-\mu_{T_{\text {linear }}}\right)^{(n-i)}\left(e(x)-\mu_{e}\right)^{i} p(x) d x
\end{aligned}
$$

The first term in on the right hand side of Equation 6.7 is the $n^{\text {th }}$ moment of the linear approximation of $\mathrm{T}$ about the linear approximation of the mean. The second term on method. If the uncertainties 6.7 can be determined by any standard Monte Carlo linear moments about the mean are

$$
\begin{aligned}
& \mu_{2 T, \text { linear }}=\sum_{i} a_{i}^{2} \mu_{2 x_{i}} \\
& \mu_{3 T \text {, linear }}=\sum_{i} a_{i}^{3} \mu_{3 x_{i}} \\
& \mu_{4 T, \text { linear }}=\sum_{i} a_{i}^{4} \mu_{4 x_{i}}+3 \sum_{i} \sum_{j \neq i} a_{i}^{2} a_{j}^{2} \mu_{2 x_{i}} \mu_{2 x_{j}} .
\end{aligned}
$$

Equations $6.8-6.10$ also can be used if the uncertainties are not statistically independent by transforming the correlated random uncertainty variables into independent random
variables.

If the approximation error is small, the nonlinear cosrections to the linear approximations of the moments should be smail. The standard error of estimation for the Monte Carlo the total moment.

The linear variate method of Monte Carlo can be used as an efficient method for evaluating the cumulative distribution function for the critical effluent temperature. The steps in this

1. Find a linear approximation for the critical effluent temperature.

2. Transform the correlated uncertainty variables into uncorrelated random variables.

3. Determine the linear estimates of the moments for the critical effluent temperature.

4. Generate random numbers for the uncertainty variables.

5. Evaluate the critical effluent temperature and the linear approximation of the critical effluent temperanure for each set of randorn variables.

6. Determine the error in the linear estimates of the moments. 
7. Obtain estimates of the moments from the linear approximation and the error in the linear approximation.

8. Estimate the cumulative distribution function from the moments.

The first step in applying the linear variate method is to obtain a linear approximation of the model. For the flow instability limits calculations, the linear approximation is obtained by linearizing the model about the nominal values of the uncertainty variables without the effects of cavizarion included. This approximation was chosen for several reasons. First, when nominal values of the parameters are used, cavitation is predicted only at the highest values of the inlet temperature. Second, if cavitation does occur, its effect on the critical effluent temperature is relatively small [3]. Third, previous studies show that the effects of nonlinearitie: are relatively small if cavitation does not occur [4], so the linear approximatior of the non-cavitating model is reasonably good. Finally, it is convenient to express the results as a deviation from the nominal case without cavitation.

The linear approximation is obtained from a series expansion about the nominal values of the parar eiers. For most parameters, the nominal values are equal to the mean value. The two $: x c e p t i o n s$ are the inlet temperature and the subcooled boiling heat transfer coefficient. The detailed form of the linear approximation of Equation 6.1 is:

$$
\begin{aligned}
\mathrm{T}_{\text {cr linear }}= & \mathrm{T}_{\mathrm{cr}}+\sum_{\mathrm{i}} \mathrm{a}_{\mathrm{i}}\left(\gamma_{\mathrm{i}}-\gamma_{\mathrm{i}_{0}}\right) \\
= & \mathrm{T}_{\mathrm{cr} 0}+\left(\varepsilon-\varepsilon_{0}\right)+\beta_{\mathrm{hw}} \beta_{\text {void }} \Delta \mathrm{T}_{\text {ideal }}\left(\mathrm{z}_{0}\right)\left(\beta_{3 \mathrm{D}}-\beta_{3 \mathrm{D}_{0}}\right) \\
& +\left(1+\beta_{\mathrm{hw}} \beta_{\text {void }} \beta_{3 \mathrm{D}_{0}} \frac{\partial \Delta \mathrm{T}_{\text {ideal }}\left(\mathrm{z}_{0}\right)}{\partial \mathrm{T}_{\text {in }}}\right)\left(\mathrm{T}_{\mathrm{in}}-\mathrm{T}_{\text {in }}\right) \\
& +\beta_{\mathrm{hw}} \beta_{\text {void }} \beta_{3 \mathrm{D}_{0}} \sum_{\mathrm{i}} \frac{\partial \Delta \mathrm{T}_{\text {ideal }}\left(\mathrm{z}_{0}\right)}{\partial \gamma_{\mathrm{i}}}\left(\gamma_{\mathrm{i}}-\gamma_{\mathrm{i}_{0}}\right)
\end{aligned}
$$

The subscript 0 in this equation indicates the reference value of the variable. The limiting axisymmetric temperature rise with no cavitation, $\Delta \mathrm{T}_{\text {ideal, }}$ is determined from the FLOWTRAN model. The derivatives of the axisymmetric temperature rise are estimated from finite perturbations to the axisymmetric FLOWTRAN model.

The next two steps in the linear variate analysis are to calculate the moments of the distribution using the linear approximation and generate random values of the uncertainty variables for the Monte Carlo calculations. Both of these steps must incorporate the effects of the worst case covariance. The effects of covariance are included by defining a new set of variables.

There are three sets of correlated uncertainty variables in the model. These are the input parameters obtained from TRAC, the ratio of pump flow at cutoff to the pump flow at onset aid thic roquircd net positive suction head for pump cutoff, and the change in the pressure drop in the pump suction piping and the required net positive suction for onset of 
cavitation. The assumption of total correlation implies that each group of correlated uncertainties can be described by a single random variable. If the correlated variables are normally distributed, as are the correlated variables for a Mark 22 assembly, they are related to the common random variable by a simple expression:

$$
x_{i j}=\mu_{x_{i j}}+r_{i j} \sigma_{x_{i j}} c_{j}
$$

where

$$
\begin{aligned}
& x_{i j}=\text { the random uncertainty variable } i \text { in the correlated group } j \\
& \mu_{x_{i j}}=\text { the mean value for } x_{i j} \\
& r_{i j}=\text { the worst case correlation coefficient between } x_{i j} \text { and } c_{j} \\
& \sigma_{x_{i j}}=\text { the standard deviation for } x_{i j} \\
& c_{j}=\text { the common random variable for correlated group } j, c \text { is a unit } \\
& \text { normal deviate for one of the correlated variables }
\end{aligned}
$$

Because the common random variable $c_{j}$ is a unit normal deviate, it is a zero mean random variable with a standard deviation of unity. The variable $\mathrm{c}$ is statistically independent of the random uncertainty variables that are not in correlated group $j$. Because the worst case covariance is used in the analysis, the correlation coefficient in Equation 6.12 is either +1 or -1 . Equation 6.12 will generate a normally distributed random variable $x_{i j}$ with the correct mean and standard deviation that also is totally correlated with the other uncertainties in the correlated group $\mathrm{j}$.

The worst case correlation coefficients in Equation 6.12 are determined from the sensitivity coefficients in the linear approximation. First, one of the uncertainties, say $x_{\mathbf{k j}}$, in correlated group $j$ is selected as the reference uncertainty. The correlation coefficient between $x_{k j}$ and the common random variable for group $j$ is assumed to be +1 . The correlation coefficients for the other uncertainty variables with the common random variable are given by the following equation:

$$
r_{i j}=\frac{a_{i j} a_{k j}}{\left|a_{i j} a_{k j}\right|}
$$

Using these correlation coefficients will result in the largest standard deviation for the critical effluent temperature.

The linear estimates of the moments can be obtained by expressing the linear model in terms of the common random variables. This trans ormation is obtained by replacing all of the uncertainties in a correlate group by the common random variable. The sensitivity coefficient for the common random variable for correlated group $j$ is

$$
a_{c_{j}}=\sum_{i \in g r o u p j} l a_{i j} l \sigma_{x_{i j}}
$$


Linear estimates of the moments of the critical effluent temperature are obtained using the transformed linear model and Equation 6.6 and Equations 6.8 - 6.10.

The next step in the linear variate analysis is to generate random numbers for the uncertainty variables. A Latin hypercube sampling procedure is used for the limits analysis [5]. In the case of the groups of correlated variables, a unit normal random number was generated for the common random variable for each group. The correlated uncertainty variables in the model were determined from Equation 6.12. The random numbers for all variables except the asymmetric effects multiplier where obtained from the random number generator given by Forsythe et al. [6]. This algorithm as implemented on a Macintosh II gave a reasonably uniform distribution and insignificant autocorrelation. The random numbers for the asymmetric effects multiplier were generated from the Monte Carlo procedure described in this chapter.

Once the random sets of the uncertainty variables have been generated, the UNCERT Version 16.3 code was used to evaluate the critical effluent temperature for each set of parameters. The UNCERT Version 16.3 code considers the effects of cavitation on the critical effluent temperature. The linear approximation given by Equation 6.11 is also evaluated using the same sets of random input parameters. From these results, the error in the linear approximation can be determined for each realization of random variables.

The error in the linear estimate of the mean is obtained by averaging the set of errors in the linear approximation obtained for the Monte Carlo sample. In a similar manner, the errors in the higher order moments are obtained by averaging the summation in the integral of the second term on the right hand side of Equation 6.7. The linear variate estimates of the moments are obtained by adding the correction obtained from the Monte Carlo analysis to the linear estimates of the moments.

The linear variate Monte Carlo method will yield accurate estimates of the moments of the critical effluent temperature. The cumulative distribution function for the critical effluent temperature must be estimated from these moments. A probability distribution is uniquely characterized by an infinite set of moments. A reasonable approximation of a distribution can be obtained using a finite number of moments. The Pearson system of distributions can be used to estimate the cumulative distribution function from the first four moments of a distribution [7].

The Pearson system of distributions is a family of 13 empirical distributions, which includes the normal distribution. The discribution type as well as its parameters are obtained from the the first four moments. Details of the Pearson distributions and the procedure for obtaining the distribution type and parameters are given by Elderton and Johnson [7].

By using this procedure and the estimates of the first four moments obtained from the linear variate method, a reasonable estimate of the cumulative distribution function for the critical effluent temperature can be obtained.

To illustrate the effects of nonlinearities, moments for a Mark 22 charge with a nominal inlet temperature of $30^{\circ} \mathrm{C}$ were determined, and the results are given in Table 6.1 . A comparison of the linear approximation without cavitation with the results of the linear variate estimates shows that the effects of cavitation and other nonlinearities are relatively minor when the inlet temperature is $30^{\circ} \mathrm{C}$. The skewness of both the linear and nonlinear estimates show that the disuribution for the critical effluent temperature is nearly symmetric. The second and fourth moments obtained by linear variate Monte Carlo are smaller than the 
linear estimates, which indicates that the actual distribution is narrower than the distribution obtained from the linear approximation.

The cumulative distribution functions obtained from the linear variate estimate of the moments and the linear estimate of the moments are plotted in Figure 6.1. Both distributions are approximately normal. The occurrence of cavitation should increase the probability of $\rightarrow x c e e d i n g$ the Stanton number criterion; but the other nonlinearities tend to decrease the rrobability in the lower portions of the distribution. Figure 6.1 shows that the linear variate estimate of the distribution lies below the distribution obtained from the linear model without cavitation.

Table 6.1

Moments for the Critical Effluent Temperature for a Mark 22 Assembly in Flowzone 1

With a Nominal Inlet Temperature of $30^{\circ} \mathrm{C}$

\begin{tabular}{|l|c|c|c|}
\hline & Linear Approx. & $\begin{array}{c}\text { Linear Variate } \\
\text { Estimates }\end{array}$ & $\begin{array}{c}\text { Standard Error of } \\
\text { Estimation }\end{array}$ \\
\hline Mean & 72.281 & 72.243 & 0.021 \\
Second Moment about the Mean & 10.602 & 9.862 & 0.171 \\
Third Moment about the Mean & 1.12 & 6.33 & 1.66 \\
Fourth Moment about the Mean & 335.5 & 277.8 & 14.8 \\
Standard Deviation & 3.256 & 3.140 & - \\
Skewness & 0.0010 & 0.0418 & - \\
Kurtosis & 2.985 & 2.856 & - \\
\hline
\end{tabular}




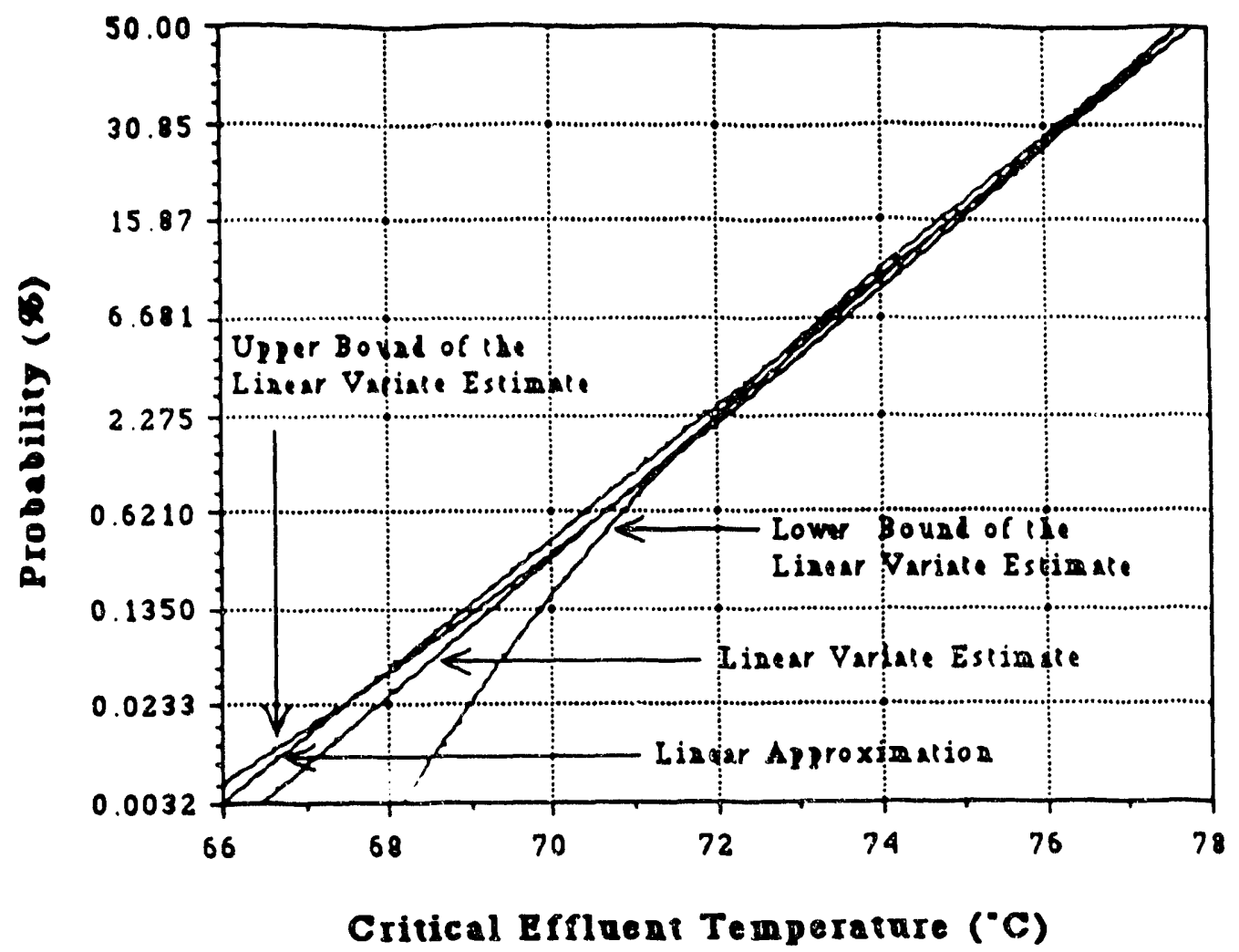

Figure 6.1

Estimates of the cumulative distribution function for the critical effluent temperature of a Mark 22 assembly with an inlet temperature of $30^{\circ} \mathrm{C}$.

\section{References}

1. Kubic, W. L. and A. M. White, "Estimating Uncertainty in Thermal-Hydraulics Codes Using the Linear Variate Method," ANS Winter Meeting, San Francisco (November, 1989).

2. Hammersley, J. M., and D. C. Handscomb, Monte Carlo Methods, Chapman and Hall, London (1964).

3. White, A. M., "FI Limits Using Cavitation Multiplier Approach," Westinghouse Savannah River Company Memorandum NES-RFI-890123, FIU-89-64, Rev. 2 (1989).

4. Kubic, W. L., "The Effect of Nonlinearities in the FLOWTRAN Model on the Flow Instability Limits Uncertainty Analysis," Westinghouse Savannah River Company Memorandum, NES-RFI-900049, FIU-90-24, (1990).

5. McKay, M . D., R. J. Beckman, and W. J. Conover, "A Comparison of Three Methods for Selecting Values of Input Variables in the Analysis of Output from a Computer Code," Technometrics ,21:239-245 (1979). 
6. Forsythe, G. E., M. A. Malcolm, and C. B. Moler, Computer Methods for

Mathematical Computations, Prentice-Hall, Inc., Englewood Cliffs, N.J. (1977). 7. Elderton, W. P., and N. L. Johnson, Systems of Frequency Curves, Cambridge
University Press, London (1969). 


\section{CORE PROBABILITY CALCULATIONS}

The flowzone effluent temperature limits for the flow instability phase of the double-ended guillotine break loss-of-ccolant accident must be such that there is a least an $84 \%$ probability that no assembly in the core exceeds the Stanton number criterion. The previous chapter described the method used to estimate the probability of not exceeding the Stantor' number criterion in a single assembly. This chapter discusses the methods used to estimate the probability of not exceeding the Stanton number criterion for the entire core from the single assembly results.

\subsection{The Assumption of Statistically Independent Assemblies}

The problem of determining the probability of not exceeding the Stanton number criterion for the entire core is complicated by the fact that the assemblies are not statistically independent. The critical effluent temperatures for pairs of assemblies will be correlated because the uncertainties that affect one assembly are not statistically independent of the uncerainties that affect other assemblies. To account for the correlation between assemblies, the covariance between the critical effluent temperatures of all pairs of assemblies in the core must be determined. Determining these covariances is both difficult and time consuming. As a result of practical considerations, the assemblies are assumed to be statistically independent. This assumption has relatively little impact on the effluent temperature limits and is shown to be conservative in Appendix $\mathrm{E}$.

In Appendix $E$, the assumption of statistical independence is shown to be conservative if the covariance of the critical effluent temperatures for all pairs of assemblies is positive. Appendix $E$ also shows that the covariance in the critical effluent temperatures for a pair of assemblies must be positive, so the assumption of statistical independence is conservative. Correlation between assemblies is primarily the result of uncertainties that are common to all assemblies. These common uncertainties tend to affect all assemblies in the same manner, so the correlation between the assemblies must be positive.

In addition to demonstrating that the assumption of statistical independence is conservative, the amount of conservatism introduced by the assumption was estimated. The degree of conservatism depends on the fraction of the variance due to common uncertainies. A rank ordering of the uncertainties indicates that approximately $75 \%$ of the variance in the critical effluent temperature is the result of uncertainties that are common to all assemblies [1]. A simple study of the effect of common uncertainty parameters [2] indicates that this assumption will result in about a $1{ }^{\circ} \mathrm{C}$ reduction in the effluent temperature limit.

\subsection{Estimating the Distribution for All Assemblies}

The assumption of statistical independence eliminates the need to consider the covariance between assemblies, but cumulative distribution functions for the critical effluent temperatures still are required for every assembly. In principle, the cistributions could be obtained by applying the linear variate method of Monte Carlo to every assembly in the reactor. This approach, however, is not practical. First, the TRAC noding scheme is not detailed enough to provide boundary conditions for every assembly. Second, the nonlinear probability calculations require too much computer time to be periormed for more tiari a few assemblies. Because of these limitations, approximations must be made in order to obtain a distribution for every assembly. 
The approximate method for obtaining the cumulative distribution functions is based on three observations. First, accurate estimates of the nulative distribution functions are required only over a limited range of critical effluent temperatures. Second, the effects of cavitation and other nonlinearities are relatively small. Third, sensitivity studies show that the effects of cavitation and other nonlinearities are relatively constant for all assemblies. The basic approach is to assume that the distribution for every assembly is normal and then obtain approximate values for the means and standard deviations for all assemblies.

Although the distribution obtained from the linear variate Monte Carlo analysis may not be normal, a normal distribution can be used in the analysis. Only a portion of the lower tail is required for the limits calculations. If an assembly effluent temperature limit is greater than iาe mean critical effluent temperature minus 2.0 standard deviations, the desired core probability is not obtained. Assemblies with limits less than the mean minus 4.0 standard deviations have such a small probability of failure that they do not contribute significantly to the overall probability of failure in the core. Therefore, accurate estimates of the cumulative distribution functions are needed only over a range of between 2.0 and 4.0 standard deviations below the mean. Because accuracy is required for only a limited range, it is possible to find a normal distribution that bounds the actual distribution over the range of interest. The concept of a bounding normal distribution is illustrated in Figure 7.1. The bounding distribution will be called the effective normal distribution, and it is characterized by an effective mean and an effoctive standard deviation.

The effective normal distribution of an assembly is determined using the following procedure:

1. The cumulative distribution function for an assembly is determined using the linear variate method of Monte Carlo.

2. This cumulative distribution function is plotted on normal probability graph paper.

3. A straight line is drawn on this plot that bounds the actual distribution over the desired range of critical effluent temperatures. The straight line is the effective distribution.

4. The effective mean is the critical effluent temperature corresponding to $50 \%$ probability on the effective cumulative distribution function.

5. The effective standard deviation is equal to $1 /$ slope of the effective cumulative distribution function.

Because the effects of cavitation and other nonlinearities are relatively small $[3,4]$, the difference between the effective normal distribution and the normal distribution obtained from the linear model without cavitation is expected to be small. This observation suggests that the effoctive distribution can be represented as a small correction to the distribution obtained from the linear approximation without cavitation.

An additive correction is used to relate the effective mean to the mean obtained from the linear approximation without cavitation.

$$
\mu_{T_{\text {cr,efc }}}=\mu_{T_{\text {cr,linear }}}+\delta_{c a}
$$




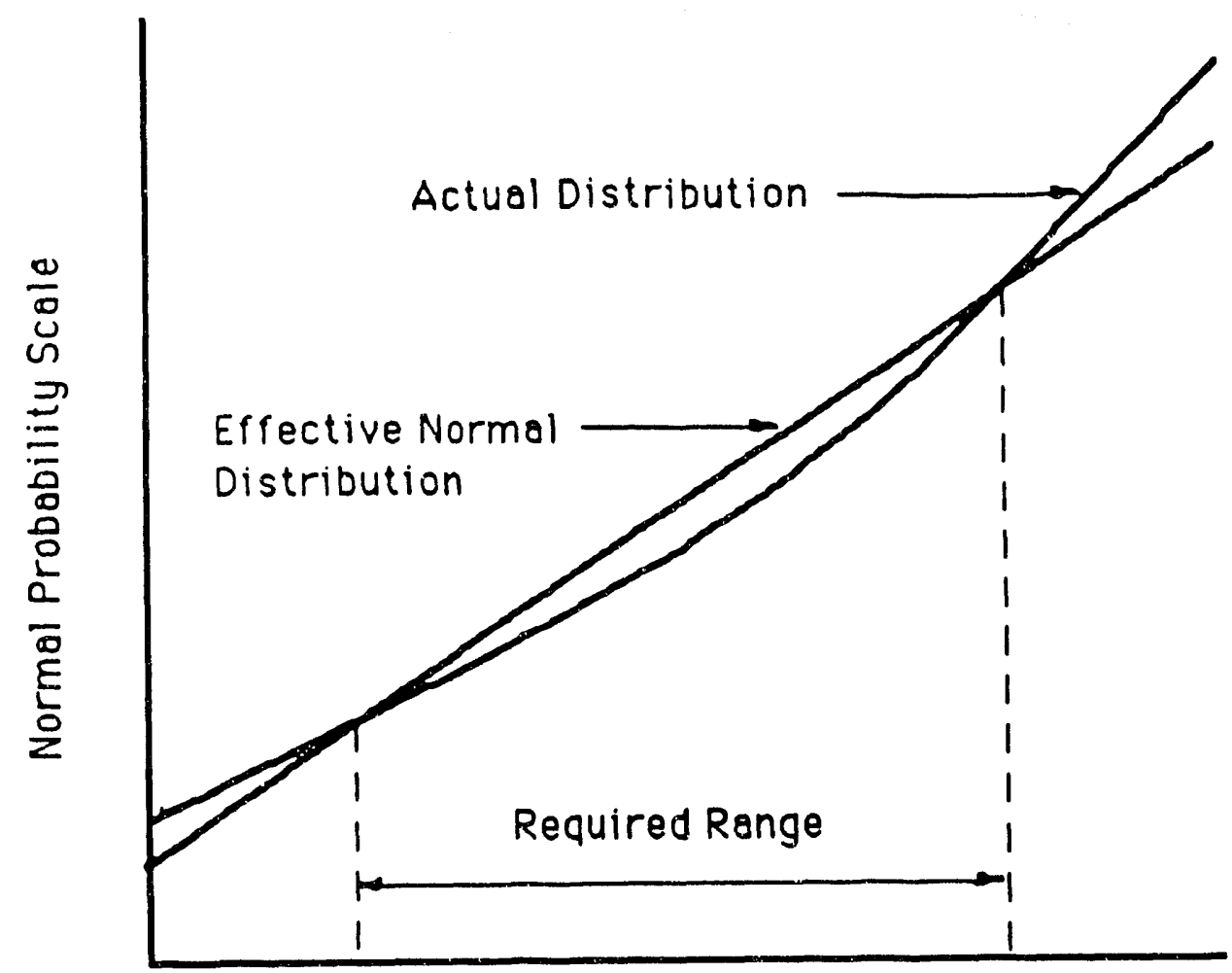

\section{Critical Effluent Temperature}

Figure 7.1

The effective normal distribution for the critical effluent temperature.

Sensitivity studies have shown the the additive correction, $\delta_{\text {cav }}$, is nearly constant for all assemblies. The value of $\delta_{\text {cav }}$ is determined from the analysis of the most limiting assembly in flowzone 1 , because the effects of cavitation are the greatest for this assembly. A multiplicative correction is used to relate the effective standard deviation to the standard deviation obtained from the linear approximation without cavitation.

$$
\sigma_{\mathrm{T}_{\mathrm{ct}, \mathrm{efc}}}=\alpha_{\mathrm{cav}} \sigma_{\mathrm{T}_{\mathrm{cr}, \mathrm{linear}}}
$$

The correction factor, $\alpha_{\text {cav }}$, is assumed to be constant. The value used for $\alpha_{c a v}$ is based on the most limiting assembly in flowzone 1.

The corrections defined by Equations 7.1 and 7.2 eliminate the need to perform the nonlinear analysis for every assembly. However, linear estimates of the mean and standard deviations are required for every assembly. 
For a given assembly, the linear estimate of the mean is obtained from Equation 6.6. The reference value for the critical effluent temperature is:

$$
\mathrm{T}_{\mathrm{cr}_{0}}=\mathrm{T}_{\text {in }_{0}}+\beta_{\text {hw }} \beta_{\text {void }} \beta_{3 \mathrm{D}_{0}} \Delta \mathrm{T}_{\text {ideal }}\left(\mathbf{z}_{0}\right)
$$

The idealized limiting temperature rise, $\Delta \mathrm{T}_{\text {ideal }}$, is obtained from FLOWTRAN. To evaluate the reference temperature for every assemblies, the axisymmetric temperature rise is required for all assemblies. In principle, FLOWTRAN could be used to obtain the idealized limiting temperature rise for every assembly, but this is not possible in practice because the TRAC noding scheme is not detailed enough to obtain boundary conditions for every assembly and because it is too time consuming to run FLOWTRAN for every assembly. Therefore, an interpolation scheme is used to estimate the axisymmetric temperature rise for all assemblies.

The TRAC model of the plenum model contains a total of 24 assembly bearing cells. The TRAC cell pressures for the plenum and the tank bottom are cell average pressures, and they do not correspond to the pressure at any particular location in the cell. However, in the absence of large gradients, the TRAC cell pressures can be assumed to be the cell center pressures. Using this assumption, the limiting temperature rise can be computed for idealized assemblies located at the TRAC cell centers. The limiting temperature rise for the other idealized assemblies is obtained by a two-dimensional interpolation between the assemblies at the TRAC cell centers.

A cubic spline is used for interpolation in the radial direction, and a linear interpolation is used in the azimuthal direction. The procedure for the interpolation is as follows:

1. The limiting temperature rise across each assembly at each TRAC cell is evaluated at the reference conditions.

2. The reactor is divided into six azimuthal sectors such that the TRAC cell centers lie along the sector boundaries.

3. For a given assembly, the azimuthal coordinate is used to locate it in the proper sector.

4. A cubic spline is used to determine the limiting temperature rise as a function of radial position along the sector boundaries.

5. The limiting temperature rise at the assembly location is obtained by a linear interpolation between the sector boundaries at the radial coordinate of the assembly. The azimuthal position angle is used as the interpolation variable.

By using this interpolation scheme, only 24 axisymmetric FLOWTRAN runs are required to obtain the idealized limiting temperature rise for all assemblies.

The limiting temperature rises obtained from the interpolation procedure are used to determine the reference value for the critical effluent temperanure for all assemblies. The reference value is obtained from Equation 7.3. The linear approximation of the mean critical effluent temperatures is obtained from Equation 6.6 . There wiii be a smaii difference between the reference value and the mean value because the mean values of the inlet temperature and the subcooled boiling heat transfer coefficient differ from their reference values. Because the sensitivity coefficients do not vary significantly with 
position, the differences between the mean values and the reference values are relatively constant. This difference is called $\delta_{\text {ave }}$, and it is assumed to be constant. The correction for nonlinearities and cavitation is added onto the linear estimate of the mean to obtain the effective mean for all assemblies.

$$
\mu_{\mathrm{T}}=\mathrm{T}_{\text {in }}+\beta_{\text {hw }} \beta_{\text {void }} \beta_{3 \mathrm{D}_{0}} \Delta \mathrm{T}_{\text {ideal }}\left(\mathbf{z}_{0}\right)+\delta_{\text {ave }}+\delta_{\text {cav }}
$$

To characterize the effective distributions completely, the effective standard deviation must be obtained for all assemblies. According to Equation 7.2, the effective standard deviations can be obtained if the linear estimate of the standard deviation is known for all assemblies. Sensitivity studies have shown that the linear estimate of the standard deviation does not vary significantly with position in the core. These case specific studies also show that the assembly with the largest standard deviation is the most limiting assembly in flowzone 1. Therefore, the linear estimate of the standard deviation is assumed to be independent of position; and the value of the linear estimate of standard deviation is obtained from the most limiting assembly in flowzone 1.

Once the effective means and effective standard deviations for all of the assemblies have been obtained, the effective distributions are completely characterized. Because of the approximations that were made, a detailed uncertainty analysis is required only for the most limiting assembly in flowzone 1. Approximately 112 FLOWTRAN runs are required for the detailed assembly analysis. An additional 24 FLOWTRAN runs are required for the interpolation. Hence, the method outlined in this section can be used to generate estimates of the critical effluent temperature distributions for all assemblies using a reasonable amount of computer time.

\subsection{Determining the Flowzone Limits}

Because of the assumption of statistical independence, the probability of not exceeding the Stanton number criterion in the core is the product of the assembly probabilities.

$$
\operatorname{Pr}\{\mathrm{St} \leq 0.000455 \text { in Core }\}=\prod_{\text {core }} \operatorname{Pr}\{\mathrm{St} \leq 0.00455 \text { in Assembly } \mathrm{i}\}
$$

The assembly effluent temperature limits are set by flowzone, so the probability of not exceeding the Stanton number criterion in a given flowzone is a useful number to compute. The probability of not exceeding the criterion in flowzone $\mathrm{k}$ is:

$$
\operatorname{Pr}(S t \leq 0.000455 \text { in } F Z k)=\prod_{F Z k} \operatorname{Pr}(S t \leq 0.00455 \text { in Assembly i })
$$

Because of the assumption of statistical independence, the core probability is the product of the flowzone probabilities.

$$
\operatorname{Pr}(S t \leq 0.000455 \text { in Core }\}=\prod_{\text {core }} \operatorname{Pr}\{S t \leq 0.00455 \text { in } \mathrm{FZ} \mathrm{k}\}
$$


The probability of not exceeding the Stanton number criterion in a given assembly depends on the value of the assembly effluent temperature limit and the cumulative distribution function for the critical effluent temperature.

$$
\operatorname{Pr}\{\text { St } \leq 0.00455 \text { in Assembly } i\}=1-\Phi\left(\frac{T_{\operatorname{lim~i}}-\mu_{T_{c r e f c i}}}{\sigma_{T_{c r \text { efc } i}}}\right)
$$

where: $\quad \Phi(\cdot)=$ the cumulative distribution function for the standard normal distribution

$$
\begin{aligned}
T_{\text {lim } i} & =\text { the effluent temperature limit for assembly } \mathrm{i} \\
\mu_{\mathrm{T}_{\text {cr efc } \mathrm{i}}} & =\text { the effective mean for assembly } \mathrm{i} \\
\sigma_{\mathrm{T}_{\text {cr efc } \mathrm{i}}} & =\text { the effective standard deviation for assembly } \mathrm{i} .
\end{aligned}
$$

For convenience, the effluent temperature limit for a given flowzone is related to the effective mean and standard deviation for the most limiting assembly in that flowzone.

$$
\mathrm{T}_{\text {lim flowzone } k}=\mu_{\mathrm{T}_{\text {cr efc worst } k}}-\mathrm{N}_{\mathrm{k}} \sigma_{\mathrm{T}}{ }_{\mathrm{cr} \text { efc worst }}
$$

where: $\quad \mathrm{T}_{\text {lim flowzone } \mathrm{k}}=$ the effluent temperaure limit for flowzone $\mathrm{k}$

$$
\mu_{T_{\text {cr efc worst } k}=} \begin{aligned}
& \text { the lowest effective mean effluent temperature for any } \\
& \text { assembly in flowzone } k
\end{aligned}
$$

$$
\begin{gathered}
\mathrm{N}_{\mathrm{k}}=\text { the number of standard deviations, } \sigma_{\mathrm{T}} \text { cr efc worst } \\
\text { flowzone } \mathrm{k} \text { temperature limit lies below, } \mu_{\mathrm{T}} \\
\sigma_{\mathrm{T} \text { efc worst }} \\
=\text { the largest standard deviation for any assembly in the core }
\end{gathered}
$$

The core probability calculations are performed using a code called CINT [3]. CINT performs the interpolation used to obtain the critical temperature rise and the mean critical effluent temperature for all assemblies, and it also does the probability calculations. CINT generates tables of the probabilities of not exceeding the Stanton number criterion in flowzone $k$ as a function of $N_{k}, \beta$ and $\sigma$. 
The tables generated by CINT are now used to determine $\mathrm{N}_{k}$ and the effluent temperature limit for a flowzone given the probability of not exceeding the limits criterion in that flowzone.

The first step in determining the flowzone effluent temperature limits is to assume flowzone no failure probabilities that satisfy the corewide probability target. Initially, the flowzone probabilities are assumed to be equal; so if there are four flowzones, the probability of not exceeding the Stanton number criterion in each flowzone will be $0.84^{1 / 4}$. The values of $N_{k}$ for each flowzone are obtained using the assumed probabilities and the tables generated by CINT. The values, $\mathrm{N}_{\mathrm{k}}$, are used to determine effluent temperature limits for each flowzone. It should be noted that the target probability may be paritioned among the flowzones in any way, with the constraint that the product of the flowzone probabilities equals 0.84 .

The limits generated in this manner will satisfy the probability constraint, but other partitions of the corewide target probability among the flowzones may give higher core power limits. By assuming a historical radial power shape, the reactor power can be computed from the effluent temperature for a given flowzone, Massey [4]. If the flowzone limits give different core powers, the limiting core power will be bounded by that of the lowest flowzone. In order to obtain flowzone effluent temperature limits which give core powers that are approximately equal, new flowzone probabilities must be assumed, and the procedure must be repeated until the flowzone limits give the same reactor power.

To illustrate the procedure of obtaining the effluent temperature limits, consider an example. By assuming equal probabilities for each flowzone, effluent temperature limits are obtained. Based on the historical power shape, these limits correspond to reactor powers of $1200,1300,1200$, and $1200 \mathrm{MW}$ for flowzones 1 through 4, respectively. The effluent temperature limits for flowzones 1,3 , and 4 would force the reactor to operate at $1200 \mathrm{MW}$. If the probability of no failure for flowzone 2 were reduced, the effluent temperature limit for flowzone 2 is reduced and the no failure probabilities, and thus the limits for the other flowzones, could be increased. This re-partitioning of the flowzone no failure probabilities would increase the total reactor power limit. The limit for flowzone 2 may be reduced by increasing the probability of not violating the Stanton number criterion in flowzone 2 and increasing the probabilities for the other flowzones.

The constraint that is important for safety is that there be at least an $84 \%$ probability of not exceeding the Stanton number criterion in any assembly in the core. The appropriate partitioning of the flowzone no failure probabilities ensures that the maximum reactor power is achieved given the safety constraint. It should also be noted that the algorithm for obtaining a reasonable power shape is not optimal, but it gives reasonable answers.

\section{References}

1. Kubic, W. L., "The Identification and Quantification of Uncertainties for the Flow Instability Limits Uncertainty Analysis of a Mark 22 Assembly," Westinghouse Savannah River Company Memorandum, NES-RFI-900047, FIU-90-22 (1990).

2. Kubic, W. L., "The Effect of Common Uncertainties in Predicting Whole Core Probabilities," Westinghouse Savannah River Company Memorandum, NES-RCA890022 , FIU $-89-28$ (1989). 
3. Metzger J. D., "Documentation for the Computer Code CINT," Westinghouse Savannah River Company Memorandum, NES-ART-900012, FIU-90-44 (1990).

4. Massey, W., "Revised Equations for Estimating Reactor Power," E. I. du Pont de Nemours \& Company, Inc. Report, RTR-2174 (1984). 


\section{LIMITS FOR A MARK 22 CHARGE}

The previous chapters of this manual gave a detailed description of the methods used for determining the flow instability limits. These methods are based on the criterion that there is an $84 \%$ probability that no assembly in the core exceeds the Stanton number criterion. This section describes the limits calculations for the first subcycle of a Mark 22 charge in $\mathrm{K}$ Reactor.

\subsection{Uncertainty Analysis for the Most Limiting Assembly in Flowzone 1}

A detailed uncertainty analysis of the most limiting assembly in flowzone 1 constitutes the first part of the limits calculation. The distributions for the principal uncertainties affecting flowzone 1 are given in Table 5.1. The worst case covariances are given in Table 5.2. The azimuthal uncertainties were combined using the model and the Monte Carlo algorithm described in Chapter 4. The first four moments of the distribution for the 3-D multiplier and the cumulative distribution function are given in Table A.1 and Figure A.1 of Appendix A.

The nominal axisymmetric FLOWTRAN model without cavitation uses bounding values for the steady-state axial power shape, the fission power transient, and the exposure [1]. The sensitivity coefficients for the linear approximation are given in Equation 6.11 . The derivatives of the axisymmetric temperature rise, without cavitation, with respect to the uncertainty variables are needed to evaluate the sensitivity coefficients. These derivatives were estimated by perturbing the axisymmetric FLOWTRAN model about the nominal case [2]. The derivatives of the axisymmetric temperature rise, the sensitivity coefficients, and standard deviations are summarized in Appendix F.

Linear estimates of the first four moments of critical effluent temperature were obtained using Equation 6.6 and Equations 6.8 - 6.9. Covariance was considered only for the TRAC transient plenum pressure and the TRAC transient tank bottom pressure because the other possible sources of covariance only affect cavitation, which is not considered in the linear approximation. Worst case covariance was treated by the method described in Chapter 6. The linear estimates of the moments without cavitation are summarized in Tables 8.1 through 8.3.

The linear variate Monte Carlo estimates of the moments of the critical effluent temperature, including the effects of cavitation and nonlinearities, were obtained using a Monte Carlo sample size of 100 . These runs are summarized by Laurinat [3]. The moments obtained from the linear variate method are summarized in Tables 8.1 through 8.3. The major effects of cavitation and nonlinearities are to decrease the standard deviation and to increase the skewness.

The cumulative distribution functions for both the linear approximation and the linear variate estimate are approximately normal. A plot of the cumulative distribution function for lower tail of the distribution is given in Figure 8.1. This figure shows that the linear approximation overestimates the probabilities in the lower tail. 
Table 8.1

Moments for the Critical Effluent Temperature of the Most Limiting Assembly in Flowzone 1 With a Nominal Inlet Temperature of $20^{\circ} \mathrm{C}$.

\begin{tabular}{|l|c|c|c|}
\hline & Linear Approx. & $\begin{array}{c}\text { Linear Variate } \\
\text { Estimates }\end{array}$ & $\begin{array}{c}\text { Standard Error of } \\
\text { Estimation }\end{array}$ \\
\hline Mean & 66.671 & 66.643 & 0.028 \\
Second Moment about the Mean & 12.748 & 11.875 & 0.199 \\
Third Moment about the Mean & 1.51 & 8.60 & 2.16 \\
Fourth Moment about the Mean & 484.9 & 401.2 & 21.5 \\
Standard Deviation & 3.570 & 3.446 &. \\
Skewness & 0.0011 & 0.0442 &. \\
Kurtosis & 2.984 & 2.845 &. \\
\hline
\end{tabular}

Table 8.2

Moments for the Critical Effluent Temperature of the Most Limiting Assembly in Flowzone 1 With a Nominal Inlet Temperature of $30^{\circ} \mathrm{C}$.

\begin{tabular}{|l|c|c|c|}
\hline & Linear Approx. & $\begin{array}{c}\text { Linear Variate } \\
\text { Estimates }\end{array}$ & $\begin{array}{c}\text { Standard Error of } \\
\text { Estimation }\end{array}$ \\
\hline Mean & 72.281 & 72.243 & 0.021 \\
Second Moment about the Mean & 10.602 & 9.862 & 0.171 \\
Third Moment about the Mean & 1.12 & 6.33 & 1.66 \\
Fourth Moment about the Mean & 335.5 & 277.8 & 14.8 \\
Standard Deviation & 3.256 & 3.140 & - \\
Skewness & 0.0010 & 0.0418 & - \\
Kurtosis & 2.985 & 2.856 & - \\
\hline
\end{tabular}


Table 8.3

Moments for the Critical Effluent Temperature of the Most Limiting Assembly in Flowzone 1 With a Nominal Inlet Temperature of $40^{\circ} \mathrm{C}$.

\begin{tabular}{|l|c|c|c|}
\hline & Linear Approx. & $\begin{array}{c}\text { Linear Variate } \\
\text { Estimates }\end{array}$ & $\begin{array}{c}\text { Standard Error of } \\
\text { Estimation }\end{array}$ \\
\hline Mean & 77.802 & 77.674 & 0.027 \\
Second Moment about the Mean & 8.799 & 7.871 & 0.198 \\
Third Moment about the Mean & 0.78 & 5.14 & 1.69 \\
Fourth Moment about the Mean & 231.2 & 180.7 & 13.3 \\
Standard Deviation & 2.966 & 2.806 & - \\
Skewness & 0.0009 & 0.0541 & - \\
Kurtosis & 2.986 & 2.917 &. \\
\hline
\end{tabular}

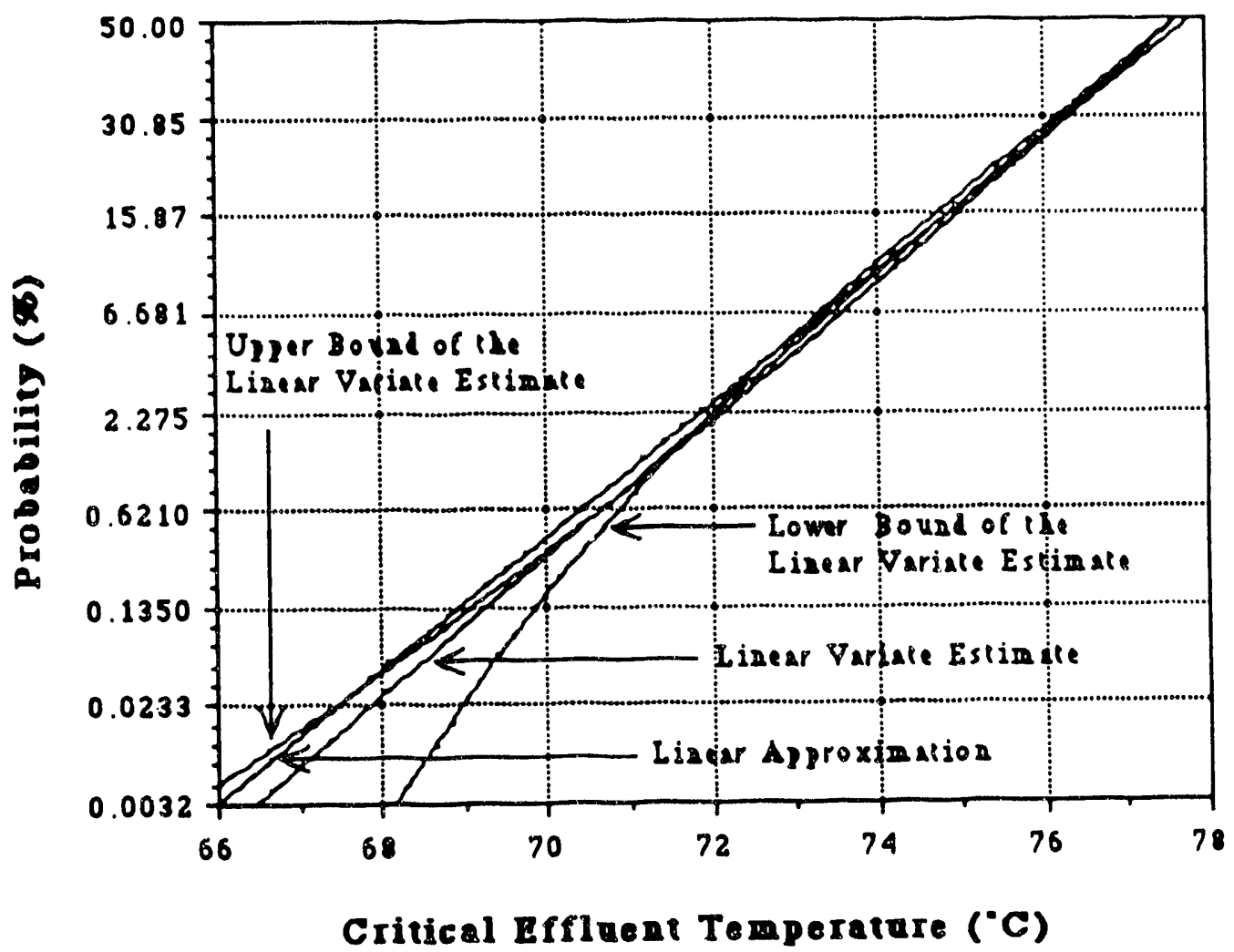

Figure 8.1

Estimates of the cumulative distribution function for the critical effluent temperature. 
This result is somewhat unexpected because cavitation should increase the probability of exceeding the Stanton number criterion. However, nonlinearities in the model other than cavitation tend to decrease the probability, and this effect is greater than the effect of cavitation. The net result is that the linear model without cavitation is conservative. The linear approximation also closely approxin ates the upper bound on the cumulative distribution function for the nonlinear model with cavitation. Therefore, the conclusion that the linear model is conservative is valid even though the Monte Carlo sample size was only 100.

Because the linear approximation of the distribution is conservative, no corrections for nonlinearities and cavitation will be included in the analysis. The linear approximation will be used as the effective distribution. The effective means and standard deviations for the most limiting assembly in each flowzone are summarized in Table 8.4. Although the linear approximation is conservative for this example, it may not be conservative in all cases.

\subsection{Assembly Limits}

The flow instability limits for each flowzone are determined by finding effluent temperature limits for each flowzone such that the probability of not exceeding the Stanton number criterion in any assembly in the core is equal to $84 \%$. The core power is maximized by appropriate partitioning of the flowzone probabilities.

Table 8.4

Effective Means and Standard Deviations for the Worst Assembly in Each Flowzone

\begin{tabular}{|l|c|c|c|}
\cline { 2 - 4 } \multicolumn{1}{c|}{} & \multicolumn{3}{c|}{ Nominal Inlet Temperature $\left.{ }^{\circ} \mathrm{C}\right)$} \\
\cline { 2 - 4 } \multicolumn{1}{c|}{} & 20 & 30 & 40 \\
\hline Effective Mean for Flowzone 1 & 66.27 & 71.87 & 77.56 \\
Effective Mean for Flowzone 2 & 63.57 & 69.39 & 75.31 \\
Effective Mean for Flowzone 4 & 62.03 & 68.00 & 74.06 \\
Effective Standard Deviation & 63.45 & 69.32 & 75.29 \\
& 3.57 & 3.26 & 2.97 \\
\hline
\end{tabular}


To compute the core probability, the axisymmetric critical temperature rise without the effects of cavitation must be computed for every TRAC cell. The results are given in Figure 8.2 for a nominal inlet temperature of $30^{\circ} \mathrm{C}$. The figure shows that the critical temperature rises in the break sector are the smallest. A small critical temperature rise corresponds to a low c-- rical effluent temperature, so the assemblies in the break sector are the most limiting assemblies. The probability of not exceeding the Stanton number criterion for any assembly in the core will be governed primarily by the assemblies in the break sector.

The CINT code and the procedure described in Chapter 7 were used to evaluate the effluent temperature limits. The limits for each flowzone are given in Table 8.5 for nominal inlet temperatures of 20,30 , and $40^{\circ} \mathrm{C}$. The total reactor power corresponding to these limits is given in Table 8.6. This table shows that the limit in terms of standard deviations below the mean is independent of temperature. This observation suggests that the core probability caiculation may only need to be performed for a single temperature.

The process control computer requires the effluent temperature limit as a function of the nominal inlet temperature. This function can be determined from the limits given in Table 8.5. A plot of the limits for flowzone 1 is given in Figure 8.3. This figure shows that the flowzone effluent temperature limit is a linear function of the nominal inlet temperature. The linear equations for the limits for all of the flowzones are given in Table 8.7.

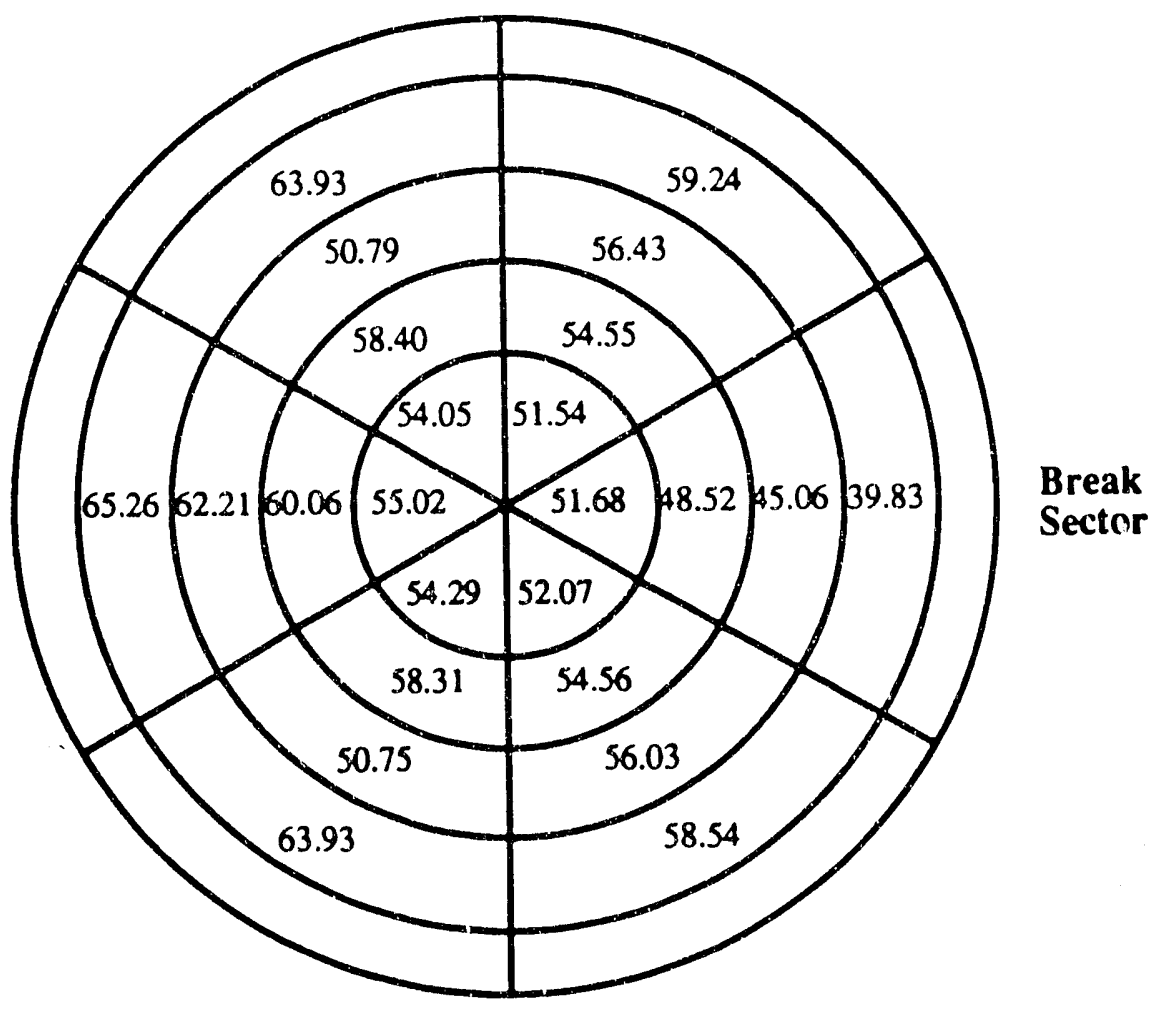

Figure 8.2

Axisymmetric limiting temperature rise at TRAC cell centers $\left(\mathrm{T}_{\mathrm{in}}=30^{\circ} \mathrm{C}\right)$. 
Table 8.5

Flow Instability Limits for Each Flowzone

\begin{tabular}{|c|c|c|c|}
\hline Flowzone Number & $\begin{array}{c}\text { Nominal Inlet } \\
\text { Temperanure }\left({ }^{\circ} \mathrm{C}\right)\end{array}$ & $\left|\frac{\mathrm{T}_{\text {limit }}-\mu_{\mathrm{T}_{\mathrm{cr}}}}{\sigma_{\mathrm{T}_{\mathrm{cr}}}}\right|$ & $\begin{array}{c}\text { Effluent Temperature } \\
\text { Limit }\left({ }^{\circ} \mathrm{C}\right)\end{array}$ \\
\hline 1 & 20 & 3.05 & $\begin{array}{l}55.37 \\
61.92 \\
60\end{array}$ \\
& 40 & 3.04 & 68.52 \\
& 20 & 2.38 & 55.08 \\
& 30 & 2.37 & 61.66 \\
& 40 & 2.37 & 68.28 \\
& 20 & 2.01 & 54.86 \\
& 30 & 2.00 & 68.46 \\
& 40 & 2.00 & 68.11 \\
\hline \multirow{2}{*}{3} & 20 & 2.20 & 55.60 \\
& 30 & 2.21 & 62.14 \\
& 40 & & \\
\hline
\end{tabular}

Table 8.6

Total Core Power for the First Cycle of a Mark 22

Charge in K Reactor

\begin{tabular}{|c|c|}
\hline Inlet Temperature $\left({ }^{\circ} \mathrm{C}\right)$ & Total Reactor Power (MW) \\
\hline 20 & 1400 \\
30 & 1260 \\
40 & 1120 \\
\hline
\end{tabular}




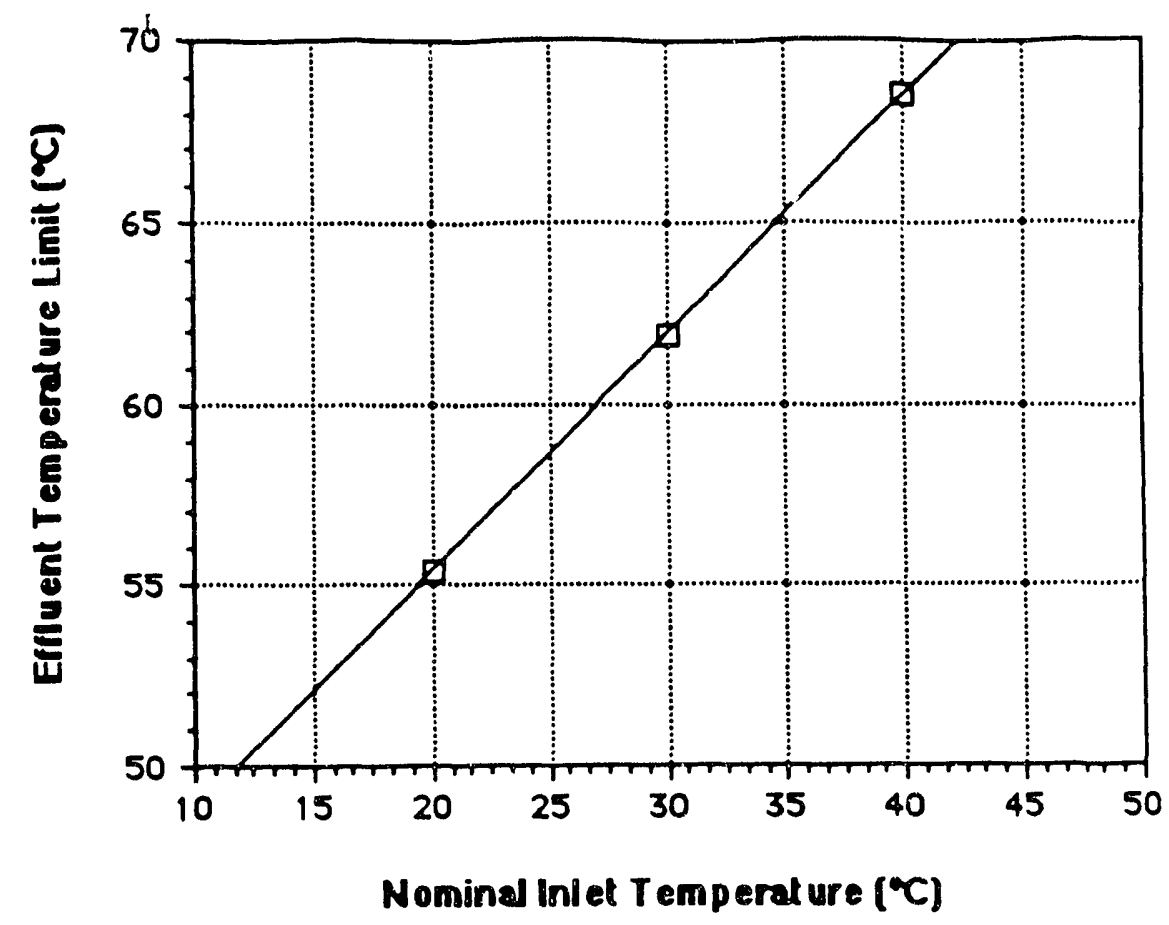

Figure 8.3

Effluent temperature limit as a function of the nominal inlet temperature for flowzone 1 .

Table 8.7

Table of Flowzone Effluent Temperature Limits as a Function of Inlet Temperature

\begin{tabular}{|c|c|}
\hline $\begin{array}{c}\text { Flowzone } \\
\text { Number }\end{array}$ & $\mathrm{T}_{\text {lim }}$ as a function of $\mathrm{T}_{\text {in }}$ \\
\hline 1 & $\mathrm{~T}_{\lim }=42.22+0.657 \mathrm{~T}_{\text {in }}$ \\
2 & $\mathrm{~T}_{\lim }=41.88+0.660 \mathrm{~T}_{\text {in }}$ \\
3 & $\mathrm{~T}_{\lim }=41.61+0.662 \mathrm{~T}_{\text {in }}$ \\
4 & $\mathrm{~T}_{\text {lim }}=42.46+0.657 \mathrm{~T}_{\text {in }}$ \\
\hline
\end{tabular}




\section{References}

1. Laurinat, J. E. "Documentation of UNCERT, Version 16-3," Westinghouse Savannah River Company Memorandum NES-RFI-900036, FIU-90-15 (1990).

2. Laurinat, J. E. "Sensitivities of FLOWTRAN OSV Limits for Different Flowzones ant at Different Assembly Inlet Temperatures," Westinghouse Savannah River Company Memorandum NES-RFI 890141, FIU-89-69 (1989).

3. Laurinat, J. E. "Monte Carlo Perturbations of LOCA-FI Limits Calculations, Revision 1," Westinghouse Savannah River Company Memorandum NES-RFI900001, FIU-90-1 (1990). 


\section{CONCLUSIONS}

This manual describes a probabilistic method of determining flow instability limits for the Savannah River reactors. The uncertainties associated with the fabrication of the fuel assemblies, the operation of the reactor, and the asserribly model are combined to estimate the probability that flow instability does not occur in any assembly during the flow instability phase of the worst postulated double-ended guillotine break loss-of-coolant accident. This probability is a measure of margin, and it forms the basis of a systematic method of determining assembly effluent temperature limits.

The probability of no flow instability cannot be calculated with absolute rigor because of the complexity of the thermal-hydraulic model and the complexity of the probability calculations. A combination of bounding analysis and probability theory was used in conjunction with numerous assumptions to obtain a practical method for computing a lower bound for the probability that no flow instability will occur in any assembly in the core during the worst double-ended guillotine break. The uncertainty analysis is based on stateof-the-art techniques and is significantly more detailed than analogous uncertainty analyses performed in the nuclear industry.

The major assumptions made in the uncertainty analysis for the K14.1 charge and the postulated accident were shown to be reasonable. These assumptions were:

1. A local Stanton number of 0.00455 was assumed to be a conservative predictor of flow instability.

2. It was assumed that the assembly model could be separated into a axisymme tric term and a non-axisymmetric term that was only a function of the azimuthal variations.

3. The cavitation effects were calculated from a single loop model and they were assumed to be the same for all assemblies.

4. The distribution for the critical effluent temperature was assumed to be sufficiently characterized by the first four moments and the Pearson system of distributions.

5. The assemblies were assumed to be statistically independent.

6. The mean values for the critical effluent temperatures were determined by interpolation between the TRAC cell results.

7. It was assumed that the uncertainties in the transient pressure boundary conditions obtained from TRAC could be described by normal distributions.

If the uncertainty analysis is applied to other charges and/or other accidents, the validity of these assumptions must be established.

To simplify the uncertainty analysis, bounding values were used to account for some of the uncertainties. Bounding distributions also were used to simplify the analysis. The primary sources of conservatism in the treatment of uncertainties were as follows:

1. Bounding values were used for the axial power shapes and the power transients.

2. A bounding shape was used for the azimuthal flux tilt across an assembly. 
3. Bounding values were used to describe the axial variations in the fuel and the lithium concentrations.

4. Conservative models were used for the effects of ribs and eccentricity.

5. Worst case values were used for the covariance of pairs of uncertainties that may be correlated.

The uncertainty analysis was specifically applied to the K14.1 subcycle and a postulated DEGB/LOCA. However, the analysis is sufficiently general that, with the proper data, it may be applied to other fuel cycles, other assembly types, other accidents and other reactors. As the amount of data for the $\mathrm{K}$ reactor and the postulated accident increases, better estimates of the magnitudes of the uncertainties will be possible. The improved estimates of the uncertainties will be incorporated into the uncertainty analysis as they become available. 


\section{ACKNOWLEDGMENTS}

The authors are deeply indebted to many individuals for their assistance with the uncertainity analysis. In particular, the insights and efforts of W. L. Kubic were invaluable to the development and implementation of the statistical modelling done in this analysis. Further, the contributions of time and ideas made by J. E. Laurinat, W. M. Massey and N. H. Kuehn to the uncertainty analysis are gratefully acknowledged. 


\section{NOMENCLATURE}

$A_{b}^{a}=$ factor relating thickness in tube $b$ to power in fuel tube $a$

$a_{i}=\frac{\partial T_{c r}\left(x_{0}\right)}{\partial \gamma_{i}}=$ sensitivity coefficient for the $i^{\text {th }}$ uncertainty parameter

$a_{c j}=$ sensitivity coefficient for common random variable $j$

$c_{p}=$ heat capacity

$e(x)=$ error term which includes cavitation effects and higher non-linear components of $T_{c r}(x)$

$F=$ conversion factor from $q^{\prime \prime}$ to $\beta_{\text {rib }}$, a constant obtained from an axisymmetric approximation

$\mathrm{G}=$ mass flux

$h\left(P_{\max }^{\text {of }}\right)=$ a quadratic polynomial expression in terms of $\mathrm{P}_{\max }^{\text {of }}$

$N_{k}=$ the number of standard deviations, $\sigma_{\mathrm{T}}{ }_{\text {cr efc worst }}$, that the flowzone $k$ temperature limit lies below, $\mu_{T_{\text {cr efc }} \text { worst }}$

$\mathrm{p}(\cdot)=$ joint probability density function

$\mathrm{P}^{2}(\cdot)=$ local power ratio in fuel tube a

$\mathbf{P}_{b}^{\mathbf{a}}(\cdot)=$ influence factor of azimuthal fuel or target variations on fuel tube a

$\mathrm{P}_{\max }^{\text {of }}=$ the maximum ratio of the power to the average power over an outer fuel subchannel

$q^{\prime \prime}=$ local heat flux

$\mathrm{q}^{\prime \prime}$ ave $=$ azimuthally averaged heat flux

$r_{i j}=$ correlation coefficient for variables $i$ and $j$

$t=$ local fuel or target material thickness

$\mathrm{t}_{\mathrm{ave}}=$ average fuel or target material thickness

$\mathrm{T}_{c \mathrm{c}}=$ critical effluent temperature

$T_{\text {bulk }}=$ bulk fluid temperature in a subchannel

$\mathrm{T}_{\text {in }}=$ assembly inlet temperature

$T_{\text {lim } i}=$ effluent temperature limit for assembly $i$

$\mathrm{T}_{\text {lim flowzone } \mathrm{k}}=$ the effluent temperature limit for flowzone $\mathrm{k}$

$T_{\max }=$ relative maximum fuel or target thickness, $\left(t_{\max }-t_{\text {ave }}\right) / t_{\text {ave }}$

$\mathrm{T}_{\text {sat }}=$ saturation temperature of heavy water

$\mathbf{x}=$ all parameters which affect the critical effluent temperature of an assembly

$x_{i}=$ uncertainty variable $i$

$x_{i j}=$ random uncertainty variable $i$ in the correlated group $j$

$y=$ parameters describing asymmetric effects, not including any axisymmetric parameters, heated wall or void effects

$\mathbf{z}=$ parameters describing axisymmetric effects, including $T_{\text {in }}$, not including any asymmetric parameters, heated wall or void effects 


\section{Greek}

$\alpha_{c a v}=$ correction to the standard deviation for cavitation and other nonlinearities

$\beta_{\text {hw }}=$ heated wall effect multipliet

$\beta_{\text {rib }}=$ rib effect multiplier

$\beta_{\text {void }}=$ void effect multiplier

$\beta_{3 D}=$ asymmetric effects multiplier

$\beta_{3 D}^{\text {no rib }}=$ the asymmetric effects multiplier without rib effects

$\delta=$ error term used to account for variables not treated explicitly in the polynomial expression for $\beta_{3 D}^{\text {no rib }}$

$\delta_{\text {ave }}=$ difference between nominal and average critical effluent temperature

$\delta_{\text {cav }}=$ correction to the mean for cavitation and other nonlinearities

$\varepsilon=$ error in effluent temperature measurement.

$\phi=$ azimuthal orientation angle

$\phi_{b}=$ azimuthal orientation angle for maximum fuel or lithium thickness in fuel or target tube b relative to the control rod

$\Phi(\cdot)=$ cumulative distribution function for the standard normal distribution

$\Delta q^{\prime \prime}=$ incremental heat flux due to rib effect

$\Delta \mathrm{T}_{\text {actual }}=$ the limiting temperature rise across an asymmetric assembly

$\Delta \mathrm{T}_{\text {actual } i}^{\text {no rib }}$ ine the ith value of the limiting temperature rise across an asymmetric assembly with no ribs

$\Delta \mathrm{T}_{\text {as }}=$ the limiting temperature rise acro.s an axisymmetric assembly.

$\Delta T_{a s}^{\text {no rib }}=$ the ith value of the limiting temperature rise actoss an axisymmetric assembly with no ribs

$\Delta \mathrm{T}_{\mathrm{cr}}=$ limitirg temperature rise for a given set of assembly paraneters

$\Delta \mathrm{T}_{\text {ideal }}=$ the limiting steady state temperature rise for an idealized assembly for a given set of assembly parameters

$\mu_{\Delta T_{\text {ideal }} \mathrm{k}}=$ mimimum mean value of $\Delta \mathrm{T}_{\text {ideal }}$ for any assembly in the $\mathrm{k}^{\text {th }}$ flowzone

$\mu_{\gamma_{i}}=$ mean of the $i^{\text {th }}$ uncertainty parameter, $\gamma_{i}$

$\mu_{T_{\text {in }}}=$ mean inlet temperature

$\mu_{\mathrm{T}_{\mathrm{c}}}=$ mean critical effluent temperanure

$\mu_{T} \quad=$ the effective mean for assembly $i$

$\mu_{-} \quad=$ the lowest effective mean effluent temperature for any assembly in cr efc worst k

flowzone $k$

$\mu_{n r}=n^{\text {th }}$ moment of $T$ about the mean 


$$
\begin{aligned}
\mu_{\mathrm{x}_{\mathrm{i}}} & =\text { first moment of variable } \mathrm{x}_{\mathrm{i}} \text { about zero } \\
\mu_{\mathrm{x}_{\mathrm{ij}}} & =\text { the mean value for } \mathrm{x}_{\mathrm{ij}} \\
\xi^{\mathrm{a}}(\cdot) & =\text { influence factor of flux tilt on power in fuel tube a } \\
\sigma & =\text { standard deviation } \\
\sigma_{\gamma_{\mathrm{i}}}^{2} & =\text { the variance of the } \mathrm{i}^{\text {th }} \text { uncertainty parameter, } \gamma_{\mathrm{i}} \\
\sigma_{\mathrm{i}} & =\text { standard deviation for variable } \mathrm{i} \\
\sigma_{\mathrm{T}}^{2} & =\text { the variance of the critical effluent temperature } \\
\sigma_{\mathrm{T}} & =\text { the effective standard deviation for assembly } \mathrm{i} . \\
\sigma_{\mathrm{T}} \text { ef efc worst } & =\text { the largest standard deviation for any assembly in the core } \\
\sigma_{\mathrm{x}_{\mathrm{ij}}} & =\text { standard deviation for } \mathrm{x}_{\mathrm{ij}} \\
\theta & =\text { azimuthal position angle relative to the control rod }
\end{aligned}
$$

\section{Superscripts}

$$
\begin{aligned}
& \text { if }=\text { inner fuel tube } \\
& \mathrm{il}=\text { inner lithium target tube } \\
& \text { of }=\text { outer fuel tube } \\
& \text { ol }=\text { outer lithium target tube }
\end{aligned}
$$

\section{Subscripts}

$$
\begin{aligned}
0 & =\text { reference value } \\
\text { efc } & =\text { effective value } \\
\text { if } & =\text { inner fuel tube } \\
\mathrm{i}, \mathrm{j}, \mathrm{k} & =\text { variable or assembly index } \\
\mathrm{il} & =\text { inner lithium target tube } \\
\text { linear } & =\text { linear approximation } \\
\text { of } & =\text { outer fuel tube } \\
\text { ol } & =\text { outer lithium target rube } \\
\text { ref } & =\text { reference value } \\
\mathrm{Tcr} & =\text { critical effluent temperanure } \\
\text { worst } & =\text { most limiting value }
\end{aligned}
$$




\section{APPENDIX A - PROPERTIES OF THE ASYMMETRIC EFFECTS MULTIPLIER}

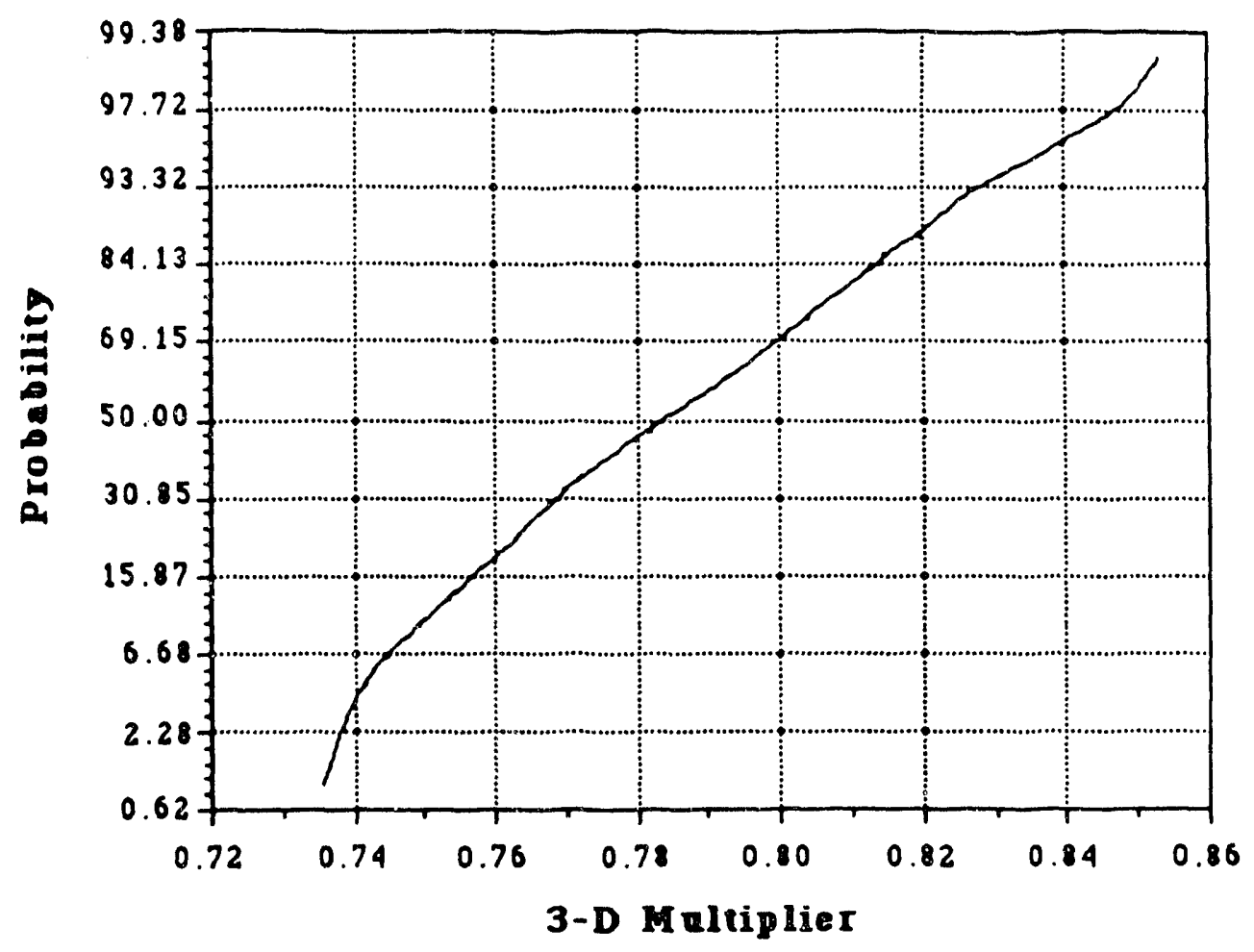

Figure A.1

The cumulative distribution function of the asymmetric effects multiplier for a Mark 22 charge at the beginning of a cycle.

Table A.1

Moments of the 3-D Multiplier for a Mark 22 Charge in $\mathrm{K}$ Reactor at the Beginning of a Cycle

Mean
Second Moment about the Mean
Third Moment about the Mean
Fourth Moment about the Mean

$$
0.7853
$$

$7.840 \times 10^{-4}$

$7.545 \times 10^{-6}$

$1.625 \times 10^{-6}$ 
Table A. 2

Results of the Three Dimensional FLOWTRAN Runs for an Inlet Temperature of $20^{\circ} \mathrm{C}$ in TRAC Cell 9. The Nominal Critical Effluent Temperature is $78.3371^{\circ} \mathrm{C}$ and the Nominal Power is $5.6067 \mathrm{MW}$.

\begin{tabular}{|c|c|c|c|c|c|}
\hline $\begin{array}{c}\text { Maximum } \\
\text { Subchannel } \\
\text { Average } \\
\begin{array}{c}\text { Power Ratio } \\
\text { in Outer } \\
\text { Fuel }\end{array}\end{array}$ & $\begin{array}{c}\text { Inner Fuel } \\
\text { Power Ratio } \\
\text { in the Same } \\
\text { Quadrant }\end{array}$ & $\begin{array}{c}\text { Critical } \\
\text { Effluent } \\
\text { Temperature } \\
\left({ }^{\circ} \mathrm{C}\right)\end{array}$ & $\begin{array}{c}\text { Critical } \\
\text { Assembly } \\
\text { Power (MW) }\end{array}$ & $\begin{array}{c}\text { 3.D } \\
\text { Multiplier }\end{array}$ & $\begin{array}{c}\text {-or in } \\
\text { he } \\
\text { Multiplier } \\
\text { Correlation }\end{array}$ \\
\hline 1.0847 & 1.0282 & 67.5136 & 4.56560 & 0.8145 & 0.0032 \\
1.1499 & 1.0951 & 65.3042 & 4.35130 & 0.7766 & 0.0026 \\
1.1316 & 1.0835 & 65.9173 & 4.41078 & 0.7871 & 0.0013 \\
1.1001 & 1.0762 & 66.9999 & 4.51580 & 0.8057 & 0.0015 \\
1.1276 & 1.1055 & 66.3019 & 4.44807 & 0.7937 & -0.0031 \\
1.1284 & 1.0689 & 66.2138 & 4.43954 & 0.7922 & -0.0020 \\
1.0638 & 1.0882 & 68.7456 & 4.68508 & 0.8356 & -0.0023 \\
1.0425 & 1.0738 & 69.1762 & 4.75390 & 0.8478 & 0.0031 \\
1.1557 & 1.0680 & 65.1762 & 4.33889 & 0.7744 & 0.0021 \\
1.0609 & 1.0761 & 68.8834 & 4.69844 & 0.8379 & -0.0024 \\
1.1558 & 1.0911 & 65.4787 & 4.36824 & 0.7796 & -0.0032 \\
1.0352 & 1.0278 & 70.0872 & 4.81516 & 0.8586 & -0.0013 \\
\hline
\end{tabular}


Table A. 3

Results of the Three Dimensional FLOWTRAN Runs for an Inlet Temperature of $30^{\circ} \mathrm{C}$ in TRAC Cell 9. The Nominal Critical Effluent Temperature is $82.7695^{\circ} \mathrm{C}$ and the Nominal Power is $5.1086 \mathrm{MW}$.

\begin{tabular}{|c|c|c|c|c|c|}
\hline $\begin{array}{c}\text { Maximum } \\
\text { Subchannel } \\
\text { Average } \\
\begin{array}{c}\text { Power Ratio } \\
\text { in Outer } \\
\text { Fuel }\end{array}\end{array}$ & $\begin{array}{c}\text { Inner Fuel } \\
\text { Power Ratio } \\
\text { in the Same } \\
\text { Quadrant }\end{array}$ & $\begin{array}{c}\text { Critical } \\
\text { Effluent } \\
\text { Temperature } \\
\left({ }^{\circ} \mathrm{C}\right)\end{array}$ & $\begin{array}{c}\text { Critical } \\
\text { Assembly } \\
\text { Power }(\mathrm{MW})\end{array}$ & $\begin{array}{c}\text { 3-D } \\
\text { Multiplier }\end{array}$ & $\begin{array}{c}\text { Error in } \\
\text { the } \\
\text { Multiplier } \\
\text { Correlation }\end{array}$ \\
\hline 1.0847 & 1.0282 & 73.0225 & 4.1663 & 0.8153 & -0.0035 \\
1.1499 & 1.0951 & 71.0377 & 3.9728 & 0.7777 & -0.0028 \\
1.1316 & 1.0835 & 71.5912 & 4.0268 & 0.7882 & -0.0014 \\
1.1001 & 1.0762 & 72.5667 & 4.1219 & 0.8067 & -0.0016 \\
1.1276 & 1.1055 & 71.9406 & 4.0608 & 0.7948 & 0.0030 \\
1.1284 & 1.0689 & 71.8741 & 4.0544 & 0.7935 & 0.0022 \\
1.0638 & 1.0882 & 74.1504 & 4.2762 & 0.8367 & 0.0023 \\
1.0425 & 1.0738 & 74.7875 & 4.3383 & 0.8487 & -0.0033 \\
1.1557 & 1.0680 & 70.9230 & 3.9617 & 0.7755 & -0.0023 \\
1.0609 & 1.0761 & 74.2690 & 4.2878 & 0.8389 & 0.0022 \\
1.1558 & 1.0911 & 71.2050 & 3.9891 & 0.7808 & 0.0031 \\
1.0352 & 1.0278 & 75.3703 & 4.3951 & 0.8598 & 0.0013 \\
\hline
\end{tabular}


Table A. 4

Results of the Three Dimensional FLOWTRAN Runs for an Inlet Temperature of $40^{\circ} \mathrm{C}$ in TRAC Cell 9. The Nominal Critical Effluent Temperature is $87.1948^{\circ} \mathrm{C}$ and the Nominal Power is 4.5989 MW..

\begin{tabular}{|c|c|c|c|c|c|}
\hline $\begin{array}{c}\text { Maximum } \\
\text { Subchannel } \\
\text { Average } \\
\text { Power Ratio } \\
\text { in Outer } \\
\text { Fuel }\end{array}$ & $\begin{array}{c}\text { Inner Fuel } \\
\text { Power Ratio } \\
\text { in :he Same } \\
\text { Quadrant }\end{array}$ & $\begin{array}{c}\text { Critical } \\
\text { Effluent } \\
\text { Temperature } \\
\left({ }^{\circ} \mathrm{C}\right)\end{array}$ & $\begin{array}{c}\text { Critical } \\
\text { Assembly } \\
\text { Power (MW) }\end{array}$ & $\begin{array}{c}\text { 3.D } \\
\text { Multiplier }\end{array}$ & $\begin{array}{c}\text { Error in } \\
\text { the } \\
\text { Multiplier } \\
\text { Correlation }\end{array}$ \\
\hline 1.0847 & 1.0282 & 78.5278 & 3.7573 & 0.8164 & 0.0036 \\
1.1499 & 1.0951 & 76.7677 & 3.5850 & 0.7791 & 0.0028 \\
1.1316 & 1.0835 & 77.2614 & 3.6334 & 0.7895 & 0.0014 \\
1.1001 & 1.0762 & 78.1297 & 3.7184 & 0.8079 & 0.0016 \\
1.1276 & 1.1055 & 77.5789 & 3.6644 & 0.7963 & -0.0032 \\
1.1284 & 1.0689 & 77.5316 & 3.6598 & 0.7952 & -0.0026 \\
1.0638 & 1.0882 & 795545 & 3.8578 & 0.8381 & -0.0024 \\
1.0425 & 1.0738 & 80.1196 & 3.9131 & 0.8501 & 0.0033 \\
1.1557 & 1.0680 & 76.6662 & 3.5751 & 0.7769 & 0.0023 \\
1.0609 & 1.0761 & 79.6552 & 3.8677 & 0.8402 & -0.0023 \\
1.1558 & 1.0911 & 76.9299 & 3.6009 & 0.7825 & -0.0033 \\
1.0352 & 1.0278 & 80.6517 & 3.9651 & 0.8614 & -0.0015 \\
\hline
\end{tabular}


Table A.5

Results of the Three Dimensional FLOWTRAN Runs for an Inlet Temperature of $30^{\circ} \mathrm{C}$ in TRAC Cell 15. The Nominal Critical Effluent Temperature is $79.6080^{\circ} \mathrm{C}$ and the Nominal Power is $4.9358 \mathrm{MW}$.

\begin{tabular}{|c|c|c|c|c|c|}
\hline $\begin{array}{c}\text { Maximum } \\
\text { Subchannel } \\
\text { Average } \\
\begin{array}{c}\text { Power Ratio } \\
\text { in Outer } \\
\text { Fuel }\end{array}\end{array}$ & $\begin{array}{c}\text { Inner Fuel } \\
\text { Power Ratio } \\
\text { in the Same } \\
\text { Quadrant }\end{array}$ & $\begin{array}{c}\text { Critical } \\
\text { Effluent } \\
\text { Temperature } \\
\left({ }^{\circ} \mathrm{C}\right)\end{array}$ & $\begin{array}{c}\text { Critical } \\
\text { Assembly } \\
\text { Power (MW) }\end{array}$ & $\begin{array}{c}\text { 3-D } \\
\text { Multiplier }\end{array}$ & $\begin{array}{c}\text { Error in } \\
\text { the } \\
\text { Multiplier } \\
\text { Correlation }\end{array}$ \\
\hline 1.0847 & 1.0282 & 70.4979 & 4.0298 & 0.8164 & 0.0033 \\
1.1499 & 1.0951 & 68.6339 & 3.8430 & 0.7788 & 0.0025 \\
1.1316 & 1.0835 & 69.1542 & 3.8951 & 0.7893 & 0.0012 \\
1.1001 & 1.0762 & 70.0708 & 3.9870 & 0.8077 & 0.0014 \\
1.1276 & 1.1055 & 69.4821 & 3.9280 & 0.7959 & -0.0032 \\
1.1284 & 1.0689 & 69.4214 & 3.9219 & 0.7947 & -0.0024 \\
1.0638 & 1.0882 & 71.5593 & 4.1361 & 0.8378 & -0.0025 \\
1.0425 & 1.0738 & 72.1572 & 4.1960 & 0.8498 & 0.0031 \\
1.1557 & 1.0680 & $r 5260$ & 3.8321 & 0.7766 & 0.0021 \\
1.0609 & 1.0761 & 71.6695 & 4.1472 & 0.8400 & -0.0024 \\
1.1558 & 1.0911 & 68.7922 & 3.8588 & 0.7820 & -0.0033 \\
1.0352 & 1.0278 & 72.7064 & 4.2510 & 0.8609 & -0.0015 \\
\hline
\end{tabular}




\section{APPENDIX B - LIST OF UNCERTAINTIES}

Table B.1

Uncertainties for the Flow Instability Limits

\begin{tabular}{|c|c|c|c|c|c|c|c|c|c|c|c|c|c|c|}
\hline \multirow[t]{2}{*}{ FLOWTRAN Input Parameter } & \multicolumn{6}{|c|}{ Source of Uncertainty } & \multicolumn{3}{|c|}{$\begin{array}{c}\text { Effect of } \\
\text { Uncerainty }\end{array}$} & \multicolumn{5}{|c|}{ Method of Treatment } \\
\hline & $\begin{array}{c}\mathrm{M} \\
\mathrm{a} \\
\mathrm{n} \\
\mathrm{u} \\
\mathrm{f} \\
\mathrm{a} \\
\mathrm{c} \\
\mathrm{t} \\
\mathrm{u} \\
\mathrm{r} \\
\mathrm{i} \\
\mathrm{n} \\
\mathrm{g}\end{array}$ & $\begin{array}{l}\text { B } \\
\text { a } \\
\text { s } \\
e\end{array}$ & $\begin{array}{l}\mathrm{O} \\
\mathrm{t} \\
\mathrm{h} \\
\mathrm{e} \\
\mathrm{r} \\
\mathrm{C} \\
\mathrm{C} \\
-\mathrm{O} \\
\mathrm{d} \\
\mathrm{e} \\
\mathrm{s}\end{array}$ & $\begin{array}{l}\mathrm{I} \\
d \\
\mathrm{e} \\
\mathrm{a} \\
\mathrm{l} \\
\mathrm{i} \\
\mathrm{s} \\
\mathrm{a} \\
\mathrm{t} \\
\mathrm{i} \\
\mathrm{d} \\
\mathrm{n} \\
\mathrm{s}\end{array}$ & $\begin{array}{l}\mathrm{M} \\
\mathrm{e} \\
\mathrm{a} \\
\mathrm{s} \\
\mathrm{u} \\
\mathrm{r} \\
\mathrm{e} \\
\mathrm{m} \\
\mathrm{c} \\
\mathrm{n} \\
\mathrm{t} \\
\mathrm{E} \\
\mathrm{r} \\
\mathrm{r} \\
\mathrm{o} \\
\mathrm{r}\end{array}$ & $\begin{array}{l}E \\
x \\
p \\
o \\
s \\
u \\
r \\
e\end{array}$ & $\begin{array}{l}\mathrm{H} \\
\mathrm{e} \\
\mathrm{a} \\
\mathrm{l} \\
\mathrm{G} \\
\mathrm{e} \\
\mathrm{n} \\
\mathrm{e} \\
\mathrm{r} \\
\mathrm{a} \\
\mathrm{l} \\
\mathrm{i} \\
\mathrm{o} \\
\mathrm{n}\end{array}$ & $\begin{array}{c}F \\
1 \\
u \\
i \\
d \\
F \\
1 \\
0 \\
w\end{array}$ & $\begin{array}{l}\mathrm{H} \\
\mathrm{e} \\
\mathrm{a} \\
\mathrm{t} \\
\mathrm{r} \\
\mathrm{r} \\
\mathrm{a} \\
\mathrm{n} \\
\mathrm{s} \\
\mathrm{f} \\
\mathrm{e} \\
\mathrm{r}\end{array}$ & $\begin{array}{c}D \\
i \\
s \\
t \\
r \\
i \\
b \\
u \\
i \\
i \\
o \\
n\end{array}$ & $\begin{array}{c}W \\
o \\
r \\
s \\
t \\
C \\
\text { a } \\
s \\
e\end{array}$ & $\begin{array}{l}D \\
e \\
m \\
o \\
s \\
\text { l } \\
r \\
a \\
\text { l } \\
e \\
d \\
\text { s } \\
\text { m } \\
a \\
\text { l } \\
\text { l }\end{array}$ & $\begin{array}{l} \\
\\
A \\
\text { s } \\
\text { s } \\
u \\
\text { m } \\
\text { e } \\
d \\
\text { d } \\
\text { m } \\
\text { a } \\
1 \\
1\end{array}$ & $\begin{array}{l}\mathrm{L} \\
\mathrm{u} \\
\mathrm{m} \\
\mathrm{p} \\
\mathrm{e} \\
\mathrm{d} \\
\mathrm{w} \\
\mathrm{i} \\
\mathrm{l} \\
\mathrm{h} \\
\mathrm{O} \\
\mathrm{l} \\
\mathrm{h} \\
\mathrm{e} \\
\mathrm{r}\end{array}$ \\
\hline $\begin{array}{l}\text { 1. Convergence Criterion } \\
\text { 2. Mesh Spacing in Inlet Region } \\
\text { 3. Mesh Spacing in Bottom End Fitting } \\
\text { 4. Heated Length Mesh Spacing } \\
\text { 5. Time Step Size } \\
\text { 6. Density of Al } \\
\text { 7. Heat Capacity of Al } \\
\text { 8. Thermal Conductivity of Al } \\
\text { 9. Density of U/Al } \\
\text { 10. Heat Capacity of U/Al } \\
\text { 11. Thermal Conductivity of U/Al } \\
\text { 12. Density of Li/Al } \\
\text { 13. Heat Capacity of Li/Al } \\
\text { 14. Thermal Conductivity of Li/Al } \\
\text { 15. Density of U } \\
\text { 16. Heat Capacity of U } \\
\text { 17. Thermal Conductivity of U } \\
\text { 18. Heavy Water Vapor Density } \\
\text { 19. Heavy Water Heat of Vaporization } \\
\text { 20. Heavy Water Liguid Density }\end{array}$ & $\begin{array}{l}\bullet \\
\bullet \\
\bullet \\
\bullet \\
\bullet \\
\bullet \\
\bullet\end{array}$ & $\begin{array}{l}\bullet \\
\bullet \\
\bullet \\
\bullet \\
\bullet \\
\bullet \\
\bullet \\
\bullet \\
\bullet \\
\bullet \\
\bullet \\
\bullet \\
\bullet \\
\bullet \\
\bullet \\
\bullet \\
\bullet\end{array}$ & & $\begin{array}{l}\bullet \\
\bullet \\
\bullet \\
\bullet \\
\bullet\end{array}$ & & • & $\cdot$ & $\begin{array}{l}\bullet \\
\bullet \\
\bullet \\
\bullet \\
\bullet \\
\bullet\end{array}$ & 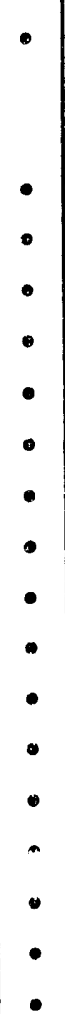 & $\begin{array}{l}\cdot \\
\cdot \\
\cdot \\
\cdot \\
\bullet \\
\cdot \\
\bullet \\
\bullet \\
\bullet \\
\bullet \\
\bullet \\
\bullet \\
\bullet \\
\bullet \\
\bullet \\
\bullet \\
\bullet\end{array}$ & & - & • & \\
\hline
\end{tabular}


Table B.1 (Continued)

Uncertainties for the Flow Instability Limits

\begin{tabular}{|c|c|c|c|c|c|c|c|c|c|c|c|c|c|c|}
\hline FLOWTRAN Input Parameter & & ourc & & & ainty & & & $\begin{array}{l}\text { frect o } \\
\text { certain }\end{array}$ & & & ethod & of $\mathrm{Tr}$ & atme & \\
\hline ' & $\begin{array}{c}M \\
\mathrm{a} \\
\mathrm{n} \\
\mathrm{u} \\
\mathrm{f} \\
\mathrm{a} \\
\mathrm{c} \\
\mathrm{t} \\
\mathrm{u} \\
\mathrm{r} \\
\mathrm{i} \\
\mathrm{n} \\
\mathrm{g}\end{array}$ & $\begin{array}{l}D \\
a \\
t \\
a \\
B \\
a \\
\text { S } \\
\text { e }\end{array}$ & $\begin{array}{l}0 \\
\text { t } \\
h \\
e \\
r \\
c \\
o \\
d \\
e \\
s\end{array}$ & $\begin{array}{l}\mathrm{I} \\
\mathrm{d} \\
\mathrm{e} \\
\mathrm{a} \\
\mathrm{l} \\
\mathrm{i} \\
\mathrm{s} \\
\mathrm{a} \\
\mathrm{t} \\
\mathrm{i} \\
\mathrm{o} \\
\mathrm{n} \\
\mathrm{s}\end{array}$ & \begin{tabular}{c|}
$\mathrm{M}$ \\
$\mathrm{e}$ \\
$\mathrm{a}$ \\
$\mathrm{s}$ \\
$\mathrm{u}$ \\
$\mathrm{r}$ \\
$\mathrm{e}$ \\
$\mathrm{m}$ \\
$\mathrm{e}$ \\
$\mathrm{n}$ \\
$\mathrm{t}$ \\
$\mathrm{E}$ \\
$\mathrm{r}$ \\
$\mathrm{r}$ \\
$\mathrm{o}$ \\
$\mathrm{r}$
\end{tabular} & $\begin{array}{l}E \\
x \\
p \\
o \\
s \\
u \\
r \\
c\end{array}$ & $\begin{array}{l}\mathrm{H} \\
\mathrm{e} \\
\mathrm{a} \\
\mathrm{l} \\
\mathrm{G} \\
\mathrm{e} \\
\mathrm{n} \\
\mathrm{e} \\
\mathrm{r} \\
\mathrm{a} \\
\mathrm{t} \\
\mathrm{i} \\
\mathrm{o} \\
\mathrm{n}\end{array}$ & $\begin{array}{c}F \\
1 \\
u \\
i \\
d \\
F \\
1 \\
o \\
w\end{array}$ & $\begin{array}{l}\mathrm{H} \\
\mathrm{e} \\
\mathrm{a} \\
\mathrm{t} \\
\mathrm{T} \\
\mathrm{r} \\
\mathrm{a} \\
\mathrm{n} \\
\mathrm{s} \\
\mathrm{f} \\
\mathrm{e} \\
\mathrm{r}\end{array}$ & $\begin{array}{l}D \\
i \\
s \\
t \\
r \\
i \\
b \\
u \\
t \\
i \\
0 \\
n\end{array}$ & $\begin{array}{l}\text { W } \\
o \\
r \\
\text { s } \\
\text { i } \\
\text { C } \\
\text { a } \\
\text { s } \\
\text { e }\end{array}$ & $\begin{array}{c}D \\
\mathrm{e} \\
\mathrm{m} \\
\mathrm{o} \\
\mathrm{s} \\
\mathrm{l} \\
\mathrm{r} \\
\mathrm{a} \\
\mathrm{t} \\
\mathrm{e} \\
\mathrm{d} \\
\mathrm{s} \\
\mathrm{m} \\
\mathrm{a} \\
\mathrm{l} \\
\mathrm{l}\end{array}$ & $\begin{array}{c}A \\
s \\
s \\
u \\
m \\
e \\
d \\
\\
s \\
m \\
a \\
1 \\
i\end{array}$ & $\begin{array}{c}\mathrm{L} \\
\mathrm{u} \\
\mathrm{m} \\
\mathrm{p} \\
\mathrm{e} \\
\mathrm{d}\end{array}$ \\
\hline $\begin{array}{l}\text { 21. Heavy Water Liquid Heat Capacity } \\
\text { 22. Heavy Water Thermal Conductivity } \\
\text { 23. Heavy Water Viscosity } \\
\text { 24. Volume Change of Vaporization - } D_{2} 0 \\
\text { 25. Heavy Water Vapor Pressure } \\
\text { 26. Heavy Water Saturation Temperature } \\
\text { 27. Henry's Law Constant for He } \\
\text { 28. Turbulent Heat Transfer Coefficient } \\
\text { 29. Subcooled Boiling Heal Trans. Coef. } \\
\text { 30. ONB Correlacion } \\
\text { 31. Heat Transfer to Moderator Tank } \\
\text { 32. Moderator Tank Temperature } \\
\text { 33. Wall Cavity Radius } \\
\text { 34. Loss Coef. from Hydraulics Manual } \\
\text { 35. Flow Area for Channel } 1 \\
\text { 36. Flow Area for Channel } 2 \\
\text { 37. Flow Area for Channel } 3 \\
\text { 38. Flow Area for Channel } 4 \\
\text { 39. Flow Area for Channel } 5 \\
\text { 40. Shell Hole Area }\end{array}$ & $\begin{array}{l}\cdot \\
\bullet \\
\bullet \\
\bullet \\
\bullet \\
\bullet \\
\bullet \\
\bullet\end{array}$ & $\begin{array}{l}\bullet \\
\bullet \\
\bullet \\
\bullet \\
\bullet \\
\bullet \\
\bullet \\
\bullet \\
\bullet \\
\bullet \\
\bullet\end{array}$ & & • & & $\begin{array}{l}\cdot \\
\bullet \\
\bullet \\
\bullet \\
\bullet \\
\bullet \\
\bullet\end{array}$ & & $\begin{array}{l} \\
\bullet \\
\bullet \\
\bullet \\
\bullet \\
\bullet \\
\bullet \\
\bullet\end{array}$ & 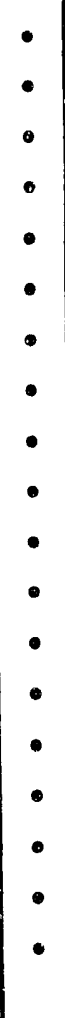 & $\begin{array}{l}\cdot \\
\bullet \\
\bullet \\
\bullet \\
\bullet \\
\bullet \\
\bullet \\
\bullet \\
\bullet \\
\bullet \\
\bullet\end{array}$ & $\bullet$ & & $\bullet$ & • \\
\hline
\end{tabular}


Table B.1 (Continued)

Uncertainties for the Flow Instability Limits

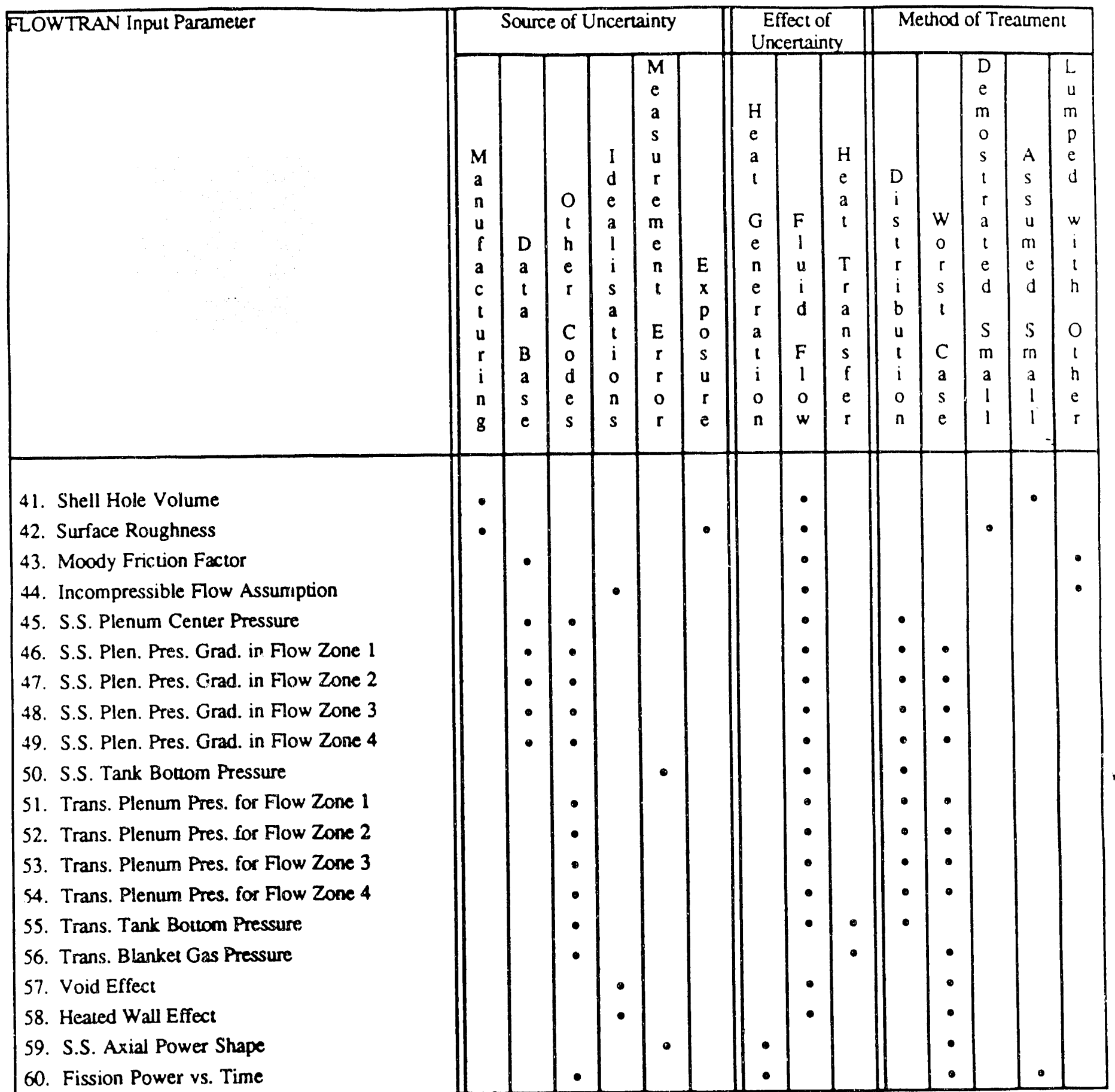


Tabie B.1 (Continued)

Uncertainties for the Flow Instability Limits

\begin{tabular}{|c|c|c|c|c|c|c|c|c|c|c|c|c|c|c|}
\hline \multirow[t]{2}{*}{ FLOWTRAN Input Parameter } & \multicolumn{6}{|c|}{ Source of Uncertainty } & \multicolumn{3}{|c|}{$\begin{array}{c}\text { Effect of } \\
\text { Uncerainty }\end{array}$} & \multicolumn{5}{|c|}{ Method of Treatment } \\
\hline & $\begin{array}{c}M \\
a \\
n \\
u \\
f \\
a \\
c \\
t \\
u \\
r \\
i \\
n \\
g\end{array}$ & $\begin{array}{l}D \\
\mathbf{a} \\
\mathrm{t} \\
\mathrm{a} \\
\mathrm{B} \\
\mathrm{a} \\
\mathrm{s} \\
\mathrm{e}\end{array}$ & $\begin{array}{l}O \\
\text { t } \\
\text { h } \\
\text { e } \\
\text { r } \\
\text { c } \\
o \\
d \\
\text { e } \\
\text { s }\end{array}$ & $\begin{array}{l}\mathrm{I} \\
\mathrm{d} \\
\mathrm{e} \\
\mathrm{a} \\
\mathrm{l} \\
\mathrm{i} \\
\mathrm{s} \\
\mathrm{a} \\
\mathrm{i} \\
\mathrm{i} \\
\mathrm{o} \\
\mathrm{n} \\
\mathrm{s}\end{array}$ & \begin{tabular}{c|}
$\mathrm{M}$ \\
$\mathrm{e}$ \\
$\mathrm{a}$ \\
$\mathrm{s}$ \\
$\mathrm{u}$ \\
$\mathrm{r}$ \\
$\mathrm{e}$ \\
$\mathrm{m}$ \\
$\mathrm{e}$ \\
$\mathrm{n}$ \\
$\mathrm{t}$ \\
$\mathrm{E}$ \\
$\mathrm{r}$ \\
$\mathrm{r}$ \\
$\mathrm{o}$ \\
$\mathrm{r}$
\end{tabular} & $\begin{array}{l}E \\
x \\
p \\
o \\
s \\
u \\
r \\
e\end{array}$ & $\begin{array}{c}\mathrm{H} \\
\mathrm{e} \\
\mathrm{a} \\
\mathrm{l} \\
\mathrm{G} \\
\mathrm{e} \\
\mathrm{n} \\
\mathrm{e} \\
\mathrm{r} \\
\mathrm{a} \\
\mathrm{l} \\
\mathrm{i} \\
\mathrm{o} \\
\mathrm{n}\end{array}$ & $\begin{array}{c}F \\
\mathrm{I} \\
\mathrm{u} \\
\mathrm{i} \\
\mathrm{d} \\
\mathrm{F} \\
\mathrm{I} \\
\mathrm{o} \\
\mathrm{w}\end{array}$ & $\begin{array}{l}\mathrm{H} \\
\mathrm{e} \\
\mathrm{a} \\
\mathrm{t} \\
\mathrm{T} \\
\mathrm{r} \\
\mathrm{a} \\
\mathrm{n} \\
\mathrm{s} \\
\mathrm{f} \\
\mathrm{e} \\
\mathrm{r}\end{array}$ & $\begin{array}{l}\mathrm{D} \\
\mathrm{i} \\
\mathrm{s} \\
\mathrm{t} \\
\mathrm{r} \\
\mathrm{i} \\
\mathrm{b} \\
\mathrm{u} \\
\mathrm{t} \\
\mathrm{i} \\
\mathrm{o} \\
\mathrm{n}\end{array}$ & $\begin{array}{c}W \\
o \\
r \\
S \\
t \\
C \\
\mathrm{C} \\
\mathrm{S} \\
\mathrm{e}\end{array}$ & $\begin{array}{c}\mathrm{D} \\
\mathrm{e} \\
\mathrm{m} \\
0 \\
\mathrm{~s} \\
\mathrm{t} \\
\mathrm{r} \\
\mathrm{a} \\
\mathrm{t} \\
\mathrm{e} \\
\mathrm{d} \\
\mathrm{s} \\
\mathrm{m} \\
\mathrm{a} \\
\mathrm{l} \\
\mathrm{l}\end{array}$ & $\begin{array}{c}A \\
\mathrm{~s} \\
\mathrm{~s} \\
\mathrm{u} \\
\mathrm{m} \\
\mathrm{e} \\
\mathrm{d} \\
\mathrm{s} \\
\mathrm{m} \\
\mathrm{a} \\
\mathrm{l} \\
\mathrm{l}\end{array}$ & $\begin{array}{l}\mathrm{L} \\
u \\
\mathrm{~m} \\
\mathrm{p} \\
\mathrm{e} \\
\mathrm{d} \\
\mathrm{w} \\
\mathrm{i} \\
\mathrm{l} \\
\mathrm{h} \\
\mathrm{O} \\
\mathrm{l} \\
\mathrm{h} \\
\mathrm{e} \\
\mathrm{r}\end{array}$ \\
\hline $\begin{array}{l}\text { 61. Decay Heat vs. Time } \\
\text { 62. Assembly Radial Power Distribution } \\
\text { 63. Reactor Radial Power Distribution } \\
\text { 64. Axial Power Shape vs. Time } \\
\text { 65. Exposure } \\
\text { 66. Inner Fuel Tube Power Fraction } \\
\text { 67. Heat Transfer Areas } \\
\text { 68. Inner Target Thickness } \\
\text { 69. Outer Target Thickness } \\
\text { 70. Inner Fuel Thickness } \\
\text { 71. Outer Fuel Thickness } \\
\text { 72. Heated Fuel Length } \\
\text { 73. Lithium Length } \\
\text { 74. Nonbonding of the Cladding } \\
\text { 75. Resistance of the Al2O3 Corrosion } \\
\text { 76. 3-D Multiplier } \\
\text { 77. Axial Fuel Distribution in Inner Fuel } \\
\text { 78. Axial Fuel Distribution in Outer Fuel } \\
\text { 79. Axial Li Distribution in Inner Target } \\
\text { 80. Axial Li Distribution in Outer Target }\end{array}$ & $\begin{array}{l}\bullet \\
\bullet \\
\bullet \\
\bullet \\
\bullet \\
\bullet \\
\bullet \\
\bullet \\
\bullet\end{array}$ & $\bullet$ & $\begin{array}{l}\bullet \\
\bullet \\
\bullet \\
\bullet\end{array}$ & $\begin{array}{l}\bullet \\
\bullet \\
\bullet \\
\bullet \\
\bullet \\
\bullet\end{array}$ & $\bullet$ & $\bullet$ & $\begin{array}{l}\bullet \\
\bullet \\
\bullet \\
\bullet \\
\bullet \\
\bullet \\
\bullet\end{array}$ & • & $\begin{array}{l}\bullet \\
\bullet \\
\bullet \\
\bullet \\
\bullet \\
\bullet \\
\bullet \\
\bullet \\
\bullet \\
\bullet\end{array}$ & $\begin{array}{l}\bullet \\
\bullet \\
\bullet \\
\bullet \\
\bullet \\
\bullet\end{array}$ & - & $\bullet$ & $\begin{array}{l}\bullet \\
\bullet \\
\bullet\end{array}$ & $\begin{array}{l}\bullet \\
\bullet \\
\bullet\end{array}$ \\
\hline
\end{tabular}


Table B.1 (Continued)

Uncertainties for the Flow Instability Limits

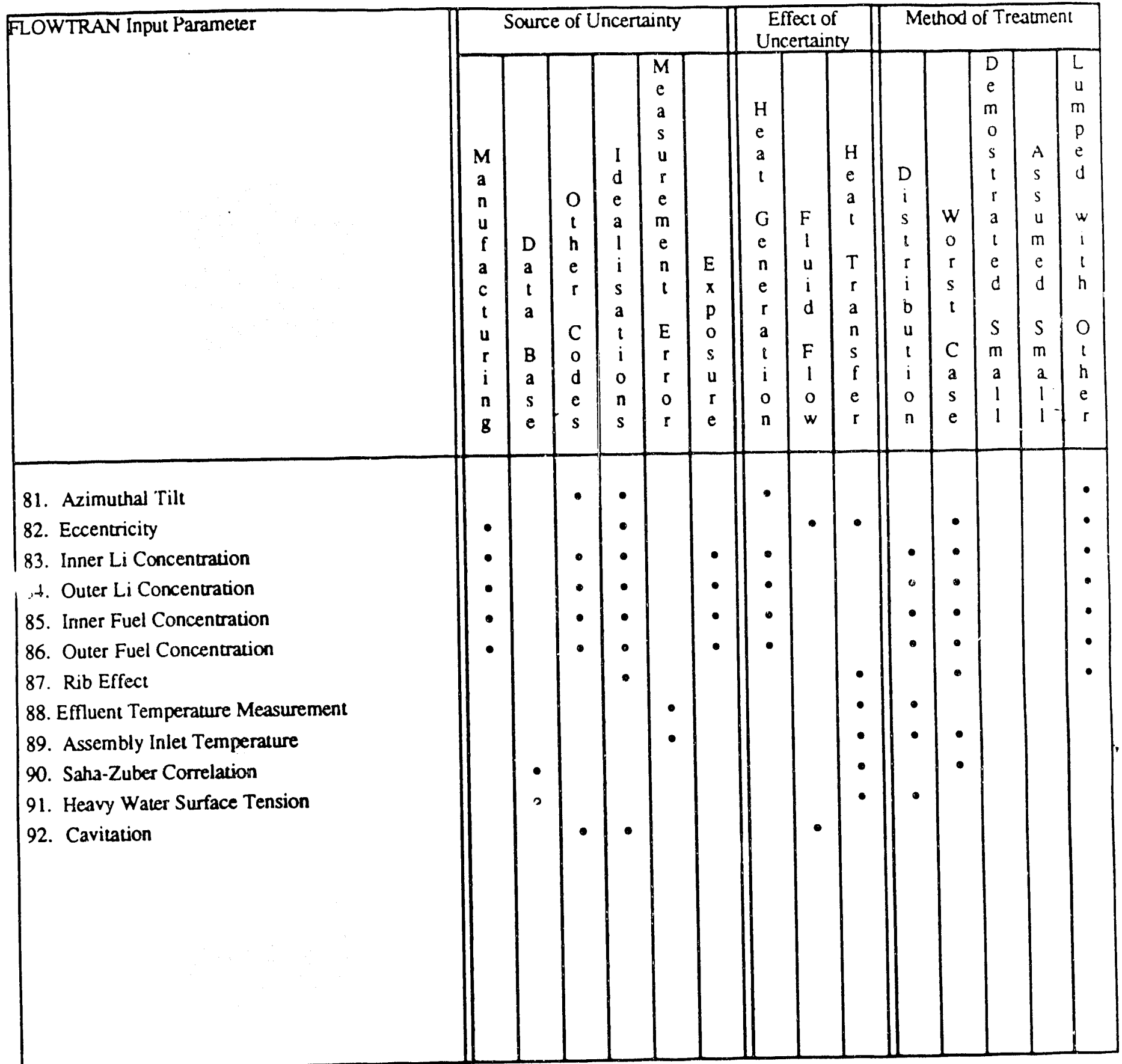


Table B.2

Sources of the Uncertainties for the Cavitation Model

\begin{tabular}{|c|c|c|}
\hline FLOWTRAN Input Parameter & Source of the Uncernainty & $\begin{array}{l}\text { Other Uncerainties With the Same } \\
\text { Source }\end{array}$ \\
\hline 1. TRAC Transient Plenum Pressure & TRAC Uncertainty & $\begin{array}{l}\text { TRAC Trans Tank Bouom Pres, } \\
\text { Trans } \Delta P \text { in Pump Succion Piping, } \\
\text { and Trans Pump Flow }\end{array}$ \\
\hline $\begin{array}{l}\text { 2. TRAC Transient Tank Bottom } \\
\text { Pressure }\end{array}$ & TRAC Uncertainty & $\begin{array}{c}\text { TRAC Trans Plenum Pres, Trans } \Delta P \\
\text { in Pump Suction Piping, and Trans } \\
\text { Pump Flow }\end{array}$ \\
\hline $\begin{array}{l}\text { 3. TRAC Transient Pressure Drop in the } \\
\text { Pump Suction }\end{array}$ & TRAC Uncertainty & $\begin{array}{c}\text { TRAC Trans Plenum Pres, Trans } \\
\text { Tank Bottom Pres, and Trans Pump } \\
\text { Flow }\end{array}$ \\
\hline 4. TRAC Transient Pump Flow & TRAC Uncertainty & $\begin{array}{l}\text { TRAC Trans Plenum Pres. Trans } \\
\text { Tank Botuom Pres, and Trans } \Delta P \text { in } \\
\text { Pump Suction Piping }\end{array}$ \\
\hline $\begin{array}{l}\text { 5. Ratio of the Pump Flow at Cut Off to } \\
\text { the Pump Flow at On Set }\end{array}$ & $\begin{array}{l}\text { Reactor Test Dáta for Onset and } \\
\text { Cutoff }\end{array}$ & $\begin{array}{c}\text { Change in } \triangle P \text { from Onset to Cutoff, } \\
\text { Req'd NPSH for Onsel, and Req'd } \\
\text { NPSH for Cutoff }\end{array}$ \\
\hline $\begin{array}{l}\text { 6. Change from Onset to Cutoff in the } \\
\text { Pressure Drop in Pump Suction } \\
\text { Piping }\end{array}$ & $\begin{array}{c}\text { Reactor Tese Data for Onset and } \\
\text { Cutoff }\end{array}$ & $\begin{array}{l}\text { Ratio of Pump Flows at Onset and } \\
\text { Cutoff, Req'd NPSH for Onseh and } \\
\text { Req'd NPSH for Cutoff }\end{array}$ \\
\hline 7. Heavy Water Liquid Density & $\begin{array}{l}\text { Experimental measurement of } \\
\text { viscosity and impurities }\end{array}$ & Heavy Water Vapor Pressure \\
\hline 8. Heavy Water Vapor Pressure & $\begin{array}{l}\text { Experimental measurement of } \\
\text { viscosity and impurities }\end{array}$ & Heavy Water Density \\
\hline $\begin{array}{l}\text { 9. Required Net Positive Suction Head } \\
\text { for Onset of Cavitation }\end{array}$ & Reactor Test Data for Onset & $\begin{array}{l}\text { Change in } \triangle P \text { from Onset to Cutoff, } \\
\text { Ratio of Pump Flows at Onset and } \\
\text { Cutoff, and Req'd NPSH for Cutoff }\end{array}$ \\
\hline $\begin{array}{l}\text { 10. Require Net Positive Suction Head for } \\
\text { Pump Cut Off }\end{array}$ & Reactor Test Data for Onset & $\begin{array}{l}\text { Change in } \triangle P \text { from Onset to Cutoff, } \\
\text { Ratio of Pump Flows at Onset and } \\
\text { Cutoff, and Req'd NPSH for Onset }\end{array}$ \\
\hline 11. Pump Suction Flow Diameler & Pump Fabrication & \\
\hline $\begin{array}{l}\text { 12. Elevation Difference Between the Tank } \\
\text { Bottom and the Pumps }\end{array}$ & Construction & $\begin{array}{l}\text { Elevation Difference Between the } \\
\text { Tank Bottom and the Plenum }\end{array}$ \\
\hline $\begin{array}{l}\text { 13. Elevation Difference Between the Tank } \\
\text { Bottom and the Plenum }\end{array}$ & Construction & $\begin{array}{l}\text { Elevation Difference Berween the } \\
\text { Tank Bottom and the Pumps }\end{array}$ \\
\hline
\end{tabular}


Table B.2 (Continued)

\section{Sources of the Uncertainties for the Cavitation Model}

\begin{tabular}{|c|c|c|}
\hline FLOWTRAN Input Parameter & Source of the Uncerainty & $\begin{array}{l}\text { Other Uncertainties with the Same } \\
\text { Source }\end{array}$ \\
\hline $\begin{array}{l}\text { 14. Ratio of the Core Power to the Flow } \\
\text { Zone } 1 \text { Assembly Power }\end{array}$ & RDAP Dala & $\begin{array}{l}\text { Ratio of Core Power to Assembly } \\
\text { Power in Flow Zones 2, 3, and } 4\end{array}$ \\
\hline $\begin{array}{l}\text { 15. Ratio of the Core Power to the Flow } \\
\text { Zone } 2 \text { Assembly Power }\end{array}$ & RDAP Data & $\begin{array}{l}\text { Ratio of Core Power to Assembly } \\
\text { Power in Flow Zones } 1,3 \text {, and } 4\end{array}$ \\
\hline $\begin{array}{l}\text { 16. Rario of the Core Power to the Flow } \\
\text { Zone } 3 \text { Assembly Power }\end{array}$ & RDAP Data & $\begin{array}{l}\text { Ratio of Core Power to Assembly } \\
\text { Power in Flow Zones } 1,2 \text {, and } 4\end{array}$ \\
\hline $\begin{array}{l}\text { 17. Ratio of the Core Power to the Flow } \\
\text { Zone } 4 \text { Assembly Power }\end{array}$ & RDAP Data & $\begin{array}{l}\text { Ratio of Core Power to Assembly } \\
\text { Power in Flow Zones } 1,2 \text {, and } 3\end{array}$ \\
\hline 18. 3-D Multiplier & Fuel Assembly Manufacturing & \\
\hline $\begin{array}{l}\text { 19. Ratio of the Core Flow to the Worst } \\
\text { Flow Zone } 1 \text { Assembly Flow }\end{array}$ & Charge Design Cakculations & $\begin{array}{c}\text { Ratio of the Core Flow to the } \\
\text { Assembly Flow in Flow Zones } 2,3 \text {; } \\
\text { and } 4\end{array}$ \\
\hline $\begin{array}{l}\text { 20. Ratio of the Core Flow to the Worst } \\
\text { Flow Zone } 2 \text { Assembly Flow }\end{array}$ & Charge Design Calculations & $\begin{array}{c}\text { Ratio of the Core Flow wo the } \\
\text { Assembly Flow in Flow Zones } 2,3 \text {, } \\
\text { and } 4\end{array}$ \\
\hline $\begin{array}{l}\text { 21. Ratio of the Core Flow to the Worst } \\
\text { Flow Zone } 3 \text { Assembly Flow }\end{array}$ & Charge Design Calculations & $\begin{array}{c}\text { Ratio of the Core Flow to the } \\
\text { Assembly Flow in Flow Zones 2, } 3 \text {. } \\
\text { and } 4\end{array}$ \\
\hline $\begin{array}{l}\text { 22. Ratio of the Core Flow to the Worst } \\
\text { Flow Zone } 4 \text { Assembly Flow }\end{array}$ & Charge Design Calculations & $\begin{array}{c}\text { Ratio of the Core Flow to the } \\
\text { Assembly Flow in Flow Zones } 2,3 . \\
\text { and } 4\end{array}$ \\
\hline 23. Plenum Average Temperaure & Inlet Thermocouple Errors & Assernbly Inlet Temperaure \\
\hline
\end{tabular}




\section{APPENDIX C - PARAMETERS FOR THE SIGNIFICANT UNCERTAINTIES}

Table C.1

Percent of Total Variance, Sensitivity Coefficients and Standard Deviations for the Significant Uncertainty Parameters Characterized by Distributions. These Quantities Were Obtained for an Assembly Inlet Temperature of $30^{\circ} \mathrm{C}$.

\begin{tabular}{|c|c|c|c|c|c|c|c|}
\hline Uncertainty & Mean & $\begin{array}{l}\text { Standard } \\
\text { Deviation }\end{array}$ & $\begin{array}{c}\text { Type of } \\
\text { Disuributio } \\
n\end{array}$ & $\begin{array}{l}\text { Source of } \\
\text { Values }\end{array}$ & $\begin{array}{l}\text { Sensitivity } \\
\text { Coefficient }\end{array}$ & $\begin{array}{l}9 \% \text { of } \\
\text { Effective } \\
\text { Variance }\end{array}$ & Rank \\
\hline $\begin{array}{l}\text { Variation in the } \\
\text { Transient Plenum } \\
\text { Pressure (psi)) }\end{array}$ & 0.0000 & 2.5000 & Normal & $\begin{array}{c}\text { TRAC } \\
\text { uncertainty }\end{array}$ & $\begin{array}{l}0.8423 \\
{ }^{\circ} \mathrm{C} / \mathrm{psi} \\
\end{array}$ & 43.89 & 1 \\
\hline $\begin{array}{l}\text { 3-D Multiplier } \\
\text { Unceraainty }\end{array}$ & 0.8011 & 0.0249 & Empirical & $\begin{array}{c}\text { Model of } \\
\text { asymmetric } \\
\text { effects }\end{array}$ & $50.28^{\circ} \mathrm{C}$ & 15.52 & 2 \\
\hline $\begin{array}{l}\text { Variation in the } \\
\text { Transient Tank Botwom } \\
\text { Pressure (psi) }\end{array}$ & 0.0000 & 1.0000 & Normal & $\begin{array}{c}\text { TRAC } \\
\text { uncertainty }\end{array}$ & $\begin{array}{r}-0.3862 \\
{ }^{\circ} \mathrm{C} / \mathrm{psi} \\
\end{array}$ & 14.77 & 3 \\
\hline $\begin{array}{l}\text { Variation in the Steady } \\
\text { State Plenum Pressure } \\
\text { Gradient (psi) }\end{array}$ & 0.0000 & 2.9 & Normal & $\begin{array}{c}\text { TRAC } \\
\text { uncertainty, test } \\
\text { dan } \\
\text { uncertainty } \\
\end{array}$ & $\begin{array}{l}-0.3290 \\
{ }^{\circ} \mathrm{C} / \mathrm{psi}\end{array}$ & 9.01 & 4 \\
\hline $\begin{array}{l}\text { Inner Fuel Tube Power } \\
\text { Fraction (\%) }\end{array}$ & 37.7 & 1.7 & Normal & $\begin{array}{c}\text { GLASS } \\
\text { calculation }\end{array}$ & $0.4851^{\circ} \mathrm{C} / \%$ & 6.73 & 5 \\
\hline $\begin{array}{l}\text { Assembly Inlet } \\
\text { Temperauure }\left({ }^{\circ} \mathrm{C}\right)\end{array}$ & $\begin{array}{c}\text { Average } \\
\text { minimum } \\
\text { reading }+ \\
1.2^{\circ} \mathrm{C} \\
\end{array}$ & 1.1000 & Normal & Plenum model & $\begin{array}{l}0.5620 \\
{ }^{\circ} \mathrm{C} /{ }^{\circ} \mathrm{C}\end{array}$ & 6.12 & 6 \\
\hline $\begin{array}{l}\text { Variation in the Steady } \\
\text { State P!enum Center } \\
\text { Pressure (psi) }\end{array}$ & 0.0000 & 1.5000 & Normal & $\begin{array}{l}\text { Test daia, } \\
\text { RLOWZONE } \\
\text { uncertainties, } \\
\text { TRAC } \\
\text { uncertainties }\end{array}$ & $\begin{array}{l}-0.3290 \\
{ }^{\circ} \mathrm{C} / \mathrm{psi}\end{array}$ & 2.41 & 7 \\
\hline $\begin{array}{l}\text { Variation in the } \\
\text { Effluent Temperaure } \\
\text { Measurement (C) }\end{array}$ & 0.0000 & 0.2250 & Normal & Data & $1.00^{\circ} \mathrm{C} /{ }^{\circ} \mathrm{C}$ & 0.50 & 8 \\
\hline Heated Fuel Length (in) & 152.0000 & 3.0 & Uniform & $\begin{array}{c}\text { Manual on fuel } \\
\text { wbes DPSTM- } \\
110 \text { ? } \\
\end{array}$ & $\begin{array}{l}0.0759 \\
{ }^{\circ} \mathrm{C} / \mathrm{in}\end{array}$ & 0.50 & 9 \\
\hline $\begin{array}{l}\text { Variation in the } \\
\text { Turbulent Heat Transfer } \\
\text { Coefficient (\%) }\end{array}$ & 0.0000 & 15.0000 & Normal & $\begin{array}{l}\text { Evaluation of } \\
\text { emrors in the } \\
\text { Bjorge \& } \\
\text { Rohsenow } \\
\text { correlation }\end{array}$ & $\begin{array}{l}0.0125 \\
{ }^{\circ} \mathrm{C} / \%\end{array}$ & 0.35 & 10 \\
\hline $\begin{array}{l}\text { Variation in the } \\
\text { Subcooled Boiling Heat } \\
\text { Transfer Coefficient (\%) }\end{array}$ & 80.0000 & 44.00 & Weibull & $\begin{array}{l}\text { Evaluation of } \\
\text { errors in the } \\
\text { Bergles \& } \\
\text { Rohsenow } \\
\text { correlation }\end{array}$ & $\begin{array}{c}-0.002876 \\
{ }^{\circ} \mathrm{C} / \%\end{array}$ & 0.16 & 11 \\
\hline
\end{tabular}




\section{APPENDIX D - AZIMUTHAL FUEL DISTRIBUTIONS}

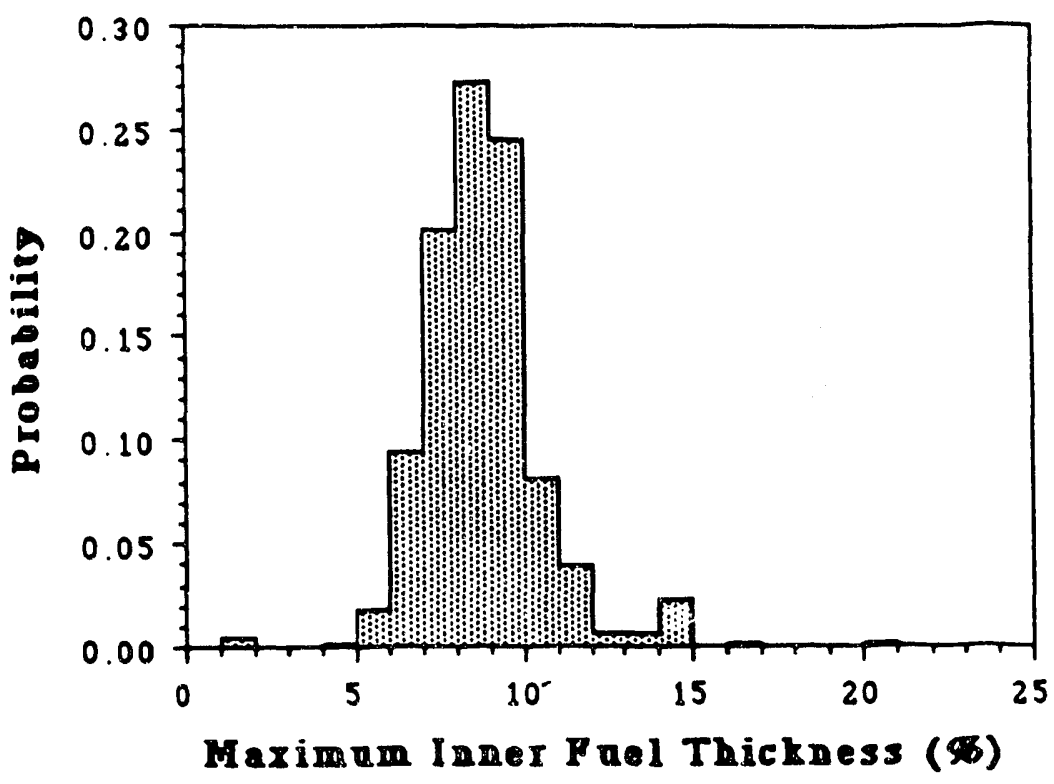

Figure D.1

Probability distribution for the maximum inner fuel thickness.

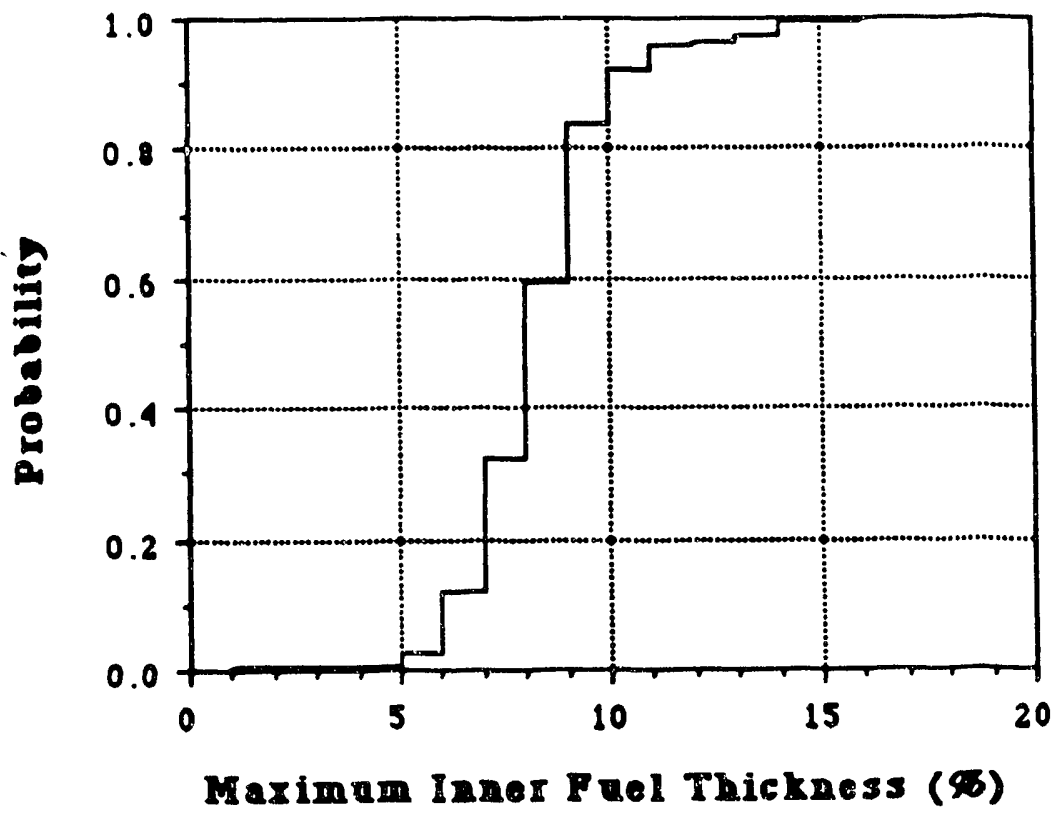

Figure D.2

Cumulative distribution function for the maximum inner fuel thickness. 


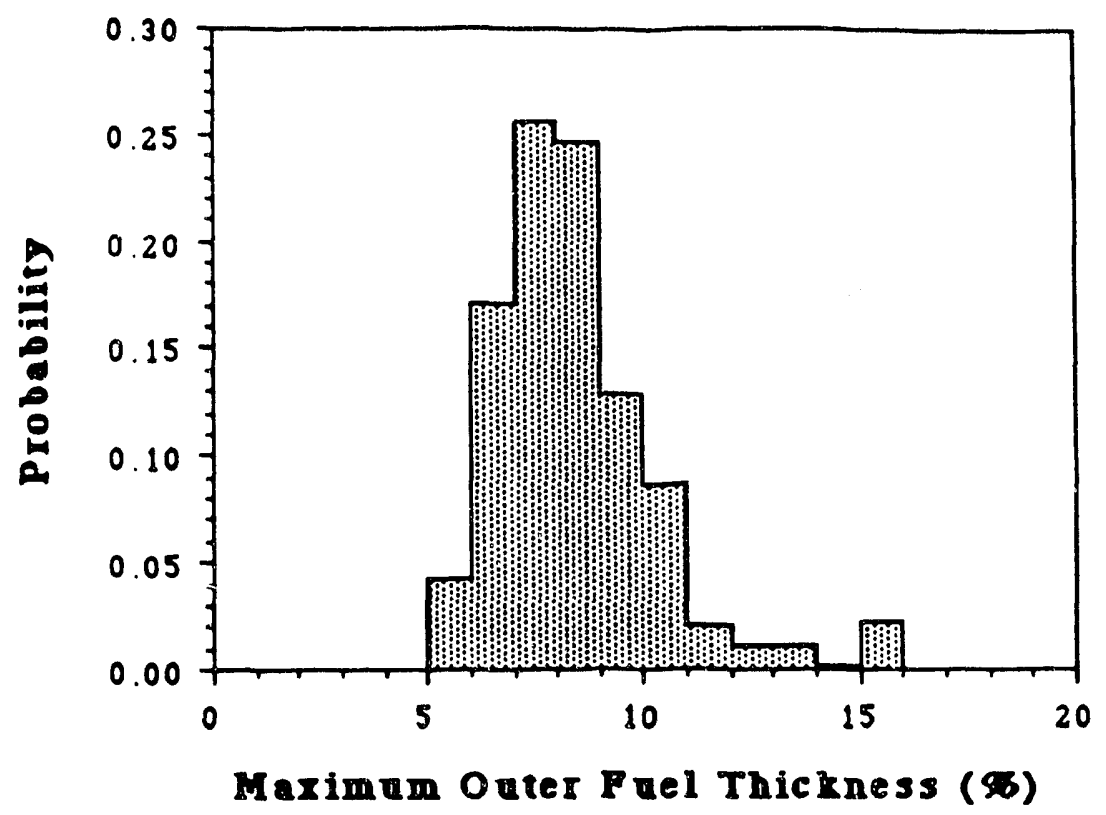

Figure D.3

Probability distribution for the maximum outer fuel thickness.

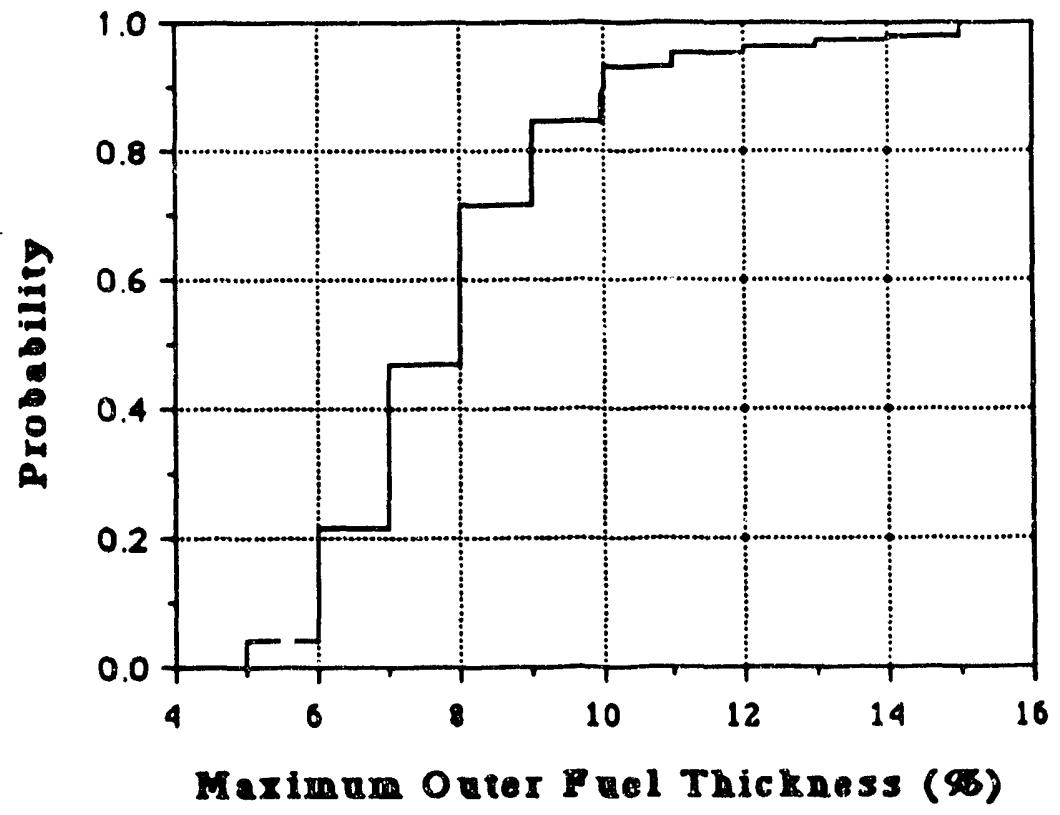

Figure D.4

Cumulative distribution function for the maximum outer fuel thickness. 


\section{APPENDIX E - JUSTIFICATION OF THE ASSUMPTION OF STATISTICALLY INDEPENDENT ASSEMBLIES}

To calculate the probability of no significant voiding at all locations in the core, it is assumed that the assemblies are statistically independent. In reality, the assemblies are not statistically independent because the uncertainties that affect one assembly are not statistically independent of the uncerainties that affect the other assemblies. In this appendix, the assumption of statistical independence is shown to underestimate the probability of no significant voiding in the model, which implies that the assumption is conservative. First it will be shown that the assumption of statistical independence is conservative if the assemblies are positively correlated. Next, it will be argued that the assemblies must be positively correlated.

\section{E.1 Proof that the Assumption is Conservative if the Assemblies are Positively Correlated}

The critical effluent temperatures for all assemblies can be represented by a vector of correlated random variables. Any vector of correlated random variables can be expressed as a function of independent random variables. Thus, the critical effluent temperature for a given assembly can be represented by a function of the following form:

$$
T_{c r, i}=f\left(x, y_{i}\right)
$$

where: $\quad T_{c r, i}=$ the critical effluent temperature for assembly $i$

$$
\mathbf{x}=\mathbf{a} \text { vector of independent random variables common to all assemblies }
$$$$
y_{i}=\text { an independent random variable unique to assembly } i \text {. }
$$

In this proof, this transformation is only a mathematical construct; but some physical meaning can be ascribed to it. This transformation can be thought of as tracing the uncertainties to their independent physical sources.

Now, let $S$ be the proposition that the model will predict that the Stanton number criterion is satisfied for every assembly in the core, and let $S_{i}$ be the proposition that the model will predict that the criterion is satisfied for assembly $i$. S is the conjunction of the $S_{i}$. A conjunction is the simultaneous truth of the propositions, and is represented by the symbol $\wedge:$

$$
\mathbf{S}=\wedge \mathbf{S}_{\mathbf{i}}
$$

Let $\operatorname{Pr}\left(S_{i} \mid x=x^{*}\right)$ be the probability of $S_{i}$ given that the vector of common random variables is equal to $x^{*}$. $\operatorname{Pr}\left(S_{i} \mid x=x^{*}\right)$ is evaluated from the probability distributions for the unique random variable, $y_{i}$. Because $\operatorname{Pr}\left(S_{i} \mid x=x^{*}\right)$ depends only on the distributions for unique random variables, these conditional probabilities are statistically independent. Therefore, the conditional probability of $S$ given $x^{*}$ is the product of the conditional probabilities for the assemblies.

$$
\operatorname{Pr}\left(\mathbf{S} \mid \mathbf{x}=\mathbf{x}^{*}\right)=\prod_{\mathbf{i}} \operatorname{Pr}\left(\mathbf{S}_{\mathbf{i}} \mid \mathbf{x}=\mathbf{x}^{*}\right)
$$


The probability of $\mathbf{S}$ can be evaluated from the conditional probabilities using the following integral:

$$
\operatorname{Pr}(\mathbf{S})=\int \operatorname{Pr}\left(\mathbf{S} \mid \mathbf{x}=\mathbf{x}^{*}\right) \mathbf{p}\left(\mathbf{x}^{*}\right) \mathrm{d} \mathbf{x}^{*}
$$

Substituting Equation E.3 into Equation E.4 gives:

$$
\operatorname{Pr}(\mathbf{S})=\int \prod_{1} \operatorname{Pr}\left(\mathbf{S}_{\mathrm{i}} \mid \mathbf{x}=\mathbf{x}^{*}\right) \mathrm{p}\left(\mathbf{x}^{*}\right) \mathrm{d} \mathbf{x}^{*}
$$

The probability of $S_{i}$ also can be evaluated from the conditional probabilities:

$$
\operatorname{Pr}\left(\mathbf{S}_{\mathfrak{i}}\right)=\int \operatorname{Pr}\left(\mathbf{S}_{\mathbf{i}} \mid \mathbf{x}=\mathbf{x}^{*}\right) \mathbf{p}\left(\mathbf{x}^{*}\right) \mathrm{d} \mathbf{x}^{*}
$$

To prove that the assumption of statistical independence is conservative, it must be demonstrated that the following inequality holds:

$$
\operatorname{Pr}(\mathbf{S}) \geq \prod_{i} \operatorname{Pr}\left(\mathbf{S}_{i}\right)
$$

This inequality implies that:

$$
\int \prod_{i} \operatorname{Pr}\left(S_{i} \mid x=x^{*}\right) p\left(x^{*}\right) d x^{*} \geq \prod_{i} \int \operatorname{Pr}\left(S_{i} \mid x=x^{*}\right) p\left(x^{*}\right) d x^{*}
$$

The conditional probabilities in Equation E.8 are functions of $x^{*}$. This equation simply states that the average of the product of these functions must be greater that the product of the averages. To determine the conditions needed to satisfy Equation E.8, it is useful to consider two arbitrary functions $g(x)$ and $h(x)$. The average values of $g(x), h(x)$, and $\mathrm{g}(\mathbf{x}) \mathbf{h}(\mathbf{x})$ are given as follows:

$$
\begin{aligned}
& <g>=\int g(x) p(x) d x \\
& <h>=\int h(x) p(x) d x \\
& <g h>=\int g(x) h(x) p(x) d x
\end{aligned}
$$


In the neighborhood of the mean of $x, g$ and $h$ can be expanded in a Taylor series:

$$
\begin{aligned}
& g(x)=g_{0}+\nabla^{\top} g_{0}(x-\mu)+\frac{1}{2}(x-\mu)^{T} \nabla^{2} g_{0}(x-\mu)+\cdots \\
& h(x)=h_{0}+\nabla^{\top} h_{0}(x-\mu)+\frac{1}{2}(x-\mu)^{T} \nabla^{2} h_{0}(x-\mu)+\cdots
\end{aligned}
$$

The average values of these functions and their product can be obtained by integrating these expansions:

$$
\begin{aligned}
& <\mathrm{g}>=\mathrm{g}_{0}+\frac{1}{2} \sigma^{\mathrm{T}} \operatorname{diag}\left(\nabla^{2} \mathrm{~g}_{0}\right) \sigma+\cdots \\
& <\mathrm{h}>=\mathrm{h}_{0}+\frac{1}{2} \sigma^{\mathrm{T}} \operatorname{diag}\left(\nabla^{2} \mathrm{~g}_{0}\right) \sigma+\cdots \\
& <\mathrm{gh}>=\mathrm{g}_{0} h_{0}+\frac{1}{2} \sigma^{\mathrm{T}} \operatorname{diag}\left(\mathrm{g}_{0} \nabla^{2} \mathrm{~h}_{0}+2 \nabla \mathrm{g}_{0} \nabla^{\mathrm{T}} \mathrm{h}_{0}+\mathrm{h}_{0} \nabla^{2} \mathrm{~g}_{0}\right) \sigma+\cdots
\end{aligned}
$$

Combining these results gives:

$$
\langle g h\rangle-\langle g\rangle\langle h\rangle=\sum_{i}\left(\frac{\partial g}{\partial x_{i}}\right)\left(\frac{\partial h}{\partial x_{i}}\right) \sigma_{i}^{2}+\cdots
$$

If the standard deviations are sufficiently small and the right-hand side of Equation (E.17) is positive, the following inequality will hold:

$$
\langle\mathrm{gh}\rangle \geq\langle\mathrm{g}\rangle\langle\mathrm{h}\rangle
$$

It also can be shown that the right-hand side of Equation (E.17) is positive if the covariance of the functions $g$ and $h$ is positive. The covariance of $g$ and $h$ is:

$$
\operatorname{Cov}[g, h]=\int(g(x)-\langle g>)(h(x)-<h>) p(x) d x
$$

By substituting the Equations E.12 - E.15 into Equation E.19 and integrating, the following expression for the covariance is obtained:

$$
\operatorname{Cov}[g, h]==\sum_{i}\left(\frac{\partial g}{\partial x_{i}}\right)\left(\frac{\partial h}{\partial x_{i}}\right) \sigma_{i}^{2}+\cdots
$$

Therefore, if the covariance is positive and the distributions are sufficiently small, the righthand side of Equation E.17 will be positive; and the inequality given by Equation E.18 is satisfied.

Now consider three arbitrary functions: $g(x), h(x)$, and $k(x)$. From the conditions derived above, it can be shown that:

$$
\begin{aligned}
& <\text { ghk }>\geq<\text { gh }><k> \\
& <\text { ghk }>\geq<\text { g }><h k>
\end{aligned}
$$


If $g, h$, and $k$ are positively correlated and the values of $g_{0}, h_{0}$ and $k_{0}$ are all positive. Substitution of Equation E.18 into Equation E.21 gives the following inequality:

$\langle$ ghk $\rangle \geq\langle$ g $\rangle\langle h\rangle\langle k\rangle$

This wethod can be used to extend the results to any number of functions. Thus, the average of the product of functions is greater than the product cf the averages if the deviations are sufficiently small.

These results for arbitrary functions now can be applied to Equation E.8. Because probabilities must be between zero and one, the condition that the functions be positive is satisfied. Now, the covariance of the conditional probabilities in Equation E. 8 must be evaluated. The covariance of the conditional probabilities can be determined from
Equation E. 20 :

$$
\begin{aligned}
& \operatorname{Cov}[\left.\operatorname{Pr}\left(\mathbf{S}_{\mathbf{i}} \mid \mathbf{x}=\mathbf{x}^{*}\right), \operatorname{Pr}\left(\mathbf{S}_{\mathbf{j}} \mid \mathbf{x}=\mathbf{x}^{*}\right)\right] \\
&=\sum_{\mathbf{k}} \frac{\partial}{\partial x_{\mathbf{k}}}\left(\operatorname{Pr}\left(\mathbf{S}_{\mathrm{i}} \mid \mathbf{x}=\mathbf{x}^{*}\right)\right) \frac{\partial}{\partial x_{\mathbf{k}}}\left(\operatorname{Pr}\left(\mathbf{S}_{\mathbf{j}} \mid \mathbf{x}=\mathbf{x}^{*}\right)\right) \sigma_{\mathbf{x}_{\mathbf{k}}}^{2}+\cdots
\end{aligned}
$$

The conditional probability can be expressed in terms of the function $f\left(x, y_{i}\right)$ :

$$
\operatorname{Pr}\left(S_{i} \mid x=x^{*}\right)=\operatorname{Pr}\left(T_{\text {limili }} \leq f\left(x^{*}, y_{i}\right)\right)
$$

where: $\quad T_{\text {limit, } i}$ is the limit for assembly $i$.

The derivative of the conditional probability is:

$$
\frac{\partial}{\partial x_{k}}\left(\operatorname{Pr}\left(S_{i} \mid x=x^{*}\right)\right)=\operatorname{PT}_{c t}\left(\Upsilon_{\text {limit, } i} ; x^{*}\right) \frac{\partial f}{\partial x_{k}^{*}}
$$

where:

$\mathrm{PT}_{\mathrm{cr}}(\cdot)$ is the probability density function for the critical effluent temperature.

Substituting Equation E.26 into Equation E.24 gives:

$$
\begin{aligned}
& \operatorname{Cov}\left[\operatorname{Pr}\left(S_{i} \mid x=x^{*}\right), \operatorname{Pr}\left(S_{j} \mid x=x^{*}\right)\right] \\
& =\operatorname{Pr}_{T_{T}}\left(T_{\text {limiLi } i} ; x^{*}\right) \operatorname{P}_{T_{C r}}\left(T_{\text {limiL } j ;} x^{*}\right) \sum_{k}\left(\frac{\partial f\left(x^{*}, y_{i j}\right)}{\partial x_{k}^{*}}\right)\left(\frac{\partial f\left(x^{*}, y_{i}\right)}{\partial x_{k}^{*}}\right) \sigma_{x_{k}}^{2}+\cdots
\end{aligned}
$$

Because a probabili $y$ density function must be positive, the product before the summation must be positive. Therefore, if the distributions are sufficiently narrow, the covariance of the joint probability will be positive if the summation is positive. By Equation E.20, the summation will be positive if the covariance of the critical effluent temperatures for a pair of assemblies is positive and the distributions are sufficiently narow. 
The results of the analysis presented in this section are simple. The assumption of statistical independent assemblies is conservative if the covariance in the critical effluent temperatures is positive for all pairs of assemblies in the core.

\section{E.2 Covariance in the Critical Emuent Temperatures}

In order to demonstrate that the assumption of statistical independence is conservative, it must be shown that the correlation between assemblies is positive. This proof cannot be done quantitatively because there is insufficient quantitative information. However, there is enough quantitative and qualitative information to argue that the assemblies must be positively correlated even though the covariances cannot be calculated directly.

In this section, a linear function is used to approximate the critical effluent temperature.

$$
T_{c r, i}=T_{c r, i, r e f}+\sum_{k} g_{i, k}\left(x_{i, k}-x_{i, k, r e f}\right)
$$

where: $\quad T_{c r, i}=$ the critical effluent temperature for assembly $i$,

$\mathrm{T}_{\mathrm{cr}, \mathrm{i}, \mathrm{ref}}=$ the reference value for the critical effluent temperature for assembly $\mathrm{i}$

$x_{i, k}=$ uncertainty variable $k$ for assembly $i$

$x_{i, k, r e f}=$ reference value for uncertainty variable $k$ for assembly $i$

$\mathrm{g}_{\mathrm{i}, \mathrm{k}}=$ the sensitivity coefficient for uncertainty variable $\mathrm{k}$ for assembly $\mathrm{i}$.

The covariance between $T_{c r, i}$ and $T_{c r j}$ is:

$$
\operatorname{Cov}\left(T_{c r, i}, T_{c r, j}\right)=\sum_{k} \sum_{i} g_{i, k} g_{j, l} \operatorname{Cov}\left(x_{i, k}, x_{j, l}\right)
$$

The approach taken here to demonstrate that the covariance must be positive is to show that all non-zero terms in Equation E.26 must be positive.

Approximately $99 \%$ of the variance in the critical effluent temperature is the result of uncertainty in the pliysical dimensions of the assembly and uncertainty in the assembly boundary conditions. The deviations in the physical dimension of a given assembly from the nominal values are relatively independent of the other assemblies; therefore, they do not contribute to the covariance in the critical effluent temperarures. However, the assembly boundary conditions are derived from a common source. For example, the transient tank bottom pressure for all assemblies is determined from TRAC. There is expected to be significant covariance in the boundary conditions for different assemblies. This covariance is expected to be the primary source of covariance in the critical effluent temperatures.

The boundary conditions that have the most significant impact on the uncertainty in the critical effluent temperature are the transient plenum pressure, the transient tank bottom pressure, the steady-state plenum pressure gradient, the assembly inlet temperature, and the steady-state plenum center pressure. These uncertainties account for about $75 \%$ of the total variance in the critical effluent temperature. The effect of each of these uncertainties on the covariance in the critical effluent temperature will be examined in detail. 
1. Transient Plejum Pressure for Assembly i with the Transient Plenum Pressure for Assembly $j$ - The transient plenum pressure is obtained from TRAC. The uncertainty in this quantity accounts for about $44 \%$ of the variance in the critical effluent temperature for a given assembly, and it is the result of uncertainty in the loss coefficients for the plenum and the break, uncertainty in cavitation parameters, and errors introduced by the noding of the plenum. Sensitivity studies have shown that changes in the loss coefficients and cavitation parameters change all of the plenum pressures in the same direction. Thus, if a change in a loss coefficient increases the pressure at one location in the plenum, that change also increases the pressures at the other locations. Because changes in the primitive uncertainties in TRAC changes all plenum pressures in the sarne direction, the transient plenum pressures are expected to be positively correlated. Perturbations of the assembly model have shown that the sensitivity coefficients for the transient plenum pressure are positive for all assemblies. A positive covariance and positive sensitivity coefficients result in a positive in Equation E.26.

2. Transient Tank Bottom Pressure for Assembly i with the Transient Tank Bottom Pressure for Assembly $j$ - The transient tank bottom pressure is obtained from TRAC, and it accounts for about $15 \%$ of the variance in the critical effluent temperature. The uncertainty in the transient tank bottom pressure is primarily the result of uncertainty in modelling the blanket gas expansion. The effect of errors in the blanket gas pressure will be the same for all locations; therefore, the covariance for the transient tank bottom pressure for assembly $i$ and assembly $j$ is expected to be positive. The sensitivity coefficients for the transient tank bottom pressure are negative for all assemblies, so this source of correlation contributes a positive term to Equation E.26.

3. Transient Plenum Pressure for Assembly i with the Transient Tank Bottom Pressure for Assembly $j$ - Both the uncertainty in the transient plenum pressure and the uncertainty in the transient tank bottom pressure are the result of uncertainty in the TRAC model, so there may be some statistical correlation between these uncertainties. In the assembly uncertainty analysis, worst case covariance was used for this pair of uncertainties. Using the worst case covariance for this pair results in a positive contribution to the covariance in the critical effluent temperatures for the assemblies.

4. Steady-State Plenum Pressure Gradient for Assembly i with the Steady-State Plenum Pressure Gradient for Assembly $j$ - The steady-state pressure gradient is obtained using a correlation based on reactor test data. The uncertainty in the correlation accounts for about $9 \%$ of the variance in the critical effluent temperature. The actual pressure will deviate from the correlarion because of fluctuations in the flow. These pressure fluctuations at adjacent locations will tend to be in the same direction, which corresponds to a positive correlation. The sensitivity coefficient for the steady-state plenum pressure gradient is negative for all assemblies; therefore, this source of correlation results in a positive contribution to the covariance in the critical effluent temperatures.

5. Inlet Temperanure for Assembly i with the Inlet Temperanure for Assembly $\mathrm{j}$ - The uncertainty in the assembly inlet temperatures is the result of variations in the six inlet temperatures, errors in the temperaure measurements, and uncertainty in the plenum mixing. This uncertainty accounts for about $6 \%$ of the variance in the critical effluent temperature. A no mixing model is used to evaluate the uncertainty in the inlet temperauure. Based on the no mixing model, the correlation coefficient for the inlet temperature between a pair of assemblies will be either +1 or $\bar{U}$. The 
sensitivity coefficients for the inlet temperature are positive for all assemblies, so this source of correlation contributes a positive term to Equation E.26.

6. Steady-State Plenum Center Pressure for Assembly i with the Steady-State Plenum Center Pressure for Assembly j - The steady-state plenum center pressure is a parameter that is common to all assemblies. By definition, the correlation coefficient for a random variable with itself will be +1 . Because the sensitivity coefficients for this uncertainty are negative for all assemblies, this source of correlation results in a positive contribution to the covariance in the critical effluent temperatures.

Although there are other uncertainties that contribute to the correlation between assemblies, the six sources of covariance listed above are the primary sources. All of these six sources are expected to contribute a positive term to covariance in critical effluent temperature for pairs of assemblies. Therefore, the covariance in critical effluent temperature for all pairs of assemblies is expected to be positive.

\section{E.3 Conclusions}

This appendix has presented detailed arguments justifying the assertion that the assumption of statistically independent assemblies is conservative. First, it was shown mathematically that this assumption will underestimate the probability of satisfying the Stanton number criterion if the covariance in the critical effluent temperatures for all pairs of assemblies is positive. Next, knowledge of the system and the uncertainties was used to argue that the covariance in the critical effluent temperature must be positive. Hence, the assumpion of statistical independence is conservative. 


\section{APPENDIX F - SUMMARY OF SENSITIVITY COEFFICIENTS}

Table F.1

Linear Approximation of the Critical Effluent Temperature Without the Effects of Cavitation for a Nominal Inlet Temperature of $20^{\circ} \mathrm{C}$. the Reference Value for the Critical Effuent Temperature is $65.9429^{\circ} \mathrm{C}$.

\begin{tabular}{|c|c|c|c|c|c|}
\hline Uncertainty & $\begin{array}{l}\text { Reference } \\
\text { Value }\end{array}$ & $\begin{array}{l}\text { Derivaive of } \\
\text { Axisyminam } \\
\Delta \mathrm{T} \text { withor } \\
\text { Casiation }\end{array}$ & $\begin{array}{l}\text { Derivarive } \\
\text { of the } \\
\text { Critical } \\
\text { Effluent } \\
\text { Temp. }\end{array}$ & Mean Value & $\begin{array}{l}\text { Standard } \\
\text { Deviation }\end{array}$ \\
\hline Trans. Plenum Pres. (psi) & 0.00 & 1.18 & 0.9267 & 0.00 & 2.5 \\
\hline 3-D Multiplier & 0.7853 & - & 58.50 & $.785 ?$ & .028 \\
\hline Trans. Tank Bottom Pres.(psi) & 0.00 & -0.597 & -0.4688 & 0.00 & 1.00 \\
\hline Inner Fuel Power Fraction & .377 & -83.2 & -65.34 & 0.377 & 0.017 \\
\hline Assembly inlet Temp. $\left({ }^{\circ} \mathrm{C}\right)$ & 40.0 & -0.559 & -0.5610 & 41.2 & 1.1 \\
\hline $\begin{array}{l}\text { S.S. Plenum Center Pres. } \\
\text { (psi) }\end{array}$ & 0.00 & -0.465 & -0.3652 & 0.00 & 1.5 \\
\hline $\begin{array}{l}\text { Effluent Temperaure } \\
\text { Measuremcist }\left({ }^{\circ} \mathrm{C}\right)\end{array}$ & 0.00 & - & 1.0000 & 0.00 & 0.225 \\
\hline Heated Fuel Length (in.) & 152.0 & -0.127 & 0.0997 & 152.0 & 3.0 \\
\hline $\begin{array}{l}\text { Turbulent Heat Trans Cœef. } \\
(\%)\end{array}$ & 0.00 & 0.0178 & 0.01398 & 0.00 & 15 \\
\hline $\begin{array}{l}\text { Subcooled Boil Heat Trans. } \\
\text { Coef. (\%) }\end{array}$ & 100 & -0.00347 & -0.00273 & 80 & 44 \\
\hline Required NPSH for Onset (ft) & 0.00 & 0.00 & 0.00 & 0.00 & 0.30 \\
\hline Required NPSH for Cutoff (ft) & 0.00 & 0.00 & 0.00 & 0.00 & 0.30 \\
\hline TRAC Pump Flow (gpm) & 0.00 & 0.00 & 0.00 & +375 & 875 \\
\hline $\begin{array}{l}\text { TRAC } \triangle P \text { from Tank to } \\
\text { Pump (\%) }\end{array}$ & 0.00 & 0.00 & 0.00 & 0.00 & 3.0 \\
\hline $\begin{array}{l}\text { Change in } \Delta P \text { in Pump } \\
\text { Suction Piping (psi) }\end{array}$ & 6.45 & 0.00 & 0.00 & 6.45 & 0.74 \\
\hline $\begin{array}{l}\text { Pump Flow Cutoff + } \\
\text { Pump Flow at Onset }\end{array}$ & 0.9892 & 0.00 & 0.00 & 0.9892 & 0.0007 \\
\hline
\end{tabular}


Table F.2

Linear Approximation of the Critical Effluent Temperature Without the Effects of Cavitation for a Nominal Inlet Temperature of $30^{\circ} \mathrm{C}$. the Reference Value for the Critical Efruent Temperature is $71.5575^{\circ} \mathrm{C}$.

\begin{tabular}{|c|c|c|c|c|c|}
\hline Uncerainty & $\begin{array}{l}\text { Reference } \\
\text { Value }\end{array}$ & $\begin{array}{c}\text { Darivaive of } \\
\text { Axisymmatic } \\
\Delta \mathrm{T} \text { without } \\
\text { Cavitaion }\end{array}$ & $\begin{array}{l}\text { Derivative } \\
\text { of the } \\
\text { Critical } \\
\text { Effluent } \\
\text { Ternp. }\end{array}$ & Mean Value & $\begin{array}{l}\text { Standard } \\
\text { Deviation }\end{array}$ \\
\hline Trans. Plenum Pres. (psi) & 0.00 & 1.090 & 0.8560 & 0.00 & 2.5 \\
\hline 3-D Multiplier & 0.7853 & - & 52.92 & .7853 & .028 \\
\hline Trans. Tank Bottom Pres.(psi) & 0.00 & -0.513 & -0.4029 & 0.00 & 1.00 \\
\hline Inner Fuel Power Fraction & .377 & -74.3 & -58.35 & 0.377 & 0.017 \\
\hline Assembly Inlet Temp. $\left({ }^{\circ} \mathrm{C}\right)$ & 40.0 & -0.559 & -0.5610 & 41.2 & 1.1 \\
\hline $\begin{array}{l}\text { S.S. Plenum Center Pres. } \\
\text { (psi) }\end{array}$ & 0.00 & -0.421 & -0.3306 & 0.00 & 1.5 \\
\hline $\begin{array}{l}\text { Effluent Temperature } \\
\text { Measurement }\left({ }^{\circ} \mathrm{C}\right)\end{array}$ & 0.00 & - & 1.0000 & 0.00 & 0.225 \\
\hline Heated Fuel Length (in.) & 152.0 & -0.114 & 0.0895 & 152.0 & 3.0 \\
\hline $\begin{array}{l}\text { Turbulent Heat Trans Coef. } \\
\left(\mathscr{Q}_{0}\right)\end{array}$ & 0.00 & 0.0163 & 0.01280 & 0.00 & 15 \\
\hline $\begin{array}{l}\text { Subcooled Boil Heal Trans. } \\
\text { Coef. }(\%)\end{array}$ & 100 & -0.00319 & -0.00251 & 80 & 44 \\
\hline Required NPSH for Onset (ft) & 0.00 & 0.00 & 0.00 & 0.00 & 0.30 \\
\hline Required NPSH for Cutoff (ft) & 0.00 & 0.00 & 0.00 & 0.00 & 0.30 \\
\hline TRAC Pump Flow (gpm) & 0.00 & 0.00 & 0.00 & +375 & 875 \\
\hline $\begin{array}{l}\text { TRAC } \triangle P \text { from Tank to } \\
\text { Pump (\$) }\end{array}$ & 0.00 & 0.00 & 0.00 & 0.00 & 3.0 \\
\hline $\begin{array}{l}\text { Change in } \triangle P \text { in Pump } \\
\text { Suction Piping (psi) }\end{array}$ & 6.45 & 0.00 & 0.00 & 6.45 & 0.74 \\
\hline $\begin{array}{l}\text { Pump Flow at Cutoff }+ \\
\text { Pump Flow a Onset }\end{array}$ & 0.9892 & 0.00 & 0.00 & 0.9892 & 0.0007 \\
\hline
\end{tabular}


Table F.2

Linear Approximation of the Critical Emuent Temperature Without the Effects of Cavitation for a Nominal Inlet Temperature of $40^{\circ} \mathrm{C}$. the Reference Value for the Critical Efnuent Temperature is $77.0827^{\circ} \mathrm{C}$.

\begin{tabular}{|c|c|c|c|c|c|}
\hline Uncertainty & $\begin{array}{l}\text { Reference } \\
\text { Value }\end{array}$ & $\begin{array}{l}\text { Daivaine of } \\
\text { Axisymmatic } \\
\Delta \mathrm{T} \text { withat } \\
\text { Caviation }\end{array}$ & $\begin{array}{c}\text { Derivative } \\
\text { of the } \\
\text { Critical } \\
\text { Effluent } \\
\text { Temp. }\end{array}$ & Mean Value & $\begin{array}{l}\text { Standard } \\
\text { Deviation }\end{array}$ \\
\hline Trans. Plenum Pres. (psi) & 0.00 & 1.010 & 0.7932 & 0.00 & 2.5 \\
\hline 3-D Multiplier & 0.7853 & - & 47.02 & .7853 & .028 \\
\hline Trans. Tank Boutom Pres.(psi) & 0.00 & -0.403 & -0.3377 & 0.00 & 1.00 \\
\hline Inner Fuel Power Fraction & .377 & -65.5 & -51.44 & 0.377 & 0.017 \\
\hline Assembly Inlet Temp. $\left({ }^{\circ} \mathrm{C}\right)$ & 40.0 & -0.560 & -0.5602 & 41.2 & 1.1 \\
\hline $\begin{array}{l}\text { S.S. Plenum Center Pres. } \\
\text { (psi) }\end{array}$ & 0.00 & -0.377 & -0.3377 & 0.00 & 1.5 \\
\hline $\begin{array}{l}\text { Effluent Temperaure } \\
\text { Measurement }\left({ }^{\circ} \mathrm{C}\right)\end{array}$ & 0.00 & - & 1.0000 & 0.00 & 0.225 \\
\hline Heated Fuel Length (in.) & 152.0 & -0.102 & 0.0801 & 152.0 & 3.0 \\
\hline $\begin{array}{l}\text { Turbulent Heat Trans Coef. } \\
(\mathscr{\%})\end{array}$ & 0.00 & 0.0155 & 0.01217 & 0.00 & 15 \\
\hline $\begin{array}{l}\text { Subcooled Boil Heat Trans. } \\
\text { Coef. (\$) }\end{array}$ & 100 & -0.00300 & -0.00236 & 80 & 44 \\
\hline Required NESH for Onset (ft) & 0.00 & 0.00 & 0.00 & 0.00 & 0.30 \\
\hline Required NPSH for Cutoff (ft) & 0.00 & 0.00 & 0.00 & 0.00 & 0.30 \\
\hline TRAC Pump Flow (gpm) & 0.00 & 0.00 & 0.00 & +375 & 875 \\
\hline $\begin{array}{l}\text { TRAC } \triangle P \text { from Tank to } \\
\text { Pump (\%) }\end{array}$ & 0.00 & 0.00 & 0.00 & 0.00 & 3.0 \\
\hline $\begin{array}{l}\text { Change in } \triangle P \text { in Pump } \\
\text { Suction Piping (psi) }\end{array}$ & 6.45 & 0.00 & 0.00 & 6.45 & 0.74 \\
\hline $\begin{array}{l}\text { Pump Flow \& Culoff }+ \\
\text { Pump Flow at Onset }\end{array}$ & 0.9892 & 0.00 & 0.00 & 0.9892 & 0.0007 \\
\hline
\end{tabular}



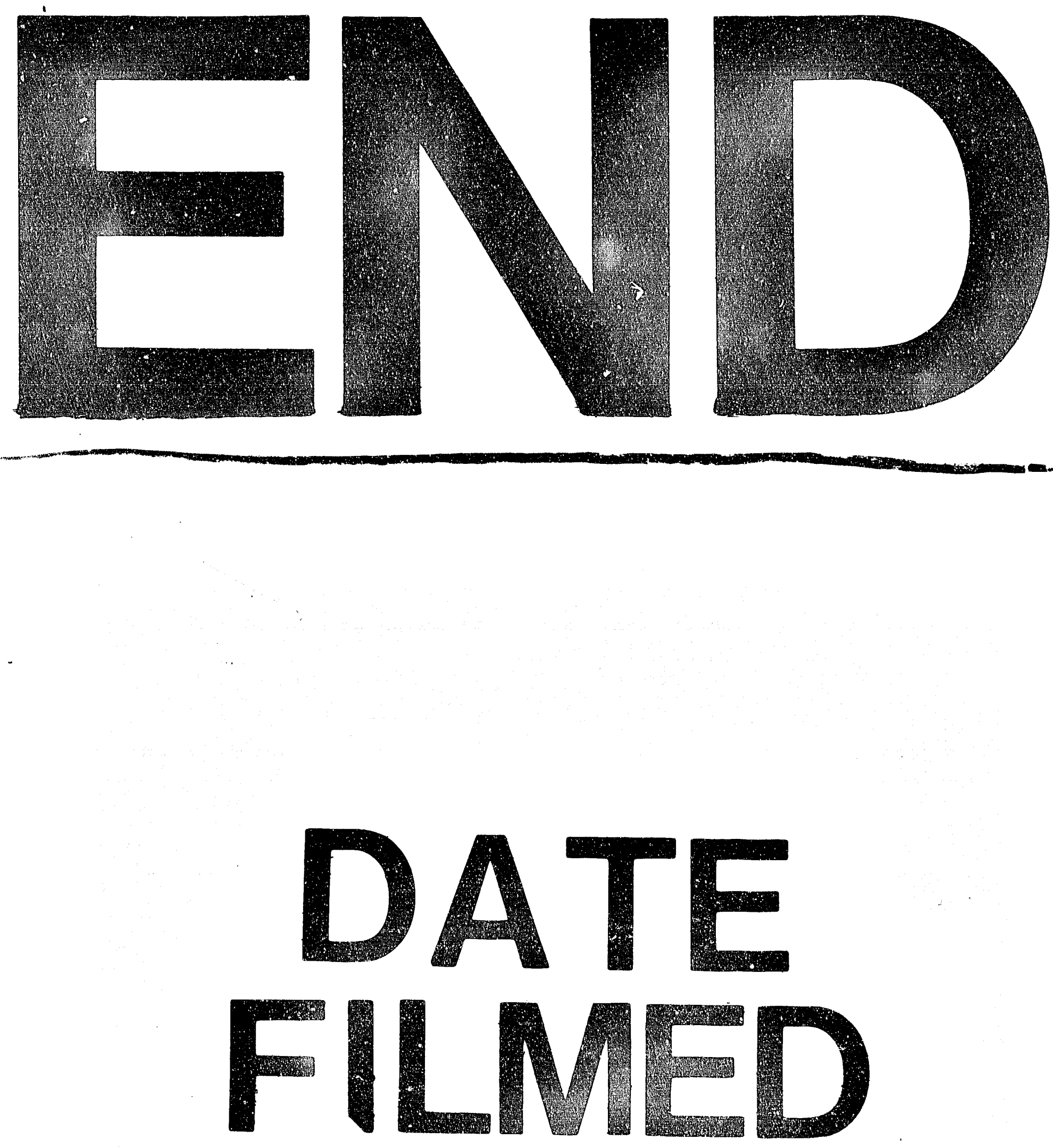

$$
3 \longdiv { 2 4 } 9 3
$$




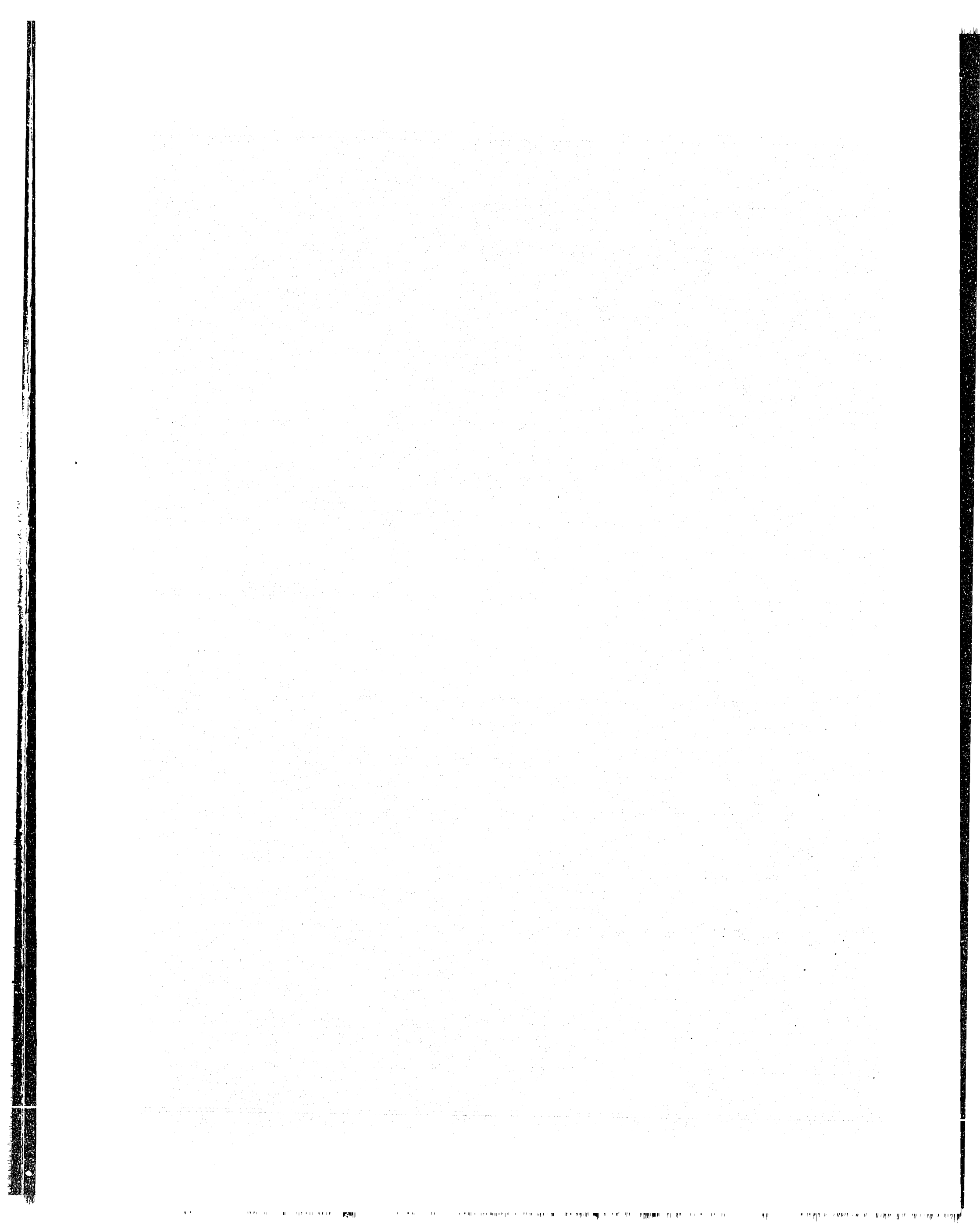

